UNIVERSIDADE ESTADUAL PAULISTA

PROGRAMA DE PÓS-GRADUAÇÃO EM ENGENHARIA DE PRODUÇÃO

LUÍS FERNANDO SELMO PALHARES

MODELO DE ANÁLISE CONJUNTA APLICADO AO MERCADO IMOBILIÁRIO

\title{
BAURU
}

Janeiro/2010 
Luís Fernando Selmo Palhares

\section{MODELO DE ANÁLISE CONJUNTA APLICADO AO MERCADO IMOBILIÁRIO}

Dissertação apresentada ao Programa de PósGraduação em Engenharia de Produção da Universidade Estadual Paulista como requisito parcial para obtenção do grau de Mestre em Engenharia de Produção.

Orientador: Prof. Dr. Manoel Henrique Salgado

Bauru

2010 
Palhares, Luís Fernando Selmo.

Modelo de análise conjunta aplicado ao mercado imobiliário / Luís Fernando Selmo Palhares, 2010.

$147 \mathrm{f}$.

Orientador: Manoel Henrique Salgado

Dissertação (Mestrado)-Universidade Estadual Paulista. Faculdade de Engenharia, Bauru, 2010

1. Mercado imobiliário. 2. Condomínio residencial. 3. Tomada decisão. 4. Análise conjunta. I. Universidade Estadual Paulista. Faculdade de Engenharia. II. Título. 


\section{Ine 9 UNIVERSIDAde ESTADUAL PAULISTA \\ UneSp "JULLO DE MESOUTA FILHO"

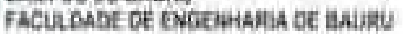

ATA DA DEFESA PÚBLICA DA DISSERTAÇÃO DE MESTRADO DE LUIS FERNANDO SELMO PALHARES, DISCENTE DO PROGRAMA DE POS-GRADUACÁO EM ENGENHARIA DE PRODUCAAOO, DO(A) FACULDADE DE ENGENHARIA DE BAURU.

Aos 25 dias do men de janeiro do ano de 2010, an 09:30 horas, no(a) ANFITEATRO DA. POS. GRADUAÇAO, reuniu-se a Contissan Examination da Defesa Püblica. componta petos seguintes membras. Prot Di MANOEL HENQIOUE SALGADO do(a) Departamento do Engenharia do Produça / Faculdade de Engerharia de Baurti. Prot. Dr. JAIR WAGNER DE SOUZA MANFRINATO dofa) Departansento de Engonhara de Produçalo / Faculdade de Engenharia de Boxrs, Prot Dr. ROGERIO ANDRADE FLAUZINO do(a) Depanamunto de Engenhara Elettrica / Escota de Engenthariz

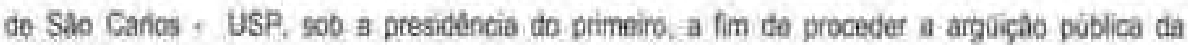
DISSERTACȦO DE MESTRADO de LUIS FERNANDO SELMO PALHARES, Intiliado MOOELO DE ANALISE CONJUNTA APLICADO AO MERTCADO IMOBLLIARIO" ADOS a exposiçá, o discente to arguide oraimente pelos membros di Comissalo Examiradora. fendo recubido o conceilo final.

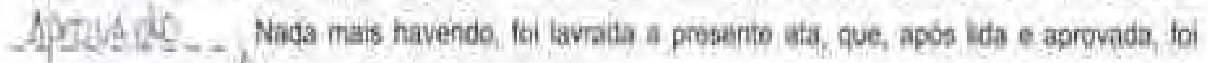
assinada poios mophibros da Comissdo Exaninadora.

Prol. Dr. MANOEL HENRIOUE SALGADO

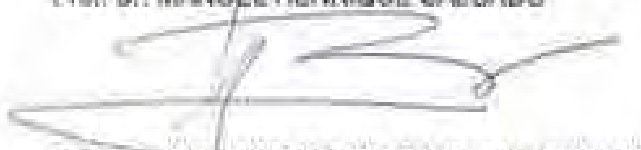

Ptol Dr. JAIRINAGNER DE SOUZA MANFRINATO

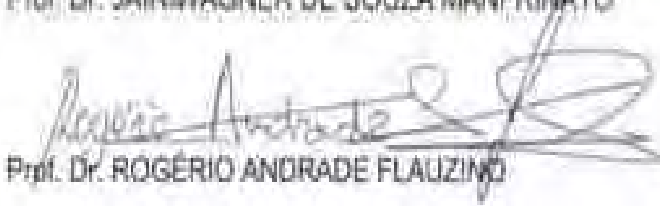


À minha esposa Arlete; aos meus filhos: Luís Gabriel e Lucas, pelo incentivo, compreensão e colaboração, dedico este trabalho. 


\section{AGRADECIMENTOS}

Ao Prof. Dr. Manoel Henrique Salgado pelo apoio, confiança e ajuda durante a execução e lapidação deste trabalho.

Ao Prof. Dr. Cláudio Vidrih Ferreira pela amizade, surgindo com a mão amiga nos momentos mais delicados.

A minha família, a esposa Arlete e os filhos Gabriel e Lucas que não mediram esforços, incentivos e abdicações durante a jornada do mestrado.

Aos funcionários da pós-graduação da Unesp Bauru, em especial à Célia e ao Gustavo.

Ao professor e colega Euro pela inestimável colaboração no aprendizado do software SPSS.

Aos amigos Daniel César, Luiz Gonzaga e Franciluz que conseguiram colaborar nas atribuições profissionais e deram importantes sugestões no aprimoramento do experimento e na a elaboração da pesquisa.

Aos colegas de profissão e profissionais do ramo imobiliário que prontamente se interessaram e levaram a sério a pesquisa.

E a todos que, direta ou indiretamente, contribuíram para a realização deste trabalho. 


\section{SUMÁRIO}

1 - INTRODUÇÃO 15

$\begin{array}{ll}1.1-\text { Objetivo } & 17\end{array}$

$\begin{array}{ll}1.2 \text { - Estrutura do trabalho } & 17\end{array}$

2 - REVISÃO DA LITERATURA 19

$\begin{array}{ll}2.1-\text { O Consumidor } & 19\end{array}$

2.2 - Fatores de influência no comportamento de compra 20

$\begin{array}{ll}2.2 .1 \text { - Fatores culturais } & 21\end{array}$

$\begin{array}{ll}2.2 .2 \text { - Fatores sociais } & 21\end{array}$

2.2.3 - Fatores pessoais $\quad 22$

$\begin{array}{ll}2.2 .4 \text { - Fatores psicológicos } & 23\end{array}$

2.2.5 - Comportamento de compra 25

2.3 - Análise conjunta $\quad 27$

2.3.1 - A função utilidade na análise conjunta 31

2.3.2 - Planejamento do experimento de análise conjunta 32

2.3.2.1 - Estágio 1: Os objetivos da análise conjunta 34

2.3.2.2 - Estágio 2: O projeto de uma análise conjunta 35

2.3.2.3 - Estágio 3: Pressupostos da análise conjunta 43

2.3.2.4 - Estágio 4: Estimação do modelo de análise conjunta 43

2.3.2.5 - Estágio 5: Interpretação dos resultados 47

2.3.2.6 - Estágio 6: Validação dos resultados 48

2.3.2.7. - Estágio 7: Aplicação dos resultados da análise conjunta 49

2.4 - Cenário de referência do mercado imobiliário 51

2.4.1 - Potencialidades do Mercado Habitacional 51

2.4.2 - O crescimento da classe C mundial e reflexos no Brasil 55

2.4.3 - Pesquisa Nacional por Amostra de Domicílios - PNAD 2008

2.4.3.1 - As classes Econômicas 62

2.4.3.2 - Ano I D.C - O primeiro ano depois da crise 64

2.4.3.2.1 - Índice de Gini $\quad 64$ 
2.4.3.2.2 - O efeito da crise nas classes sociais $\quad 66$

2.4.3.3 - O perfil da Moradia $\quad 66$

2.4.4 - Plano Minha Casa, Minha Vida 70

3 - METODOLOGIA DA PESQUISA $\quad 72$

3.1 - Descrição do objeto de estudo: 72

3.2 - Amostragem 74

3.3 - Técnica estatística e delineamento fatorial fracionário 76

4 - UMA APLICAÇÃO NO MERCADO IMOBILIÁRIO 78

4.1 - Diferenças jurídicas entre condomínios e loteamentos 78

4.2 - Condomínio Residencial Horizontal 80

4.3 - Análise conjunta $\quad 81$

4.3.1 - Estágio 1: Identificação e seleção das variáveis 81

4.3.2 - Estágio 2: Estruturação do experimento 88

4.3.2.1 - Seleção da abordagem $\quad 88$

4.3.2.2 - Planejamento dos estímulos $\quad 89$

4.3.2.3 - Coleta de dados $\quad 89$

4.3.3 - Estágio 3: Pressupostos 93

4.3.4 - Estágio 4: Estimação do modelo 93

4.3.5 - Estágio 5: Interpretação dos resultados 97

4.3.5.1 - Análise agregada 99

4.3.5.2 - Análise desagregada 100

4.3.5.3 - A função de utilidade estimada $\quad 102$

4.3.6 - Estágio 6: Validação dos resultados 103

4.3.7 - Estágio 7: Aplicação dos resultados - Simulador de escolha 106

$\begin{array}{ll}4.3 .8 \text { - Considerações finais } & 109\end{array}$

5 - CONCLUSÕES E RECOMENDAÇÕES 111

REFERÊNCIAS BIBLIOGRÁFICAS 113

$\begin{array}{ll}\text { ANEXO } 01-\text { Resultados da análise conjunta } & 119\end{array}$ 


\section{RESUMO}

PALHARES, L.F.S. (2009). Modelo de análise conjunta aplicado ao mercado imobiliário Condomínio residencial horizontal. Dissertação (Mestrado) - Faculdade de Engenharia, Universidade Estadual Paulista, Bauru, 2009.

Os condomínios residenciais horizontais despertam grande interesse no mercado imobiliário e o correto planejamento do produto a ser lançado é preponderante para o sucesso do empreendimento.

Visando o estudo da estrutura de preferência de compra do consumidor de imóvel residencial, foram determinados seis atributos relevantes para o estudo: área da unidade, tipologia (isolado ou geminado), equipamentos de lazer, localização, preço e área verde, obtendo-se a importância relativa desses atributos (fatores), definidos com base em discussões com especialistas do setor imobiliário e operadores do mercado.

O trabalho utilizou a técnica estatística da análise conjunta para estimar a função utilidade desses fatores. Para tanto foi pesquisada uma amostra não aleatória composta de 27 profissionais especialistas da área imobiliária da cidade de Bauru, os quais ordenaram 19 perfis completos compostos por níveis de cada fator e elaborados por meio de delineamento fatorial fracionário.

Conclui-se que as principais variáveis (fatores) da função de utilidade, como medida de preferência do consumidor, na aquisição da unidade habitacional, são: área da unidade com $51,85 \%$ de importância e o preço do imóvel, com 20,30\% de importância.

Verifica-se ainda que quanto ao fator tipologia, no qual está sendo medida a preferência por unidades isoladas ou geminadas, conforme o pressuposto inicial, há rejeição do mercado à unidades geminadas, porém os resultados levam a conclusão que no conjunto das variáveis medidas, este atributo não tem grande relevância, apresentando 9,89\% de importância relativa. 
A existência de ampla área verde, com bosque e trilha para caminhada, ao contrário do pressuposto inicial, demonstrou pequena relevância na preferência do consumidor.

Palavras-chave: Mercado imobiliário, condomínio residencial, tomada decisão, análise conjunta. 


\section{ABSTRACT}

PALHARES, L.F.S. (2009). Conjoint Analysis model applicated to Real Estate Market Horizontal Residential Condominium. M.Sc. Dissertation - Faculdade de Engenharia, Universidade Estadual Paulista, Bauru, 2009.

The horizontal residential condominiuns arouse big interest in the real estate market and the correct product's planning to be launched is predominant for the enterprise's success.

Aspiring the study consumer's purchase preference structure of residential property, it was determined six relevant attributes for the study: unity area, typology (isolate or geminate), leisure's equipments, localization, price and green area, achiving the relative importance of these attributes (factors), defined based on discussions with real estate sector's experts and market's operators.

The paper utilized the statistical technique of conjoint analysis to estimate the utility function of these attributes. It was inquired a non-aleatory sample composed of 27 real estate sector's professional experts from the city of Bauru, which ordered (disposed) 19 complete profiles composed by levels from each factor and elaborated through fractional factorial delineation.

It is concluded that the main variables (factors) from the utility function, as a measure of consumer's preference, at the act of acquiring the habitacional unity, are: unity area with $51,85 \%$ of importance and the property price, with $20,30 \%$ of importance.

It can be still verified that for the typology factor, in which it's measured the preference for isolate or geminate unities, according the initial purpose, there is a market's rejection to the geminate unities, however the results conclude that in the measured variables group, this attribute doesn't have a big relevance, introducing a relative importance of 9,89\%.

The existence of a wide green area, with forest and walk footpath, in despite of the initial purpose, has demonstrated a small relevance on the consumer's preference. 
Palavras-chave: Real Estate market, Residential condominium, Making-decision, Conjoint analysis. 


\section{LISTA DE FIGURAS}

Figura 01 Modelo de comportamento do consumidor

Figura 02 Fatores que influenciam o comportamento do consumidor

Figura 03 Pirâmide de hierarquia das necessidades de Maslow

Figura 04 Interface entre a oferta e a demanda, no mercado imobiliário

Figura 05 Estágios do diagrama de decisão da análise conjunta

Figura 06 Os três tipos básicos de relação entre níveis fatoriais em análise conjunta

Figura 07 PIB dos 25 maiores países, em 2007

Figura 08 Previsão do PIB dos 25 maiores países, em 2050

Figura 09 Previsão de crescimento da classe média mundial

Figura 10 Previsão de distribuição mundial de renda

Figura 11 Previsão de expansão da classe média mundial Renda per capita (US\$)

Figura 12 Renda per capita (US\$) - ano base 2007

Figura 13 Previsão para 2050 da renda per capita (US\$) - valor base US\$ 2007

Figura 14 Mobilidade social por classes - Período 2003 / 2008

Figura 15 Índice de Gini

Figura 16 Variação das classes econômicas pré versus pós-crise

Figura 17 Evolução do percentual da população com 3 banheiros ou mais

Figura 18 Evolução da população por condição de ocupação 
Figura 20 Dados geográficos da cidade de Bauru

Figura 21 Região de influência das cidades

Figura 22 Exemplos das fotografias apresentadas aos respondentes

Figura 23 Exemplo do formato de cartão apresentado aos respondentes

Figura 24 Comportamento dos fatores

Figura 25 Importância relativa dos atributos - análise agregada 99

Figura 26 Comparativo de importâncias relativas entre respondentes 102

Figura 27 Resumo das importâncias relativa dos atributos 105 


\section{LISTA DE TABELAS}

Tabela 01 Tipos de comportamento de compra

Tabela 02 Comparação de metodologias conjuntas alternativas

Tabela 03 Definição das Classes Econômicas

Tabela 04 Classes Econômicas, população e distribuição

Tabela 05 Número de banheiros por classe social - PNAD 2008

Tabela 06 Distribuição de financiamento da casa própria, por classe social

Tabela 07 Evolução percentual da população por condição de ocupação do domicílio

Tabela 08 Planejamento fatorial

Tabela 09 Características preselecionadas - definição dos atributos

Tabela 10 Atributos selecionados e níveis do experimento

Tabela 11 Informação prévia aos respondentes

Tabela 12 Ordenação dos cartões dos respondentes

Tabela 13 Utilidades parciais estimadas pelo modelo

Tabela 14 Coeficientes de correlação do modelo

Tabela 15 Forma de relação entre os níveis e efeito no termo de erro

Tabela 16 Relação entre níveis para os atributos

Tabela 17 Resumo dos resultados da estimação do modelo

Tabela 18 Tabela de resumo dos resultados da estimação do respondente 7

Tabela 19 Tabela de resumo dos resultados da estimação do respondente 25 
Tabela 20 Validação dos resultados da análise conjunta 104

$\begin{array}{lll}\text { Tabela } 21 & \text { Perfis da simulação - Fase } 1 & 107\end{array}$

Tabela 22 Simulação de probabilidade de preferência - Fase 1 108

Tabela 23 Simulação de probabilidade de preferência, entre produtos de 3 dormitórios 109

Tabela 24 Simulação de probabilidade de preferência - Participação de mercado 109 


\section{LISTA DE SIGLAS}

ABEP Associação Brasileira de Empresas de Pesquisa

AHP Analytic Hierarchy Process - Análise Hierárquica de Atributos

Ano I D.C Primeiro Ano depois da crise financeira mundial de 2008

BRIC Bloco de países formado por Brasil, Rússia, Índia e China

CPS Centro de Políticas Sociais

CRI Certificado de Recebíveis Imobiliários

FGV Fundação Getúlio Vargas

FGHab Fundo Garantidor da Habitação Popular

GDP Gross Domestic Product, Produto Interno Bruto ou PIB.

IBGE Instituto Brasileiro de Geografia e Estatística

IBOPE Instituto Brasileiro de Opinião Pública e Estatística

IBRE Instituto Brasileiro de Economia da FGV

IGC Instituto Geográfico e Cartográfico

N11 Next-11 - tradução livre - próximas 11 economias mundiais a crescer.

PlanHab Plano Nacional de habitação elaborado pelo Ministério das Cidades

PMCMV Plano Minha Casa Minha Vida

PME Pesquisa mensal do emprego

PNAD Pesquisa Nacional por Amostra de Domicílios

SFI Sistema de Financiamento Imobiliário 


\section{INTRODUÇÃO}

O desenvolvimento e o lançamento de empreendimentos residenciais necessitam de análises cada vez mais profundas em relação ao potencial de mercado, com enfoque nas características intrínsecas e extrínsecas do empreendimento, a fim de verificar quais atributos, ou conjunto de atributos detêm a preferência do consumidor e que mais interferem nas condições comerciais dos imóveis.

A premissa adotada é que um imóvel terá tanto mais qualidade quanto seus atributos, relacionados com localização, vizinhança, área construída, padrão construtivo, equipamentos de lazer e disponibilidade de área verde, se aproximar daquilo que deseja o comprador.

Analisando-se o conjunto de atributos inferidos do mercado é possível entender o comportamento da demanda e assim formatar o produto imobiliário de acordo com estas preferências, resultando em velocidade de venda dentro dos padrões desejados e retorno do investimento nos índices planejados. Ressalva feita que a demanda habitacional esta relacionada a outras condições, tais como público alvo e linhas de crédito.

O entendimento da estrutura de preferência do consumidor, representado pela importância relativa dos atributos analisados, permitem a análise de lucratividade e segmentação do produto.

O planejamento do imóvel em função do conjunto de atributos não pode somente ser realizado baseado na percepção e no ponto de vista do empreendedor. Deve ser resultado de pesquisa de mercado estruturada com base em atributos relevantes e concluída por ferramenta gerencial que forneça modelos com aderência ao mercado real e estatisticamente significativo.

Ao definir um novo empreendimento imobiliário, um problema comumente enfrentado é a identificação do conjunto de características que os clientes têm preferência e, ao mesmo tempo, atribuem valor monetário à presença delas no produto.

A primeira etapa para a consolidação da pesquisa foi a determinação da técnica estatística a ser utilizada. Estudos iniciais com a regressão linear múltipla indicaram 
impossibilidade da utilização, pois a técnica baseada em comparação de dados de mercado, exige que existam elementos amostrais a serem coletados, para que haja inferência estatística do comportamento da variáveis estudadas. Pelo fato de ser um produto inexistente e inovador no mercado, não há amostras a serem coletadas.

Em seguida analisou-se a aplicação da técnica Delphi, na qual os atributos selecionados são hierarquizados, resultam numa matriz de atributos e obtida a importância relativa dos mesmos. As características básicas desta técnica é que as opiniões dos especialistas (componentes da amostra) são coletadas em diversas rodadas de aplicação de questionários, buscando a convergência de opiniões. Estudos analisados mostraram que ao utilizarmos fatores relevantes, a convergência de opiniões torna a matriz de atributos uniforme, impossibilitando identificar o grau de importância relativa entre os atributos.

A utilização da técnica AHP (Analytic Hierarchy Process - Processo de Análise Hierárquica) que identifica a preferência do consumidor por meio de comparação aos pares entre alternativas, embora determine a importância relativa dos atributos não fornece a função utilidade, ou seja, não relaciona a importância relativa estimada com o produto em análise. Dessa forma, a pesquisa não atingiria o objetivo final.

Por meio do livro dos autores Hair, Tatham, Anderson e Black (2005), que apresenta uma visão geral de grande número de técnicas de análise multivariada, assim como oferece linhas gerais para a aplicação destas técnicas, o qual se tornou a base e linha mestra deste trabalho, é que houve a seleção da técnica de análise conjunta.

Portanto a técnica estatística adotada é a análise conjunta na qual todos os atributos são analisados conjuntamente, ou cuidadosamente agregados como sugere a denominação da técnica, com a estimação de parâmetros individuais para cada nível dos fatores selecionado, que resultam na utilidade total do produto atribuída pelo comprador. Além de atender os requisitos de determinação da importância relativa dos atributos e fornecer a função utilidade, a técnica permite a simulação de lançamento de produtos, indicando a probabilidade de preferência do consumidor, servindo de ferramenta de suporte à tomada de decisão. 


\section{1 - Objetivo}

O presente trabalho tem por objetivo identificar quais atributos, na ótica do consumidor, são relevantes na ocasião da aquisição do produto imobiliário condomínio residencial horizontal e estimar a função de utilidade, de modo a obter a importância relativa destes atributos e de seus níveis.

A metodologia utilizada é a técnica estatística de análise conjunta, que na pesquisa desenvolvida, determina a estrutura de preferência do consumidor de unidade habitacional em condomínio horizontal para a cidade de Bauru. A análise conjunta permite, com base na importância relativa dos atributos, traduzir os critérios de escolha dos consumidores.

Como objetivo secundário, mostrar que a utilização desta técnica, como ferramenta de suporte à tomada de decisão, pode auxiliar o processo de orientação, formatação e definição do empreendimento imobiliário. Adicionalmente, por meio de simulações, permitir estimar os efeitos da concorrência, analisando-se os efeitos das variáveis constantes do estudo. Ainda, permitir identificar segmentação de mercado, com exploração de nichos mais rentáveis ou com demanda reprimida.

\section{2 - Estrutura do trabalho}

A estrutura do trabalho foi elaborada com um capítulo introdutório do tema de pesquisa, bem como a formulação do problema e os respectivos objetivos.

No Capítulo 2, é apresentada a revisão de literatura, descrevendo brevemente os fatores que influenciam o comportamento de compra, abordando o cenário de referência do mercado imobiliário, descrevendo as potencialidades do mercado habitacional brasileiro, o crescimento da classe $\mathrm{C}$ (público alvo do produto em análise na pesquisa) no mundo e no Brasil e os dados da recém divulgada PNAD 2008 do IBGE, que demonstra a evolução das classes sociais, o panorama após crise e o perfil de moradia do brasileiro. 
Neste Capítulo, ainda, análise conjunta com abordagem de todos os estágios que envolvem o planejamento do experimento, os pressupostos, a estimação, interpretação, validação e aplicação dos resultados.

O Capítulo 3 descreve a metodologia de aplicação da pesquisa. No Capítulo 4 é descrita a aplicação da análise conjunta no mercado imobiliário, com descrição do objeto de estudo, identificação e seleção das variáveis relevantes, os resultados da pesquisa e análise dos resultados.

Por fim, o Capítulo 5 encerra o trabalho com as conclusões sobre o método aplicado e com proposições de trabalhos futuros. 


\section{REVISÃO DA LITERATURA}

\section{1 - O Consumidor}

Para Kotler (1999), as empresas que entenderem como os consumidores respondem aos diferentes atributos e características dos produtos, a preços e estímulos de marketing, terão uma vantagem competitiva sobre seus concorrentes.

Ainda, segundo Kotler (2000), o campo do comportamento do consumidor estuda como as pessoas, grupos e organizações selecionam, compram, usam e descartam artigos, serviços, idéias ou experiências para satisfazer as necessidades de seus desejos.

O ponto de partida é o modelo de estímulo-resposta do comportamento do consumidor, mostrado na Figura 1.

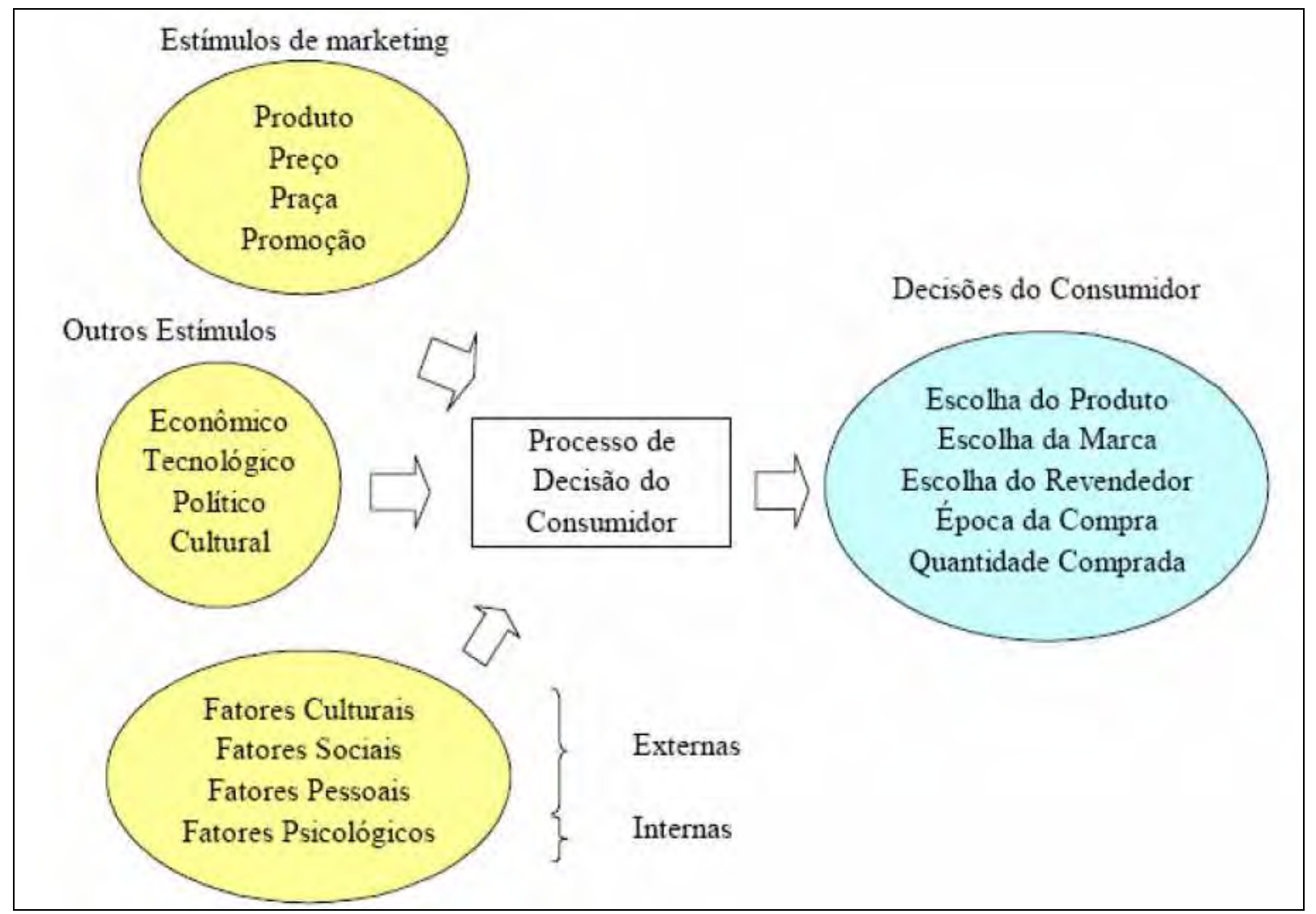

Figura 1: Modelo de comportamento do consumidor.

Fonte: Adaptado de KOTLER, P. (1999) 
Observa-se que muitas características e forças individuais influenciam o comportamento de compra. A escolha do consumidor é resultado de um complexo processo interativo influenciado por estímulos de marketing (produto, preço, praça e promoção), econômicos, tecnológicos e políticos, além de fatores culturais, sociais, pessoais e psicológicos que determinam o processo de decisão do consumidor. Muitos destes fatores podem não ser influenciados por estratégias de marketing, entretanto, o conhecimento e influência destes fatores no processo de escolha são essenciais para o gestor.

Capturar o que motiva comportamentos e direciona o indivíduo a avaliar positivamente um bem assim como o consumidor atribui valor a determinadas escolhas é essencial como princípio conceitual para o modelo quantitativo que se apresenta.

Importante mostrar que o consumidor age de acordo com um "comportamento de mercado", onde os "padrões comuns" são influenciados por atitudes e percepções dos indivíduos, resultante de hábitos, experiências passadas, informações de mercado e atributos do produto, que o permitem assumir preferências. As decisões de compra são decorrentes de um processo pessoal de maximização das preferências.

\section{2 - Fatores de influência no comportamento de compra}

Conforme Kotler (1998), os principais fatores que influenciam o comportamento de compra do consumidor estão resumidos na Figura 2.

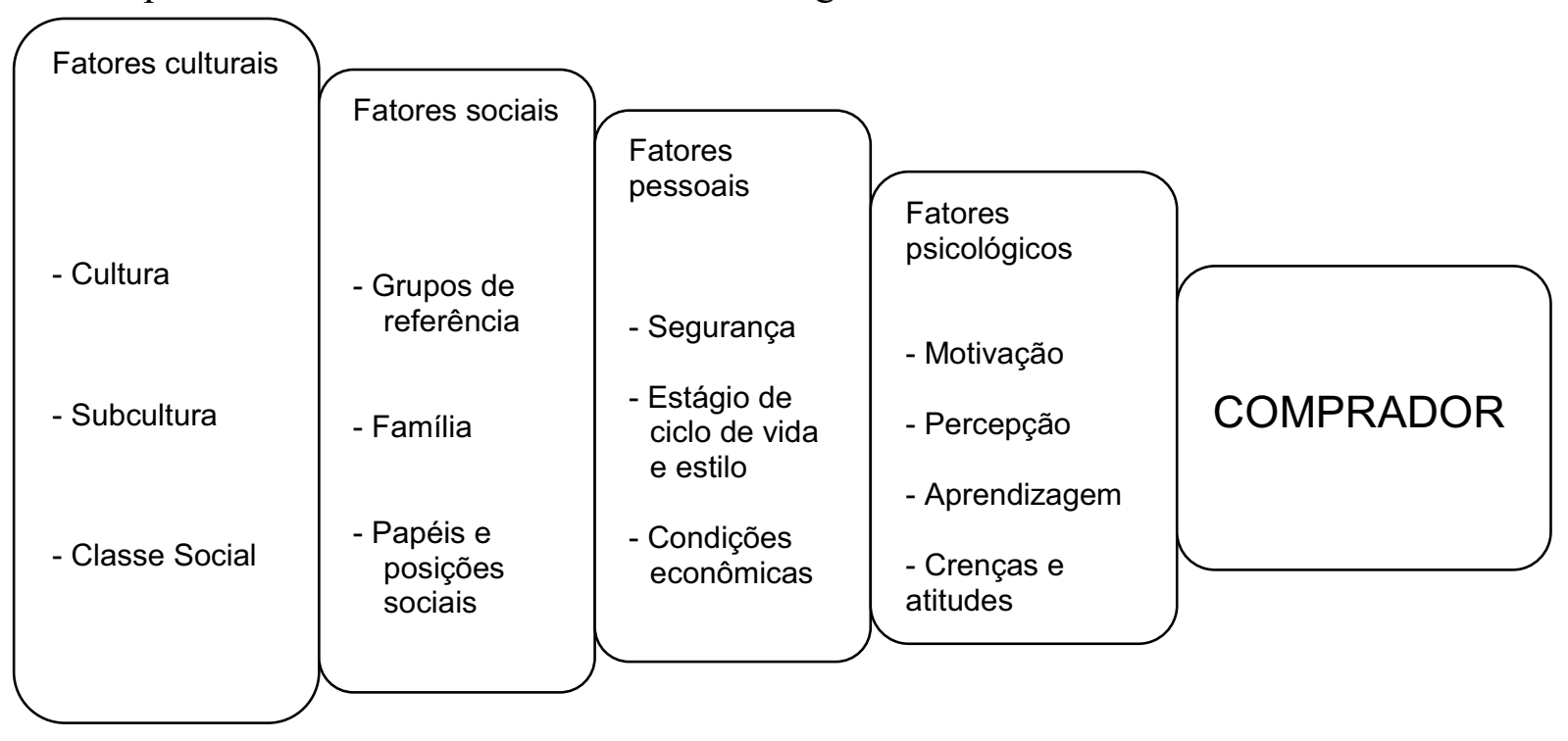

Figura 2: fatores que influenciam o comportamento

Fonte: Adaptado de Kotler, P. (1998) 


\subsection{1 - Fatores culturais}

Os fatores culturais exercem a mais ampla e profunda influência sobre o comportamento do consumidor. Os papéis exercidos pela cultura, subcultura e classe social são particular e especialmente importantes.

A cultura é representada pelo conjunto de valores, preferência, percepções e comportamentos adquiridos desde o nascimento e reforçados durante a vida. No Brasil, as pessoas estão expostas aos valores dados à necessidades tais como acesso à moradia própria, conforto material, realização e sucesso pessoal e profissional, dentre outros.

A subcultura é identificada quando surgem características regionais, religiosas, de orientação sexual e que possibilitam identificar nichos ou segmentos de mercado.

A classe social, representada pela estratificação de toda a sociedade, cujos membros compartilham valores, anseios, interesses e comportamento similares.

Conforme Kotler (1998), as classes sociais não refletem apenas a renda, mas também outros indicadores como ocupação, nível educacional, orientação de valor e padrão de moradia.

As classes sociais mostram preferências distintas de marcas e produtos em muitas áreas, incluindo vestuário, móveis, automóveis e imóveis.

No Brasil, decorrente de avanços na política pública de distribuição de renda, do crescimento do país e melhoria do nível de salário e renda, houve nos últimos anos grande mobilidade social positiva, com grande diminuição da classe E e crescimento das classes $\mathrm{C}$ e D.

O florescimento da classe $\mathrm{C}$ brasileira, tratada no Capítulo 2, aliada às condições econômicas favoráveis (diminuição do juro e alongamento do prazo nas linhas de crédito) trazem enormes influências sobre o comportamento de compra, gerando relevância em estudos de mercado diante desta nova realidade.

\subsection{2 - Fatores sociais}

O comportamento do consumidor também é influenciado por fatores sociais como grupos de referência, famílias e papéis e posições sociais. 
Grupos de referência, segundo Kotler (1998), são aqueles que têm influência direta (face-a-face) ou indireta sobre as atitudes ou comportamento da pessoa.

Grupos de referência que têm influência direta são denominados grupos de afinidade, compostos por família, amigos, colegas de trabalho e religião.

Os grupos de referência influenciam o indivíduo a novos estilos de vida, comportamentos e atitudes.

A família é a organização de compra de produtos de consumo mais importante da sociedade e alvo de extensas pesquisas.

O "papel” significa a posição do indivíduo dentro de um grupo específico, na família assume o papel de filho, no clube de sócio, na empresa em que trabalha com seu cargo. Cada papel significa uma posição social. A posição social representa o status de cada papel. Pode-se exemplificar, por ordem decrescente de status: o juiz de direito, o gerente de empresa e o funcionário administrativo.

\subsection{3 - Fatores pessoais}

$\mathrm{Na}$ sociedade atual, a segurança é a questão mais importante para a almejada qualidade de vida do indivíduo, seja a segurança pessoal, familiar ou patrimonial.

$\mathrm{O}$ ciclo de vida familiar inicia-se quando o individuo é solteiro, recém-casado, com filhos pequenos, adolescentes ou sem filhos, casais maduros e com filhos dependentes, com filhos já fora de casa, aposentado, solitário que trabalha e solitário aposentado. (KOTLER, 1998).

Idade, ocupação, situação econômica, estilo de vida e personalidade também influenciam o padrão de consumo dos indivíduos.

Solomon (2002) define estilo de vida, sob o ponto de vista econômico, como o modo escolhido pelo indivíduo para distribuir a renda auferida, tanto em termos de diferentes produtos e serviços quanto de alternativas específicas dentro dessas categorias. 


\subsection{4 - Fatores psicológicos}

Kotler (1999), ainda declara que as escolhas de compra são influenciadas por quatro fatores psicológicos - motivação, percepção, aprendizagem e crenças e atitudes.

Os psicólogos desenvolveram teorias sobre a motivação humana que implicam no comportamento do consumidor. As três teorias mais conhecidas, são:

\section{- Teoria da motivação de Freud}

Yanaze (2007) relata que, em psicologia, a motivação da escolha ocorre, em parte, no nível do inconsciente. Sigmund Freud, confirmando essa afirmação, concluiu que uma pessoa não pode entender totalmente suas motivações, pois existem forças psicológicas inconscientes que formam seu comportamento. Gade, 1980 (apud Yanaze, 2007), confirma isto quando coloca que, "na situação de compra, o consumidor tende a agir de forma emocional e compulsiva, reagindo no nível inconsciente a imagens e produtos que seu subconsciente associa ao produto". Portanto, à luz desta teoria, é o inconsciente que move o comportamento.

\section{- Teoria da motivação de Maslow}

Maslow formulou o que hoje se conhece como hierarquia das necessidades e pode ser classificada em cinco níveis, conforme mostra a Figura 3. 


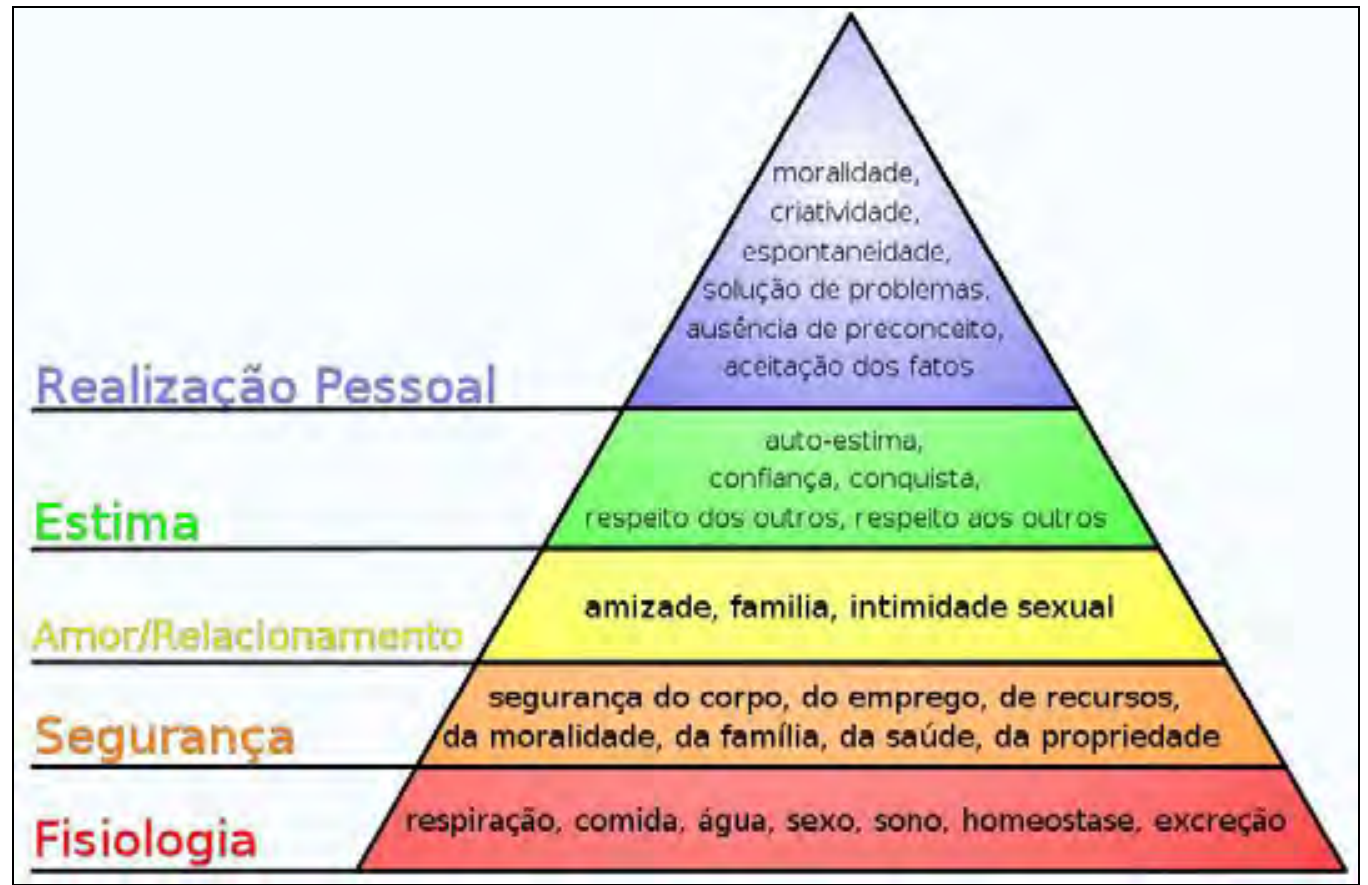

Figura 3: Pirâmide de hierarquia das necessidades de Maslow.

Fonte: Finkelstein, J. (2007). Disponível em www.en.wikipedia.org.

A hierarquia consiste em que a pessoa procura satisfazer as necessidades na forma piramidal, da mais urgente (fisiológica) à menos urgente (realização pessoal).

Cobra (1992) afirma que dentro desta hierarquia não existe um relacionamento estanque. $\mathrm{Na}$ verdade, esses fatores aparecem isoladamente ou hierarquizados ou em conjunto, isto é, ocorrem simultaneamente.

Karsaklian (2004) alerta que não se deve confundir necessidade e desejo. Ao contrário das necessidades, os desejos são fortemente estimulados pelas ações mercadológicas. Enquanto uma necessidade nem sempre é visivelmente expressada, pois pode ser latente, os desejos são uma tomada de consciência.

\section{- Teoria da motivação de Herzberg}

Herzberg, desenvolveu teoria de comportamento, na qual o comportamento de compra é efeito de dois fatores: insatisfatórios (que causam insatisfação) e 
satisfatórios. A ausência de fatores insatisafatórios não é suficiente para ocorrer a compra, complementarmente os fatores de satisfação devem estar ativamente presentes.

Conforme exemplifica Kotler (1998), o processo de compra de um computador Apple sem que haja a garantia do fabricante é motivo e causa insatisfação. Contudo, a presença da garantia não seria um fator de satisfação de compra, já que não se trata de uma fonte de satisfação inerente ao produto. A facilidade de uso do equipamento seria um fator de satisfação e aumentaria a disposição de compra.

Kotler (1998) considera que esta teoria de motivação tem duas implicações. Primeiro, deve-se evitar a presença de fatores insatisfatórios no processo de compra, pois embora não colabore com a efetivação, pode prejudicá-la. Segundo, devem-se identificar os fatores de satisfação, que motivam a compra e fornecê-los.

\subsection{5 - Comportamento de Compra}

A tomada de decisão do consumidor varia de acordo com o produto a ser adquirido. Há grandes diferenças entre comprar uma pasta de dente, um tênis, um computador e um imóvel. Assael, 1987 (apud Kotler, 1998) distinguiu quatro tipos de comportamento de compra baseados no grau de envolvimento do comprador e nas diferenças entre as marcas/produtos, mostrados na Tabela 1.

Tabela 1: Tipos de comportamento de compra

Alto envolvimento

Baixo envolvimento

Diferenças significativas entre

as marcas
Comportamento de compra

complexa
Comportamento de compra que busca variedade
Poucas diferenças entre as marcas
Comportamento de compra com dissonância reduzida
Comportamento de compra habitual 
No caso do mercado imobiliário, os consumidores enfrentam um comportamento de compra complexa, pois estão altamente envolvidos na compra e há diferenças significativas entre as marcas ou produtos. Este comportamento, geralmente, ocorre quando o produto é caro, comprado infrequentemente e altamente auto-expressivo.

Neste processo, o consumidor desenvolve sua crença sobre o produto colhendo informações sobre o mesmo, por meio de atributos, ponderados por sua importância relativa.

Em resumo, conforme Engel, Blackwell e Miniard (2000), todas as variáveis que influenciam o consumo e o comportamento do consumidor interagem com a situação de uso do produto e a solução de marketing, para definir o produto, envolve analisar medidas múltiplas, apresentadas na forma de modelo estatístico com alto poder de predição.

O modelo estatístico deve atender o objetivo final da pesquisa que é simular a penetração de mercado do produto em função de seus atributos e identificar o grupo demográfico alvo que é receptivo às estratégias de marketing.

Mc Fadden (2001) discorre sobre a importância da interação interdisciplinar entre a pesquisa de mercado e análise econômica de escolha. Os métodos experimentais utilizados na pesquisa de mercado permitem a elucidação e modelagem do processo de tomada de decisão. A maioria das variáveis e métodos utilizados para medir as preferências declaradas e reveladas vêm da psicologia aplicada. De modo específico, análise conjunta, um método para obter preferências declaradas por meio de um desenho experimental clássico, provê dados que aliados ao apropriado conhecimento do consumidor podem melhorar consideravelmente a habilidade de predizer as decisões do consumidor.

Conforme Yanaze (2007), como a demanda é resultado da conjunção de necessidades, desejos, expectativas e poder aquisitivo, as empresas devem analisar o mercado consumidor segundo estes critérios e por meio de adequado instrumento, no caso deste trabalho com a utilização da análise conjunta, para elaborarem o produto que atenda suas metas de lucratividade. Esta técnica será objeto de estudo na seção 3 deste Capítulo e aplicação no Capítulo 4.

Do ponto de vista do consumidor, o imóvel terá tanto mais utilidade quanto seus atributos se aproximarem daquilo que deseja, lembrando que as demais ofertas existentes no mercado servem de referenciais. 
A Figura 4 mostra que o processo de compra ocorre na linha divisória que é a interface de equilíbrio entre os anseios do consumidor determinados pela utilidade percebida (UC) e pelo preço correspondente (PC), e o preço do produto (PE) e atributos apresentados pelo empreendedor (UE).

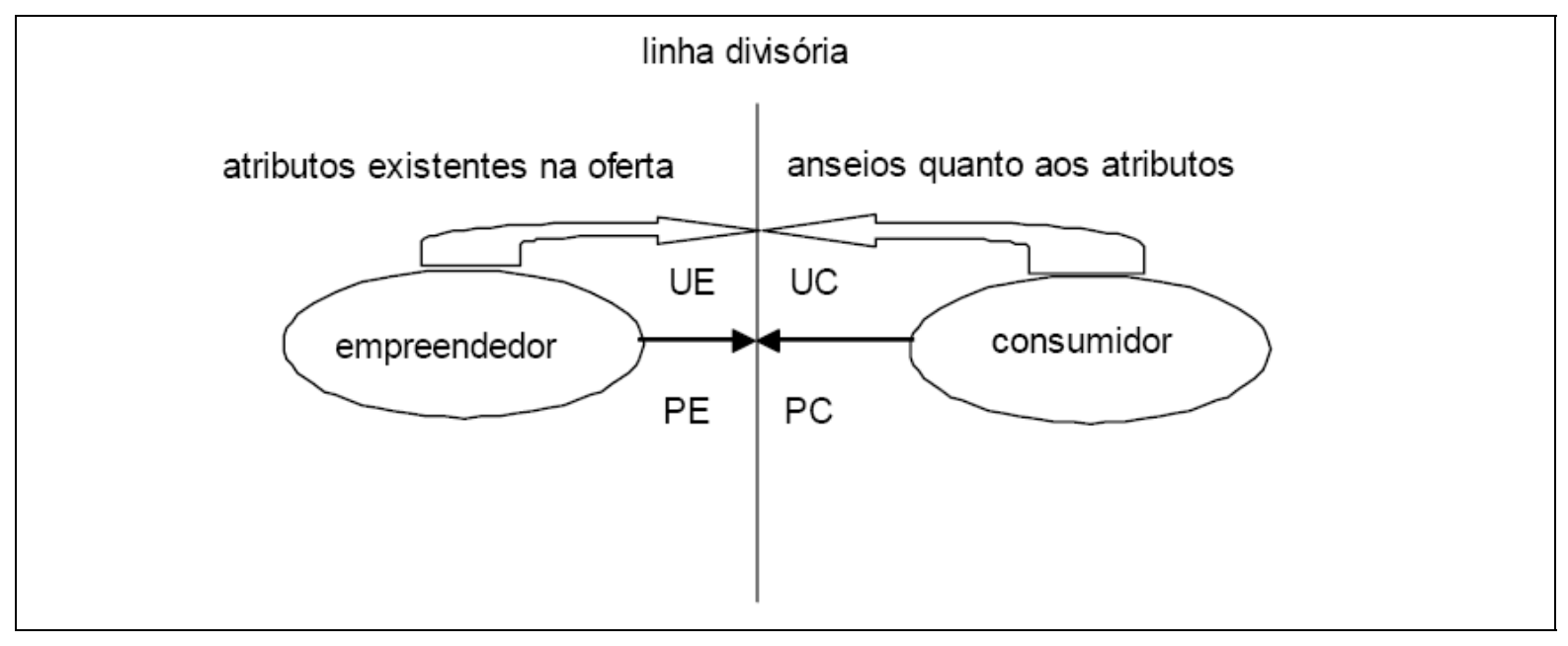

Figura 4: Interface entre a oferta e a demanda por atributos, no mercado imobiliário Fonte: Lima Júnior, 1993

Entretanto, para efetivação de uma transação, outros fatores como: econômicos, financeiros e conjunturais estão presentes concomitantemente. Verificou-se os fatores que influenciam no processo de tomada de decisão da compra e o comportamento do consumidor; mas há a necessidade de serem abordados outros fatores associados às características econômicas, financeiras, sociais e conjunturais que influem e são determinantes para a conclusão da transação.

\section{3 - Análise Conjunta}

A referência principal deste trabalho, em vista da dificuldade de textos e escassez de publicações, assim como as informações bibliográficas foram extraídas do livro "Análise Multivariada de Dados" dos autores Hair, Anderson, Tatham e Black (2005). 
Embora a criação da análise conjunta tenha ocorrido por volta de 1920, há concordância que o ano de 1964 marca o início de práticas conjuntas, com o primeiro artigo publicado por Luce, psicólogo matemático e o estatístico Tukey. Ainda em 1964 surgiram contribuições teóricas de Krantz (1964), Tversky (1967) e o desenvolvimento de algoritmos por Kruskal (1965), Carrol (1969) e Young (1969). (GREEN e SRINAVASAN, 1978).

Ainda de acordo com Green e Srinivasan (1978), medições conjuntas, da maneira utilizada por psicólogos matemáticos, tem como preocupação inicial as condições sob as quais existem escalas de medidas tanto para as variáveis independentes quanto para a variável dependente, dada em função dos efeitos conjuntos das variáveis independentes e uma regra de composição pré-definida.

Programas de computador têm sido desenvolvidos e aplicados em testes quando um conjunto de dados possui as condições necessárias para aplicação de várias regras de composição (por exemplo: regra aditiva) formuladas pelo pesquisador (Ullrich and Painter (1974), Barron (1977), apud Green e Srinivasan (1978)). Entretanto, aplicações por psicólogos matemáticos e pesquisadores de mercado tem enfatizado os aspectos de escala encontrar valores de escalas numéricas adequados, adotando que uma regra específica de composição é aplicada, possivelmente com algum erro. Desse modo, parece ser coerente adotar o nome "análise conjunta" para denominar modelos e técnicas que enfatizem a transformação de respostas subjetivas em parâmetros estimados.

Enquanto a metodologia conjunta foi brevemente discutida no artigo de Green e Rao (1969) e no livro de Green e Carmone (1970), o primeiro e detalhado artigo orientado ao consumidor surgiu em 1971 escrito por Green e Rao. Na seqüência, uma série de artigos de algoritmos e/ou aplicações (Green, Carmone e Wind, 1972; Srinivasan e Shocker, 1973; Johnson, 1974; Westwood, Lunn e Beazley,1974) apareceram em várias revistas científicas. Justificativas teóricas para modelagem multiatributos da preferência do consumidor foram fornecidas para a literatura crescente nos modelos de valores estimados de FishbeinRosenberg e a "nova" teoria econômica de escolha do consumidor (Lancaster, 1971; Ratchford, 1975). Entretanto, geralmente os economistas tem se interessado mais nos resultados agregados das estruturas multiatributos das utilidades do que na estimação da função utilidade individual em si. 
Hair et al. (2005, p. 323) definem análise conjunta:

Técnica multivariada usada especificamente para entender como os respondentes desenvolvem preferências por produtos ou serviços. É baseada na premissa simples de que os consumidores avaliam o valor de um produto/serviço/idéias (real ou hipotética) combinando as quantias separadas de valor fornecidas por cada atributo.

A análise conjunta é para predizer as preferências do consumidor e ferramenta do processo de tomada de decisão. É largamente utilizada na indústria, para lançamento de produtos ou serviços novos e reposicionamento de produtos (segmentação de mercados). Tem como premissa básica, determinar a importância relativa que os consumidores dão a atributos relevantes, assim como a utilidade que eles associam aos níveis de atributos.

A utilidade, é a base conceitual para medir valor em análise conjunta e traduz o julgamento subjetivo de preferência, por um indivíduo, que representa o valor ou utilidade integral e completa de um produto ou serviço. (HAIR et al., 2005).

Green e Srinivasan (1990) afirmam que desde o início da década de 70 que a análise conjunta tem recebido considerável atenção da indústria e da comunidade acadêmica como o principal conjunto de técnicas para medir a preferência de compra, quando se analisa produtos e serviços que possuem atributos diversos.

A literatura técnica utiliza como denominação "fatores" ao tratar das características do produto em análise. Neste trabalho, para facilitar a explicação de determinados procedimentos, utilizar-se-á, em relaxamento ao rigor técnico, indistintamente, termos sinônimos, como atributos, variáveis ou variáveis independentes.

A singularidade da análise conjunta, dentre os métodos multivariados deve-se ao fato que o pesquisador primeiro constrói o produto, por meio da seleção dos atributos (fatores) e seus diversos níveis, para então, apresentar aos respondentes, os quais fornecerão suas avaliações gerais. Desta forma o pesquisador pedirá aos respondentes que escolham, dentre as opções oferecidas, aquelas que maior preferência têm. As escolhas demonstrarão as preferências assinaladas pelos respondentes, e serão avaliadas de modo individual (nível 
desagregado) com as conclusões obtidas no nível agregado, ou seja, no conjunto de todos os respondentes.

Hair et al (2005) destaca os principais diferenciais da análise conjunta em relação à outros métodos estatísticos:

- Técnica decomposicional;

- Estimativa pode ser realizada em nível individual, ou seja, para cada elemento da amostra (respondente), além de também realizar a estimativa conjunta (nível agregado).

Nas técnicas composicionais, tais como regressão múltipla e análise discriminante, há a necessidade de coletar informações dos respondentes sobre diversas variáveis, para relacioná-las à variável independente e então extrair o modelo. Na análise conjunta a variável resposta é única e representada pela preferência do respondente, que é decomposta; assim o modelo fornece o parâmetro para cada nível das variáveis (fatores) em estudo.

Hair at al. (2005) enfatiza que na variável estatística conjunta (combinação linear e aditiva de efeitos das variáveis independentes sobre uma variável dependente), o pesquisador especifica os fatores e consequentemente os níveis que pretende estudar, o respondente fornece a medida dependente e a análise conjunta decompõe a resposta do respondente em efeitos para cada nível.

Esse aspecto ilustra a importância do delineamento do projeto e justifica ser preponderante para o sucesso da pesquisa. Variáveis que não foram incorporadas ao modelo, na fase de delineamento, não estarão disponíveis para análise. De outro modo, a inserção de variáveis para que seus efeitos sejam medidos esbarra na limitação do número de variáveis que podem ser analisadas pela técnica. Isto demonstra a importância da clara definição do problema de pesquisa.

Quanto a modelagem, a técnica também apresenta diferenciais. Realiza-se a análise conjunta de modo individual, sendo que cada respondente origina um modelo próprio e ajustado às suas preferências. Desta maneira, as análises individuais são denominadas desagregadas e a precisão preditiva é calculada para cada pessoa. 
Há também a opção de se realizar a análise em grupo de indivíduos que representem um segmento de mercado (ou o mercado inteiro), em nível agregado. Dessa forma ter-se-a um modelo geral que retrata este segmento, resultando em maior eficiência estatística.

\subsection{1 - A função utilidade na análise conjunta}

Castro (2006) comenta que a utilidade é a atratividade que determinado produto ou serviço exerce sobre o consumidor, resultante de uma combinação de fatores. Analisando e comparando os atributos dos produtos ou serviços, o consumidor escolhe aquele que apresentar máxima utilidade.

Conforme Malhotra (2001), o modelo matemático básico que expressa a função de utilidade é representado pela equação (1):

$$
U(X)=\sum_{i=1}^{m} \sum_{j=1}^{k_{i}} \alpha_{i j} x_{i j}
$$

em que,

$U(X)=$ utilidade global de uma alternativa

$a_{i j}=$ contribuição de valor parcial ou utilidade associada ao $j^{-\dot{s} \text { simo }}$ nível

$$
\left(j, j=1,2, \ldots, k_{i}\right) \text { do } i^{-\dot{s} s i m e} \text { atributo }(i, i=1,2, \ldots, m)
$$

$k_{i}=$ número de níveis do atributo $i$

$m=$ número de atributos

$x_{i j}=1$ quando o $j^{- \text {Esima }}$ nível do $i^{- \text {Enamo }}$ atributo está presente, ou

$=0$ em caso contrário 


\subsection{2 - Planejamento do Experimento}

O planejamento e análise dos resultados na análise conjunta exigem que o pesquisador tome várias decisões-chaves, para que o modelo obtido tenha capacidade de predição e semelhança com o mercado estudado.

Os tópicos e seqüência para realização da análise serão abordados, conforme roteiro proposto por Hair et al (2005), apresentado na figura 05, com destaque (em cor amarela e/ou em negrito) para os procedimentos utilizados neste trabalho.

\section{Estágio 1}

Estágio 2

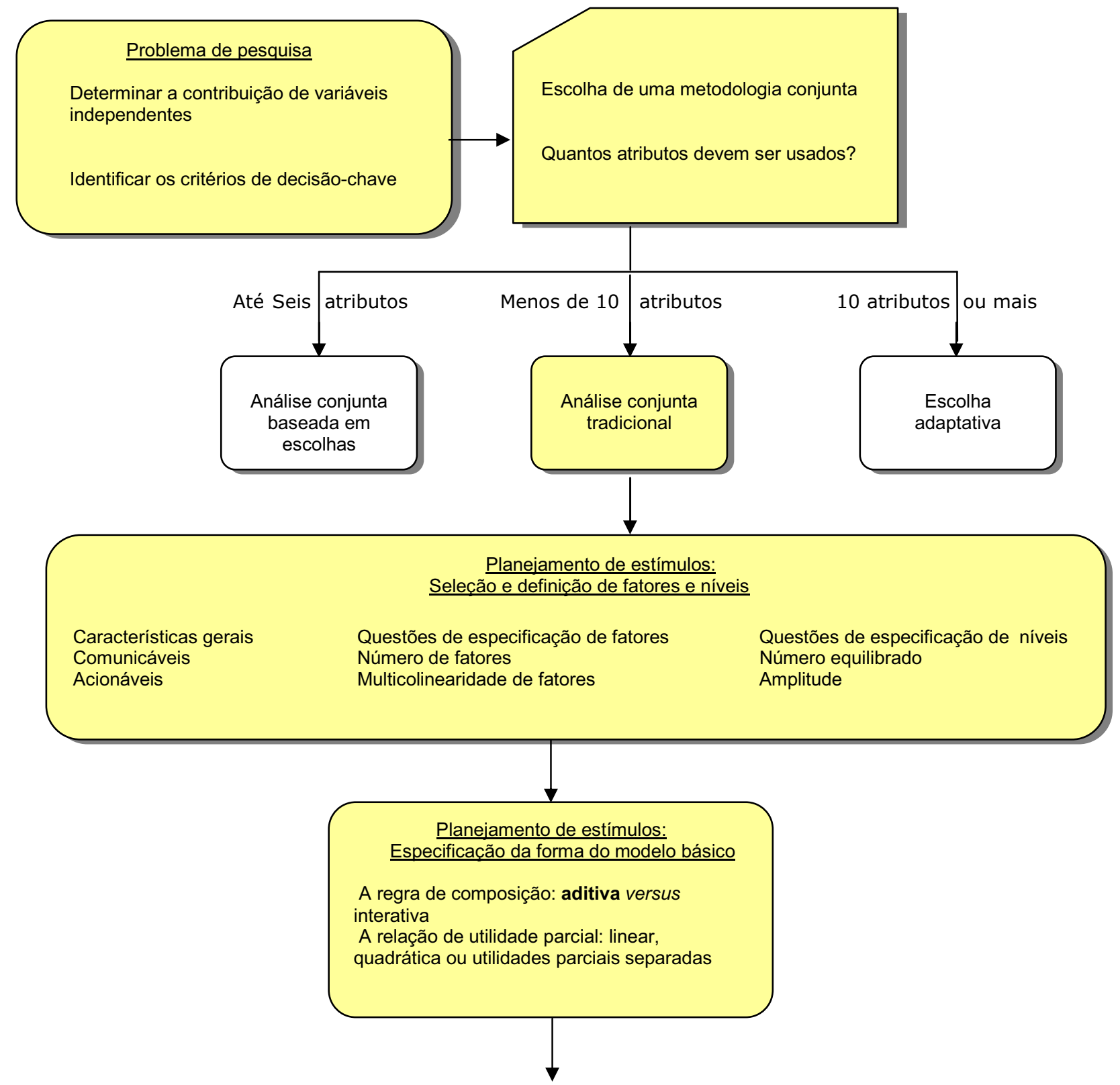




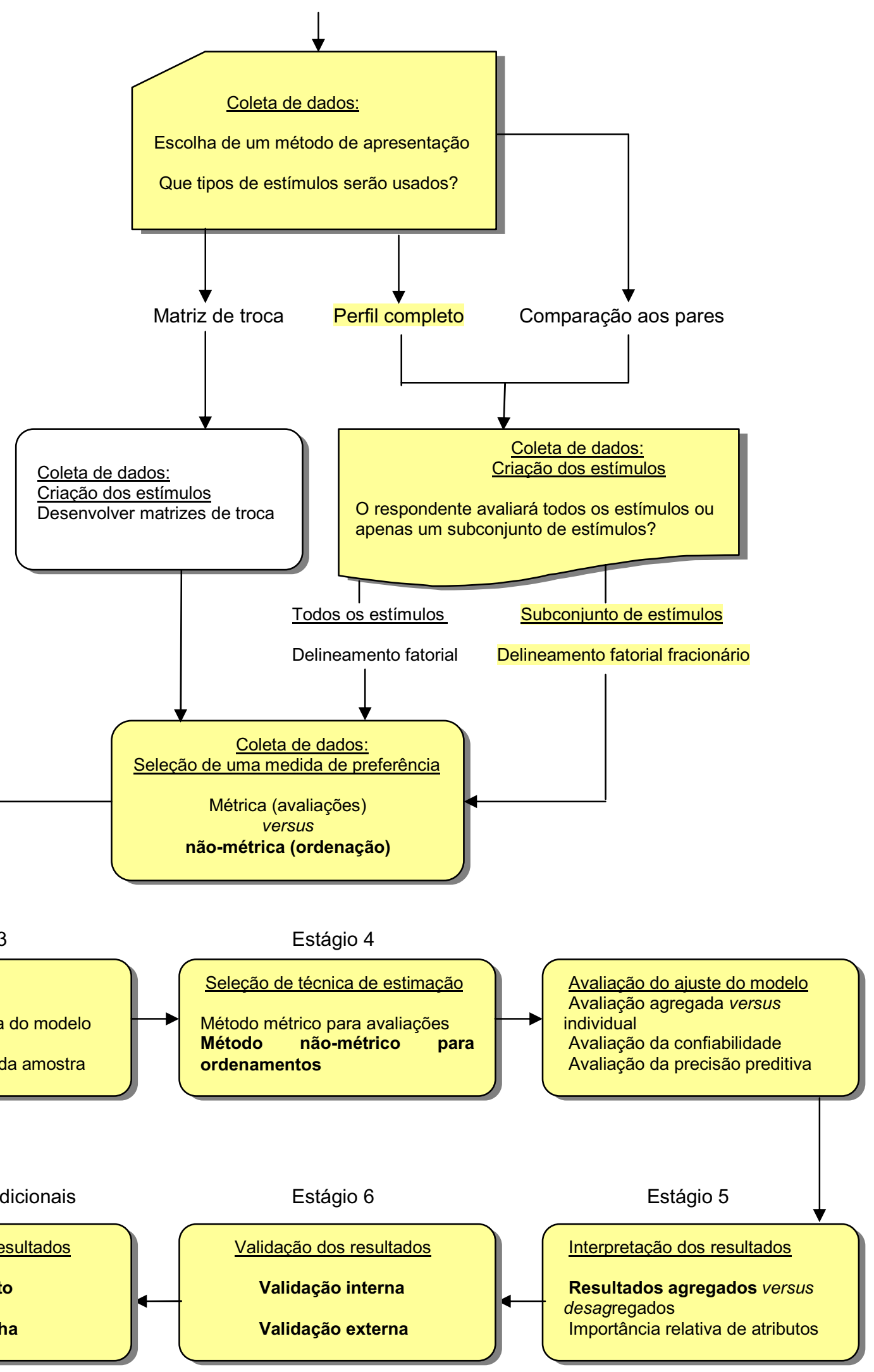

Estágio 7 Usos Adicionais

Aplicação dos resultados

Definição do produto

Simulador de escolha
Suposições

Adequação da forma do modelo

Representatividade da amostra

Perfil completo

O respondente avaliará todos os estímulos ou apenas um subconjunto de estímulos?

Subconjunto de estímulos

Delineamento fatorial Deamento fatorial fracionário 


\subsubsection{1 - Estágio 1: Os objetivos da análise conjunta}

Definir objetivos, em qualquer análise estatística é ponto de partida. $\mathrm{Na}$ análise conjunta é passo fundamental e crítico, indicativo do sucesso a ser alcançado. Hair at al (2005) destacam que o pesquisador tem que cumprir duas premissas indispensáveis:

1. Definir os fatores (atributos) e seus níveis que sejam relevantes.

No processo de escolha dos produtos há os critérios-chave que determinam a decisão de compra. O pesquisador deve entender e converter esses critérios em fatores (variáveis estatísticas) e seus diversos níveis. Ao aplicar a pesquisa, fornecer a descrição completa de todos os atributos que conferem utilidade ao produto é de suma importância, pois o respondente apenas reagirá aos estímulos (cartões) apresentados pelo pesquisador.

Importante destacar que o modelo deve conter variáveis que adicionem valor ao produto (fatores positivos que incrementam o valor da função utilidade), assim como deve conter as variáveis que diminuem o valor da função utilidade (atributos negativos) e realmente o diferenciem. Para que possam diferenciar o produto, tais fatores devem variar sensivelmente, ou seja, devem ter variação com uma razoável amplitude.

2. Definir um modelo válido

Modelos válidos permitem prever a aceitação do consumidor a qualquer combinação de atributos, mesmo aqueles que não foram originalmente avaliados por consumidores. (HAIR et al, 2005).

Ainda segundo Hair et al (2005), os modelos aditivos simples, onde as utilidades parciais dos atributos são somadas, normalmente conduzem a resultados satisfatórios. Tem como vantagem que nem todas as variáveis precisam fazer parte do modelo, apenas as variáveis relevantes. Omissões de variáveis secundárias não afetam o julgamento da preferência do consumidor. 


\subsubsection{2 - Estágio 2: O projeto}

No segundo estágio, conforme o proposto por Hair et al (2005), executa-se a estruturação do experimento, com a seleção da metodologia a ser adotada, a seleção das variáveis e níveis, o planejamento dos estímulos e a coleta de dados.

A escolha da metodologia é feita em função do número de atributos que se pretende avaliar, no nível de análise (nível individual ou agregado) e na forma do modelo adotada (aditiva ou aditiva com efeitos de interação). A Tabela 2 compara as metodologias disponíveis e os critérios e escolha.

Tabela 2: Comparação de metodologias conjuntas alternativas

\begin{tabular}{|lccc|}
\hline \multicolumn{1}{c}{ Característica } & \multicolumn{3}{c|}{ Metodologia conjunta } \\
\cline { 2 - 4 } & Tradicional & Adaptativa & Baseada em escolha \\
\hline $\begin{array}{l}\text { Número máximo de atributos } \\
\text { Nível de análise }\end{array}$ & 9 & 30 & 6 \\
Forma do modelo & Individual & Individual & Agregada \\
\hline
\end{tabular}

Fonte: Hair et al (2005)

$\mathrm{Na}$ análise em nível individual a interpretação dos resultados é feita para cada respondente. No nível agregado a análise é feita de modo global, apresentando os resultados de modo global e mais apropriada quando pretende-se analisar nichos ou o mercado como um todo.

A análise conjunta tradicional, principal forma de aplicação do método comporta a aplicação de até 9 atributos, utiliza o modelo aditivo para composição da utilidade total e trabalha com nível de análise individual (por respondente).

A análise conjunta adaptativa, da mesma forma que a tradicional, trabalha em nível individual, de forma aditiva, mas permite o uso de até 30 atributos. Foi desenvolvida para tratar com grande número de atributos, que torna a análise tradicional inviável de ser aplicada.

A Análise conjunta baseada em escolha considera os efeitos de interação dos atributos e opera apenas em nível agregado. 
Hair et al (2005) destaca que ao selecionar e determinar fatores e níveis o pesquisador deve se preocupar com que as medidas sejam comunicáveis e acionáveis.

- Entende-se por medidas comunicáveis, quando a descrição das variáveis e seus níveis são transmitidas para os respondentes, com o entendimento mais perfeito possível de todas as nuances que o pesquisador pretende analisar.

- Por medidas acionáveis, entende-se que os fatores e níveis devem ter condições de ser colocados em prática. Hair et al (2005) orienta que os atributos não devem "vagos" como qualidade ou conveniência. Os níveis não devem ser especificados em termos imprecisos como baixo, moderado ou alto.

O pesquisador, ainda, deve abordar três características: números de fatores, multicolinearidade entre os fatores e o preço como um fator.

A quantidade de fatores incluídos na análise afeta diretamente a eficiência estatística e a confiabilidade dos resultados, Hair et al (2005). Quando há acréscimo do número de fatores, consequentemente há aumento no número dos parâmetros estimados para o modelo. Para que a confiabilidade do modelo seja mantida em padrões aceitáveis, deve haver aumento na geração dos estímulos que serão apresentados aos respondentes.

O problema da falta de eficiência estatística do resultado, decorrente do número insuficiente de estímulos, não consegue ser resolvido com o aumento da quantidade de respondentes e conduz à estimação de modelos pouco confiáveis.

A multicolinearidade entre os fatores é um problema que deve ser remediado. A exemplo de outras técnicas estatísticas, busca-se no modelo elevada correlação das variáveis independentes (fatores) com a variável dependente e a menor correlação possível entre as variáveis independentes.

A correlação entre as variáveis, também denominada de correlação ambiental ou interatributos traduz-se em falta de independência entre as variáveis. No caso da análise conjunta, onde há a criação de estímulos - por meio de combinação dos níveis de todos os 
atributos, a combinação de variáveis que contém forte correlação negativa entre elas, pode resultar em combinações inacreditáveis.

Hair et al (2005) ainda orientam que este problema pode ser contornado de duas formas:

1 - Criação de superatributos

- Cria-se uma nova variável, resultado da operação algébrica entre as variáveis correlacionadas. Como exemplo, no mercado imobiliário, ao analisar variáveis para lotes de terreno, há forte correlação positiva entre os valores de área e frente (testada) do lote. Para resolver o problema cria-se nova variável (profundidade equivalente) resultante da divisão da área total pela testada do lote, retirando-se do modelo a variável frente. Tal solução também é válida para variáveis correlacionadas negativamente.

- Para atributos qualitativos e correlacionados positivamente, a solução é criar um superatributo, que conceitualmente traduza a conjugação de dois outros atributos. Há que reforçar, que a validade destas soluções está ligada com a manutenção dos prérequisitos de comunicabilidade e acionabilidade das medidas.

2 - Modificações na metodologia

- Criação de estímulos "quase" ortogonais, para eliminar estímulos inacreditáveis resultantes da correlação interatributos.

- Alterar a estimação de utilidades parciais para que obedeçam a uma relação pré-especificada e mais restritiva (menor liberdade, em cada fator, na forma de estimação dos parâmetros), utilizando relação entre níveis linear ou quadrática. 
Existe uma discussão sobre a utilização do preço como fator. Na maioria dos casos, a inclusão do preço na análise conjunta, assume-se que este fator tem grande correlação com os demais e que sua importância relativa será alta, no modelo obtido. A presença do fator preço, na análise conjunta, tem outras implicações:

- A relação preço-qualidade cause combinações não realistas.

- Outros fatores positivos, intangíveis e passíveis de avaliação, tais como os inerentes aos produtos de inovação no mercado (caso do produto i-phone da Apple), podem ter seu efeito sublimado ou mascarado pelo fator preço.

- $\quad$ Efeitos de interação do preço com a marca. Marcas premium induzem a patamares de preço maiores.

Estas características únicas do preço quando utilizado como fator não devem conduzir o pesquisador a excluir a variável preço do modelo, mas certamente merece cautela ao definir os níveis de preço, assim como na interpretação dos resultados.

$\mathrm{Na}$ análise conjunta, os níveis são efetivamente as medidas utilizadas na criação dos estímulos. Além da preocupação comum de serem medidas comunicáveis e acionáveis, o número de níveis, o equilíbrio de níveis entre fatores e o intervalo dos fatores tem efeitos diferentes sobre a avaliação dos respondentes e sobre o modelo obtido, (HAIR et al, 2005).

- Número de níveis e equilíbrio de níveis entre fatores. Recomenda-se que na elaboração da pesquisa, o pesquisador tente equilibrar ou equalizar o número de níveis nos fatores. Empiricamente, verifica-se que fatores que contém maiores números de níveis, resultam em importâncias relativas maiores no modelo. Segundo Hair et al (2005) o detalhamento do fator em muitos níveis faz com que os respondentes se concentrem naquele fator mais que nos outros. 
- Intervalo dos níveis fatoriais. A amplitude dos níveis deve ser estabelecida fora dos valores existentes, mas com a cautela de não atingirem níveis inacreditáveis. Nominalmente, níveis inaceitáveis também devem ser evitados. Critérios de relevância prática e aplicabilidade devem ser seguidos. Níveis que não são práticos e em situações reais nunca seriam aplicados devem ser evitados. O fator preço é especialmente sensível à variações de nível não reais e que conduzem a experimentos com resultados inservíveis ou óbvios demais, que desmerecem a pesquisa e sua relevância prática.

A composição do modelo pode ser aditiva ou aditiva com efeitos de interação e implica no modo que o respondente combina as utilidades parciais para obtenção da utilidade geral (HAIR et al, 2005).

- Modelo aditivo.

É a regra de composição básica e mais comum. Por meio dela a utilidade total é obtida pela soma das utilidades parciais dos fatores que compõe a análise. $\mathrm{Na}$ maioria dos casos, o modelo aditivo explica de 80 a $90 \%$ da variação de preferência e é suficiente para a maioria das aplicações.

- Modelo aditivo com acréscimo dos efeitos de interação

A partir do modelo básico são acrescidas variáveis decorrentes do efeito de interação entre os atributos e que pode resultar em utilidade total maior ou menor que o modelo básico. O ganho em variância explicada (poder de predição do modelo) é de 5 a 10\% em relação ao modelo básico.

Os termos de interação são mais substanciais em casos de julgamento de preferência que envolvam variáveis intangíveis. Em casos de avaliação de atributos estéticos, emocionais ou de marca, os efeitos de interação podem ser interessantes. 
Segundo Hair et al (2005), a importância crescente de adoção de modelos contendo termos de interação é resultado da inabilidade em descrever diferenças entre certos atributos, com as partes "inexplicadas" associadas apenas a certos níveis de um atributo.

Hair et al, (2005) define que a coleta de dados envolve as atividades de:

- Método de apresentação dos estímulos

- Tipo de variável de resposta

- Método de coleta de dados

Método de apresentação dos estímulos

A coleta dos dados, em análise conjunta, é efetuada por meio de escolhas de preferência dos respondentes aos estímulos apresentados. Os três métodos usuais para apresentação dos estímulos, são: o método de trocas, de perfil completo e de combinação aos pares.

- Método de trocas

Compara apenas atributos aos pares, classificando todas as combinações possíveis de níveis. A principal vantagem é o fato de ser simples para o respondente e fácil de administrar, porém possui limitações, tais como:

- Por comparar e escolher apenas dois fatores por vez, a análise produz resultados distantes da realidade;

- número muito grande de julgamentos são feitos pelo respondente, mesmo com pequeno número de níveis; 
- Tendência a respostas por padrão rotineiro, devido a confusão ou fadiga do respondente;

- Método de perfil completo

O método mais popular, em função de sua capacidade de redução da quantidade de estímulos, por meio da utilização de delineamentos fatoriais fracionários. Dentre as vantagens, Hair et al (2005), ressalta:

- O respondente tem interesse em ordenar ou avaliar os estímulos, já que tem visão completa do produto/serviço proposto, além de evidente realismo;

- Exige menos julgamentos;

- Cada estímulo é completo (tem todos os fatores) e contém níveis variados;

Tem como limitações, a sobrecarga de informações apresentadas ao respondente, que pode levá-lo a simplificar o processo, concentrando-se apenas em poucos fatores e a ordem como os fatores são apresentados pode ter influência na resposta (simplificação da resposta em função do efeito de ordem).

- Método de combinação aos pares

Resultado da combinação dos dois outros métodos. Trata-se de uma comparação de dois perfis, onde cada perfil contém alguns poucos atributos e o respondente geralmente utiliza uma escala para avaliação e utilizado quando há um grande número de atributos.

Tipo de variável de resposta

A variável de resposta pode ser fornecida como ordenação dos estímulos, por ordem de preferência ou a avaliação dos mesmos utilizando uma escala de Likert (de 1 a 10). 
O método de troca utiliza apenas dados ordenados como variável de resposta. Os métodos de comparação aos pares e de perfil completo permitem utilizar a variável de resposta, tanto como ordenação quanto como avaliação dos estímulos.

A medida de preferência por ordenação tem a vantagem de possuir maior confiabilidade nas respostas obtidas, dada a maior facilidade que a resposta por avaliação - para pequenas quantidades de estímulos (até 20), entretanto há maior dificuldade na coleta dos dados, que deve ser feita por meio de entrevista pessoal.

Método de coleta de dados

A entrevista pessoal, antecedida por explanação sobre os objetivos da pesquisa, detalhamento dos fatores e níveis e orientação da forma de execução, ainda é a forma mais eficaz, apesar do crescente uso da internet e de recursos computacionais.

Johnson (apud HAIR et al, 2005) conclui que a avaliação/ordenação de até 20 estímulos conduz a resultados confiáveis. Acima deste número as respostas tendem a ficar menos confiáveis e menos representativas da estrutura de preferência em análise.

Imprescindível para o sucesso da coleta confiável de dados é a execução de prétestes da coleta de dados, para avaliação das etapas envolvidas, desde a apresentação da pesquisa, do método de administração dos estímulos, da aceitação dos estímulos além de avaliação da carga de informações impostas aos respondentes. 


\subsubsection{3 - Estágio 3: Suposições da análise conjunta}

Os testes estatísticos de normalidade, homocedasticidade (variâncias iguais) e independência das variáveis são desnecessários na análise conjunta em função do delineamento estruturado do experimento conjunto e da natureza generalizada do modelo.

Ainda segundo Hair et al (2005), embora a análise conjunta não prescinda das premissas comuns às demais técnicas de dependência, há uma carga muito maior nesta técnica no que se refere às bases conceituais. Seleção de fatores não relevantes, adoção de níveis inadequados, assim como erros na especificação prévia da forma do modelo (efeitos principais ou modelo interativo) não permitem mudança ou retrocesso no decorrer do experimento e resultam em modelos que não atendem ao objetivo da pesquisa, além de não serem aderentes à realidade.

\subsubsection{4 - Estágio 4: Estimação do modelo conjunto e avaliação do ajuste geral}

Os modelos adotados, gerados a partir de programas computacionais próprios ao desenvolvimento de análises conjuntas (SPSS, SAS, Sawtooth, CONSURV e outros), fornecem estimativas de utilidades parciais dos atributos, de modo a obterem coeficientes de correlação altos, ou seja procuram estimar modelos, onde os valores preditos ou calculados, sejam o mais próximo possível dos valores observados e colhidos no experimento.

Seleção de uma técnica de estimação

As avaliações executadas por ordenação (estímulos ordenados do mais preferido ao menos preferido), resultando em medidas não métricas, exigem a aplicação de técnicas 
modificadas de análise de variância. Destacam-se MONANOVA (Análise Monotônica de Variância) e o LINMAP.

Segundo Green e Srinivasan (1978), os métodos de estimação de parâmetros em análise conjunta podem ser classificados em três categorias:

1. Métodos que assumem que a variável dependente é, na maioria das vezes, disposta em escala ordinal. Métodos que pertencem a esse grupo são MONANOVA (Kruskal 1965), PREFMAP (Carroll 1972), o procedimento de troca não-métrico de Johnson (Johnson, 1973; Nehls, Seaman e Montgomery, 1976), e LINMAP (Srinivasan e Shocker, 1973; Pekelman e Sem, 1974).

2. Métodos que assumem que a variável dependente é disposta em escala intervalar. Métodos que pertencem a esse grupo são a regressão dos mínimos quadrados ordinários (MMQO) (Johnston, 1972), e regressão pela mínima soma dos erros absolutos (Srinivasan e Shocker, 1973).

3. Métodos que relacionam a comparação de dados aos pares com um modelo probabilístico de escolha. Métodos que pertencem a esse grupo são LOGIT (McFadden, 1976; Bem-Akiva, 1973; Gensch, Golob e Recker, 1976; Green e Carmone, 1977; Punj e Staelin, 1978) e PROBIT (Goldberger, 1964; Rao e Winter 1977).

No grupo dos algoritmos projetados para uma variável dependente disposta em escala ordinal, MONANOVA é restrito ao modelo de função de utilidade parcial separada. Os métodos restantes podem ser usados tanto o modelo linear quanto para o de utilidades parciais separadas. Para o modelo quadrático, o LINMAP é o que melhor se ajusta, desde que o uso de outros métodos mostrem-se inadequados por conduzirem à valores negativos e resultando em dificuldades de interpretação (SRINIVASAN; SHOCKER, 1973).

Os algoritmos se diferem um dos outros pelas definições operacionais de seus índices de "falta de ajustamento" (poorness-of-fit), análogo à (1-R²) nos estudos de regressão múltipla, e pelo método de otimização utilizado para determinar parâmetros estimados 
para alcançar a mínima "falta de ajustamento". Enquanto não há um método prioritário para escolher entre as diferentes definições de "falta de ajustamento", testes de validade de predição empíricos poderiam guiar-nos nessa direção.

Ainda, conforme Green e Srinivasan (1978), o LINMAP difere-se dos outros por usar programação linear se comparado aos métodos clássicos de cálculo empregados pelas outras técnicas. O uso de programação linear possibilita o LINMAP obter estimativas de parâmetro globais ótimas, enquanto que os outros métodos não podem dar garantia de alcançar otimização global.

No LINMAP, valores de atributo podem ser obrigados a serem não-negativos, funções de utilidade parcial separada podem ser obrigadas a assumirem modelo linear ou do tipo quadrático, enquanto tais obrigações não podem ser impostas para os outros métodos. Tais obrigações, impostas com base no conhecimento prévio, podem ser adequados para melhorar a precisão dos parâmetros estimados, quando a razão $n / T$ (na qual T é o número de parâmetros estimados e $n$ é o número de estímulos a serem avaliados) é pequena assumindo, obviamente, que o conhecimento prévio está correto.

Desse modo, o uso da soma dos erros absolutos como medida da "falta de ajustamento" tende a produzir estimativas mais robustas do que a soma dos quadrados dos erros. Por exemplo, os parâmetros estimados não são tão afetados por “outliers" ou erros grandes na entrada de dados (BLATTBERG; SARGENT, 1971).

De outro modo, quando a razão $n / T$ é pequena, em alguns casos, o uso da programação linear produz ótimos alternados (por exemplo, diferentes conjuntos de parâmetros estimados possuem a mesma "falta de ajustamento"), o que intuitivamente é um contrasenso.

Se a preferência medida resulte em medida métrica, como é o caso da avaliação (são fornecidas notas em escala de Likert), muitos métodos podem ser utilizados, inclusive a regressão múltipla. 
Seleção da relação de utilidades parciais

Para que o modelo conjunto obtenha alto grau de aderência entre os valores observados e previstos, há a necessidade de analisar e decidir como os níveis de um fator se relacionam uns com os outros. A forma de relação das utilidades parciais pode ser especificada para cada fator separadamente. Há três formas de relacionamento, conforme ilustra a Figura 6.

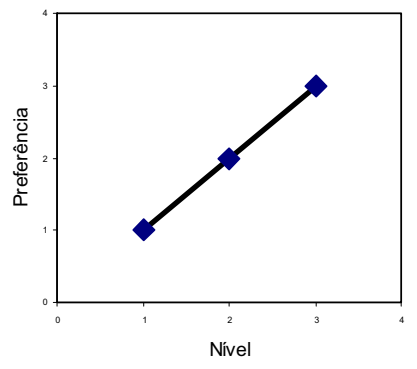

a-) Linear

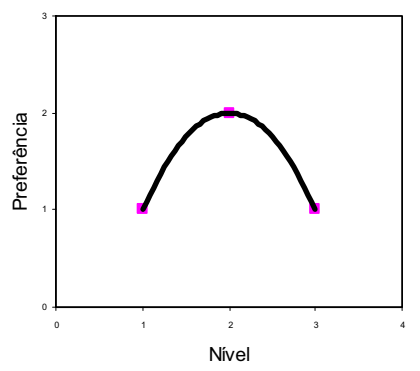

b-) Quadrática ou ideal

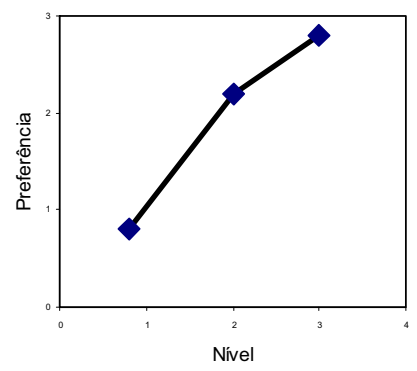

c-) Utilidade parcial

Figura 6: Os três tipos básicos de relação entre níveis fatoriais em análise conjunta. Fonte: Adaptado de hair et al (2005)

- Linear: forma mais simples e também a mais restrita, porque estima-se apenas uma utilidade parcial, a qual é multiplicada pelo valor do nível para chegar a utilidades parciais separadas para cada nível. Dependente da especificação dos níveis pode ser detalhada em forma crescente (linear positiva) ou forma decrescente (linear negativa);

- Quadrática: na qual a suposição é que o nível tenha um ponto ótimo, podendo ser ponto de máximo ou de mínimo (ideal ou anti-ideal), que resultará em forma curvilínea da relação, com a concavidade para cima ou para baixo.

- Utilidade parciais separadas: forma mais ampla, resultando em estimativas (parâmetros) separados para cada nível. Nesta forma, o número de parâmetros estimados é mais alto (um para cada nível), resultando em modelos estatísticos com maiores erros e poderes de predição menores. 
A forma de utilidade parciais separadas conduz a resultados mais precisos de como o consumidor realmente forma a preferência geral, mas ocasiona estatisticamente resultados menos eficientes. Ao adotar-se forma mais restritiva de relação das utilidades parciais (linear ou quadrática), a eficiência estatística melhora, tornando o modelo mais confiável.

Avaliação da qualidade do ajuste do modelo

A qualidade do ajuste do modelo pode ser medida tanto em nível individual (por respondente) quanto em nível agregado (para a amostra toda).

Para dados ordenados, a qualidade é medida em função do grau de correlação. São utilizados como indicadores o rô $(\rho)$ de Pearson e o tau $(\tau)$ de Kendall, além da análise do nível de significância.

\subsubsection{5 - Estágio 5: Interpretação dos resultados}

Obtido o modelo, para interpretação dos resultados são calculados os valores de utilidades parciais, para cada nível, totalizado por fatores e somados todos os fatores. Ponderando-se tais valores, obtém-se o peso de cada fator na preferência do respondente. Portanto, quanto maior a utilidade parcial (não importando se positiva ou negativa) mais significativa ela é para a utilidade geral. Gráficos de valores relativos são gerados para melhor visualização e interpretação dos resultados.

Para análise de mercados, a interpretação ocorre com resultados agregados. Não importando se a estimação foi feita a nível individual e então agregada ou se estimativas agregadas são utilizadas são feitas para o grupo de respondentes, a análise conjunta ajusta um modelo ao agregado das repostas. 
Obviamente, desta forma as análises se interpretadas em nível individual, demonstrarão pouca eficiência e poder de aderência, porém o propósito da análise, nesses casos, é de obterse a visão do mercado como um todo e não de respondentes individuais.

O propósito do estudo é que vai definir o nível da análise a ser realizada (agregada ou desagregada) e o método de interpretação.

Avaliação da importância relativa dos atributos

Com o objetivo de melhor interpretar os resultados da análise conjunta, é calculada a importância relativa dos atributos. Obtém-se a amplitude de cada fator (variação em módulo do nível mais alto ao nível mais baixo) e ao dividir pela soma das amplitudes de todos os fatores, estabelece-se a importância relativa dos atributos.

O significado prático desta medida é atribuir aos fatores constantes da pesquisa as devidas importâncias, na preferência dos respondentes.

\subsubsection{6 - Estágio 6: Validação dos resultados conjuntos}

Os resultados da análise conjunta podem ser validados interna e externamente.

\section{Validação interna}

Para validação interna do modelo, utilizam-se os estímulos retidos (holdouts), que são estímulos acrescentados ao experimento, mas que não fazem parte do cálculo estatístico. São utilizados após a estimação dos parâmetros, para medir complementarmente o grau de predição do modelo. Também denominados estímulos de validação, utilizando como medida de ajuste o tau de Kendall ao nível de significância estimado para o teste (usualmente 0,1 ou $10 \%$ ). 
Hair et al (2005) detalha o procedimento, citando que o pesquisador prepara mais cartões de estímulo que o necessário à estimação das utilidades parciais, e o respondente classifica todos ao mesmo tempo. Parâmetros do modelo conjunto estimados são utilizados para calcular a utilidade total dos cartões de validação e então comparados com a preferência real declarada pelo respondente. As amostras de validação são utilizadas, apenas, em modelos de estimação em nível individual.

\section{Validação externa}

Hair et al (2005) reforça que a validação externa do modelo conjunto envolve a habilidade de prever escolhas reais.

A representatividade da amostra coletada é fator de suma importância, para a validade externa da pesquisa. Gujarati (2006) relata "o pesquisador sempre deve ter em mente que os resultados de sua pesquisa terão a mesma qualidade dos dados coletados.”

\subsubsection{7 - Estágio7: Simuladores de escolha}

A função dos simuladores de escolha é prever o comportamento de mercado dos produtos/serviços em análise. Os simuladores indicam a participação de preferência que um estímulo real está apto a capturar, nos vários cenários permitidos pela simulação. De outro modo, após realizada a inferência da preferência dos respondentes, o pesquisador especifica o produto que pretende lançar e dentro das condições da pesquisa efetuada (em função dos dados coletados e do poder de predição do modelo) obtém o percentual de preferência do mercado. 
Há dois modelos de simuladores de escolha.

- Modelo de utilidade máxima

Neste modelo, assume-se que a preferência do mercado se dará sobre o estímulo que possui o maior escore de utilidade, calculada com a função de utilidade obtida pelo modelo. É mais adequado em casos de mercados com indivíduos de preferência amplamente diferentes e em situações que envolvam compras esporádicas e não-rotineiras. O mercado imobiliário se enquadra nesta descrição, tendo em vista as preferências diversas do universo de compradores e que compras de imóveis ocorrem a longos períodos e normalmente uma única vez no ciclo de vida do consumidor.

Apropriado para comportamento de compra complexa (alto envolvimento no processo de compra e difeenças significativas entre as marcas/produtos).

- Modelos probabilísticos

Nestes modelos utilizam-se distribuições de probabilidade de escolha. Os modelos mais comuns são o modelo logit e o BTL (Bradley-Terry-Luce), que normalmente apresentam resultados similares.

O modelo Logit, segundo Gujarati (2006) é derivado da função de distribuição acumulada (FDA) do modelo logística e tem como características principais: baixa sensibilidade nos dois extremos da função de distribuição (que é uma sigmóide) e relação entre a probabilidade e o parâmetro é não linear. Estes modelos são recomendados para produtos de compra repetitiva. 
Este modelo é apropriado para o comportamento de compras habituais, na qual há pouca diferença entre as marcas e baixo envolvimento no processo de compra.

Hair et al (2005) sintetiza “ A simulação conjunta apresenta uma visão do mercado do produto e da dinâmica de preferências que podem ser vistos na amostra em estudo”.

\section{4 - Cenário de referência do mercado imobiliário}

Para a efetivação da transação imobiliária, além do aspecto de preferência do consumidor, em relação às características do produto imobiliário há outros aspectos relevantes, que determinam a demanda de mercado.

Neste Capítulo abordar-se-á potenciais de demanda do mercado imobiliário residencial e o aumento do contingente de consumidores com capacidade de pagamento, resultado do crescimento mundial e brasileiro da classe $\mathrm{C}$, apesar e além da crise econômica mundial que assolou os mercados em 2008.

\subsection{1 - Potencialidades do Mercado Habitacional}

Trabalho elaborado pela empresa de consultoria Ernst \& Young e da Fundação Getúlio Vargas (2007), delineia cenários e apontam rota estável de crescimento do mercado habitacional até 2030 .

A indústria da construção civil encontra-se em ritmo crescente de atividades, e parte significativa dos aperfeiçoamentos demandados pelos diversos segmentos da cadeia produtiva está em curso.

Agentes de crédito oficiais (em especial a Caixa Econômica Federal), e instituições de crédito privado elevaram significativamente o volume do crédito imobiliário e reduziram 
taxas de juros. Estas medidas garantiram acesso ao crédito de parte da população antes não contemplada e permitiram rápida resposta das empresas construtoras na oferta de produtos adequados.

O sistema de financiamento habitacional brasileiro tem verificado aprimoramentos há muito requeridos por seus agentes. Os aperfeiçoamentos promoveram uma desregulamentação importante, fortaleceram as garantias oferecidas para os investidores e criaram subsídios governamentais. Entre os avanços no plano legal, vale destacar:

- Lei 9.514, de 20 de novembro de 1997: com ela foi instituído o Sistema de Financiamento Imobiliário (SFI), foram criadas as companhias securitizadoras de créditos imobiliários, estabelecidos os Certificados de Recebíveis imobiliários (CRIs) e introduzida a alienação fiduciária de bens imóveis;

- Lei 10.931, de 2 de agosto de 2004: responsável pelo aprimoramento do Patrimônio de Afetação, cujo objetivo é proteger o adquirente de imóveis; a lei também estabeleceu para os casos de disputa judicial a continuidade de pagamento da parcela da prestação sob a qual não há discordância (o chamado valor incontroverso).

- Lei 11.977, de 7 de julho de 2009: que institui o Programa Minha Casa Minha Vida, que cria mecanismos de incentivo à produção e à aquisição de novas unidades habitacionais pelas famílias com renda mensal de até 10 (dez) salários mínimos. Responsável pelo reaquecimento do mercado imobiliário nacional, pós crise econômica mundial.

Essas mudanças associadas a um ambiente macroeconômico favorável ao crescimento da renda e à queda dos juros, expandiram a oferta de crédito e atraíram o capital externo.

A elevação do país no "rating" das principais agências de classificação de risco, para grau de investimento (investment grade) foi fator adicional de alavancagem no estoque de crédito imobiliário ao país. Pré-crise, as agências Standard \& Poor's (em 30 de abril de 2008) e Fitch (em 29 de maio de 2008) havia elevado o país ao tão almejado posto de "porto seguro" para investimentos estrangeiros; em setembro de 2009, a Moody's anunciou a 
elevação da nota de crédito ao país, sobretudo pela resiliência que o mercado brasileiro demonstrou, na passagem da avassaladora crise de 2008.

As necessidades habitacionais de um país são ditadas por três elementos principais:

- Dinâmica familiar: processo de formação de novas famílias, que é influenciado pela evolução da renda e pelo crescimento populacional;

- Déficit habitacional: passivo habitacional decorrente do não atendimento das necessidades de moradia ao longo dos anos;

- Depreciação: necessidade de reposição do estoque habitacional desgastado.

Segundo a FGV (2007), o ritmo de formação das famílias é o principal determinante das necessidades habitacionais de um país. Na elaboração das projeções de crescimento de famílias, além do fator demográfico, é considerado também o crescimento de renda, por se tratar de um elemento que influencia diretamente as decisões sobre o momento de formação da família, o número de filhos e a necessidade de coabitação familiar.

A relação entre o aumento do número de habitantes e a necessidade de construção de novas moradias é direta. O crescimento populacional, por sua vez, é determinado pela fecundidade da população, por sua mortalidade e por movimentos migratórios. Mas há dois aspectos igualmente importantes na questão: o processo de urbanização e a evolução da estrutura etária.

No aspecto demográfico, dados do IBGE indicam que o Brasil cresceu, nos últimos 18 anos, á taxas de 1,5\% ao ano, superiores à média mundial de 1,4\%, passando de 146,6 milhões de habitantes em 1990, para 189,9 milhões em 2008.

Dados tabulados e disponíveis na estimativa de população do IBGE, levam à conclusão que o número de famílias no Brasil passará de 60,3 milhões para 95,5 milhões - esse crescimento de $58 \%$ representa mais que o dobro do ritmo de aumento populacional mundial. A redução da taxa de natalidade também terá reflexos no tamanho das famílias, que passará de 3,1 pessoas, em 2007, para 2,4 pessoas em 2030. 
Conforme a FGV (2007), entre 2007 e 2030, a distribuição por faixa de renda mostra que haverá aumento do número de famílias nos estratos de maior poder aquisitivo. Entretanto, haverá um encolhimento do número de famílias com renda até R \$ 1 mil, e sua participação no total passará de $53 \%$ para $31 \%$.

Ao longo desses 23 anos, pode-se antever dois períodos distintos. O primeiro período próxima década, dos 15,3 milhões de novas famílias que se formarão, 57\% estará na base da pirâmide social, com renda familiar inferior a R\$ 2 mil. No segundo período, de $2017 \mathrm{em}$ diante, essa tendência muda, e 78\% dos 19,9 milhões de novas famílias terão rendimentos entre R\$ 2 mil e R \$ 8 mil. Notadamente ocorrerá ascensão social e diminuição da base da pirâmide social.

Esses dois ciclos, com dinâmicas distintas, têm implicações na forma de condução da política habitacional e nos negócios das empresas da construção. Na primeira fase, que vai até 2017, a política habitacional fundamentada em subsídios ganha mais relevância como mecanismo de complementação da renda das famílias mais pobres. Na segunda fase, em que as faixas de menor renda diminuem, os subsídios tornam-se menos importantes.

Após 2017, os mecanismos de mercado e as condições de crédito passarão a ser ainda mais preponderantes no atendimento das necessidades habitacionais. Para as empresas, construtoras, incorporadoras ou indústrias, haverá alteração no perfil de seu público-alvo e, portanto no leque de produtos a serem oferecidos. Análises e acompanhamentos constantes do perfil do mercado comprador deverão ser feitas, para que gradualmente a linha de produtos seja adequada ao novo perfil estabelecido.

Segundo estudo elaborado pela Ernst \&Young, saliente-se que necessidade habitacional não é o mesmo que demanda por moradias. A necessidade é uma possibilidade de demanda, cuja efetivação irá depender das condições econômicas: a renda das famílias, a estrutura de financiamento (volume de recursos e taxas de juros) e a eficácia da política habitacional.

As condições macroeconômicas do Brasil indicam que haverá redução gradativa da taxa de juros dos financiamentos habitacionais, combinado com elevação do volume de recursos disponíveis (créditos de longo prazo), aliado à desburocratização dos processos de financiamento e consolidação do mercado secundário de crédito (representados pelos CRIs). 
O crescimento do fluxo de investimento habitacional leva a uma melhora ampla do bemestar das famílias e há inegável aproveitamento político de tal fato. Mas, além disso, a elevação do investimento traz benefícios para a cadeia produtiva diretamente envolvida e para toda a sociedade em virtude do aumento do emprego e da renda gerado pelos empreendimentos.

Indiscutível que as potencialidades do mercado habitacional só serão alcançadas com oferta de crédito ampla, com custos de financiamento e taxas de juros viáveis. No cenário de referência, taxas de juros a 7,5 \% a.a. viabilizam operações no setor.

As oportunidades de negócios serão condicionadas pela capacidade de diferenciação de produtos e, principalmente, pela agilidade das empresas em pesquisar o mercado e explorar segmentos rentáveis. Neste sentido, este trabalho procura mostrar a aplicação da ferramenta estatística da análise conjunta, que permite o diagnóstico das preferências do consumidor e indica quais atributos devem ser reforçados ao lançar novos empreendimentos habitacionais, visando larga aceitação de mercado, velocidade de vendas e taxas de retorno de investimento atrativas.

\subsection{2 - O crescimento da classe $\mathrm{C}$ mundial e reflexos no Brasil}

A classe média recebe muita atenção, especialmente em economias desenvolvidas. Frequentemente é reconhecida como motor do crescimento, o referencial de valores sociais e árbitro de eleições. No Brasil, como será apresentado na seção seguinte, esta classe representa 49,22 \% da população e estas alcunhas se confirmam.

Segundo Wilson; Dragusanu (2008) encontra-se em curso uma explosão sem precedentes na denominada "classe média mundial". O caso da expansão média pode ser descrito de duas formas:

- A mudança no poder de consumo em direção às economias de renda média (e longe dos países ricos). O crescimento dos BRICs e economias do N11 serão o alvo desta mudança. Por volta de 2050, no bojo destas economias estarão três dos 
BRICs (Brasil, Índia e China) e seis dos N11 (Egito, Filipinas, Indonésia, Irã, México e Vietnã) e serão responsáveis por cerca de $60 \%$ do PIB mundial.

- A mudança no poder de consumo em direção às pessoas de renda média e a explosão da denominada "classe média mundial". Nos últimos dez anos, já se tem observado expansão neste grupo, porém o ritmo de expansão alcançará seu pico em dez anos. A previsão é que cerca de 1,5 bilhões de pessoas poderão formar a classe média em 2030, representando $30 \%$ da população mundial.

Consideradas as limitações das previsões realizadas, a primeira dimensão da expansão média já é visível. O poder de consumo já está mudando dos países mais ricos em direção ao bloco em crescimento dos países de renda média.

Em 1980, as sete maiores economias no mundo correspondiam ao países desenvolvidos. Em 2007 a China (economia em desenvolvimento) já compunha este rol e por volta de 2025 poderá facilmente incluir todos os países componentes do BRIC. Em 2050, segundo as projeções de Wilson; Dragusanu (2008), apenas os Estados Unidos da América poderá permanecer.

Dados coletados por Wilson; Dragusanu (2008) indicam a posição das economias mundiais em 2007 (Figura 7) e a previsão de crescimento das economias e as novas posições para 2050, podem ser observadas na Figura 8. 
USS bi - 2007

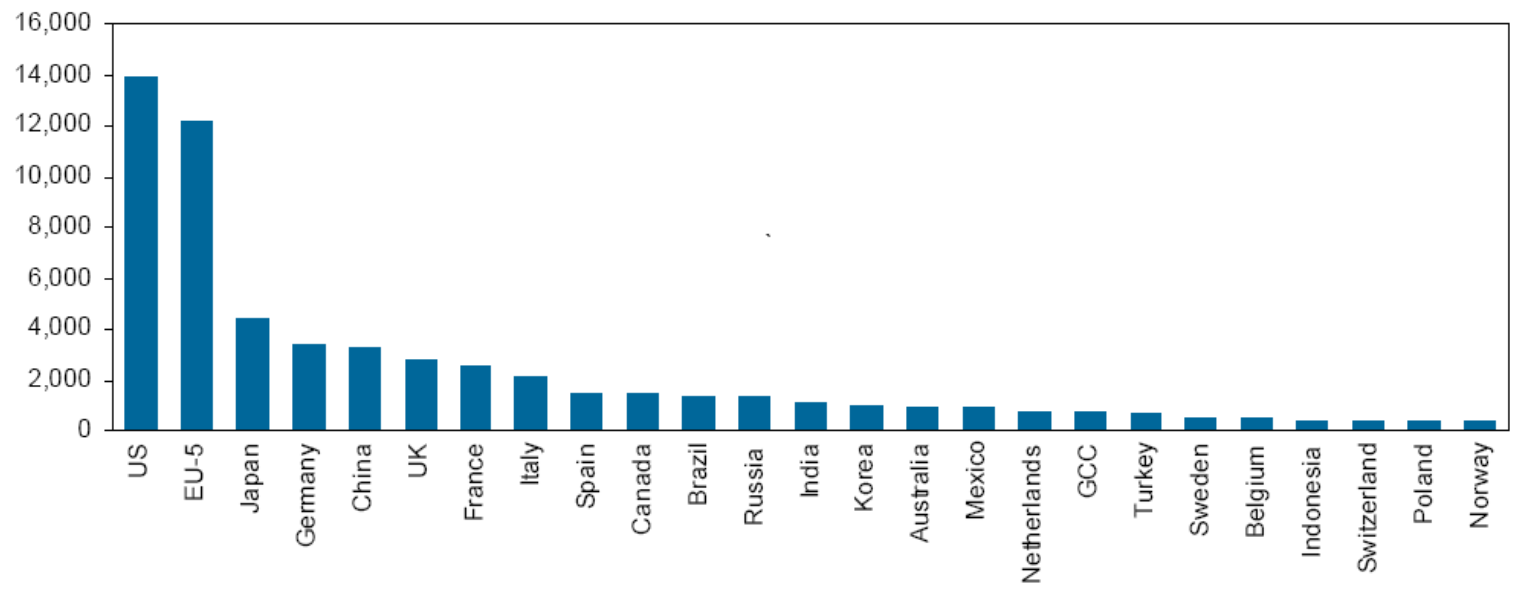

Figura 7: PIB dos 25 maiores países, em 2007. Fonte: Goldman Sachs, 2008

Fonte: Goldman Sachs, 2008

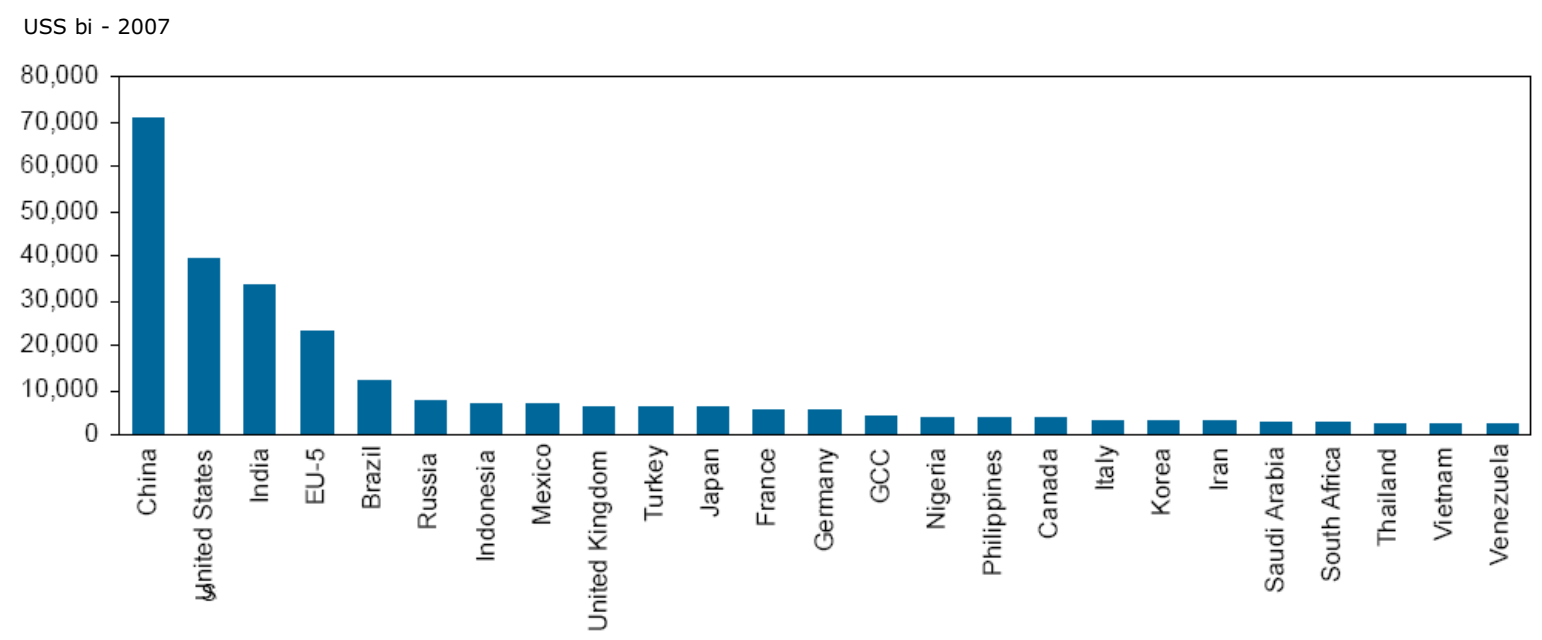

Figura 8: Previsão do PIB dos 25 maiores países, em 2050. Fonte: Goldman Sachs, 2008

Fonte: Goldman Sachs, 2008

Observa-se que o Brasil sai da posição de 11 . Economia do mundo em 2007 e alça a posição de $5^{\text {a }}$. maior economia mundial, na previsão para 2050.

A segunda dimensão da expansão média é também visível na distribuição de renda entre as pessoas. O mesmo processo de crescimento está conduzindo ao crescimento da classe média mundial. 
O estudo conduzido por Wilson; Dragusanu (2008) conclui que este grupo já está crescendo na base de 70 milhões de pessoas por ano e alcançará o pico de 90 milhões por ano por volta de 2030. Como resultado, cerca de 1,5 bilhões de pessoas poderá formar a denominada classe média mundial, em 2030, conforme se observa na Figura 9 da projeção.

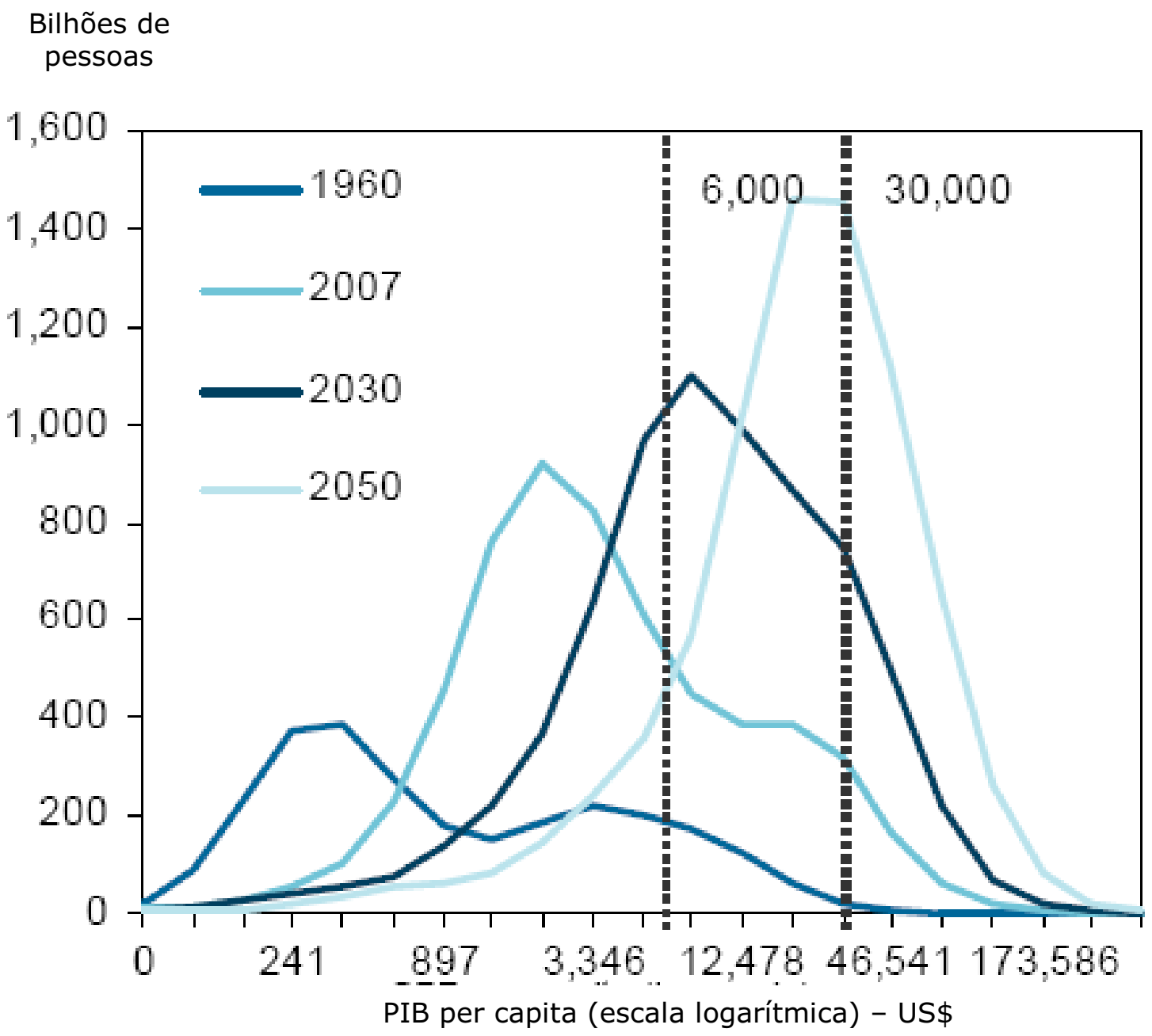

Figura 9: Previsão de crescimento da classe média mundial.

Fonte: Goldman Sachs, 2008

China e Índia são países com claras importâncias no processo de crescimento da classe média mundial, embora seja provável que o pico de crescimento na China ocorra muito antes do que na Índia.

Nas projeções elaboradas por Wilson; Dragusanu (2008), o que é surpreendente é que a melhora na distribuição mundial de renda e a expansão da classe média mundial é clara mesmo se um ou ambos desses gigantes não estão incluídos na previsão, pelo menos no passado recente neste cenário futuro projetado. A Figura 10 apresenta a distribuição de renda 
mundial excluindo China e Índia e a Figura 11 mostra a projeção da expansão da classe média separando os efeitos da China e Índia.

\section{Bilhões de}

pessoas

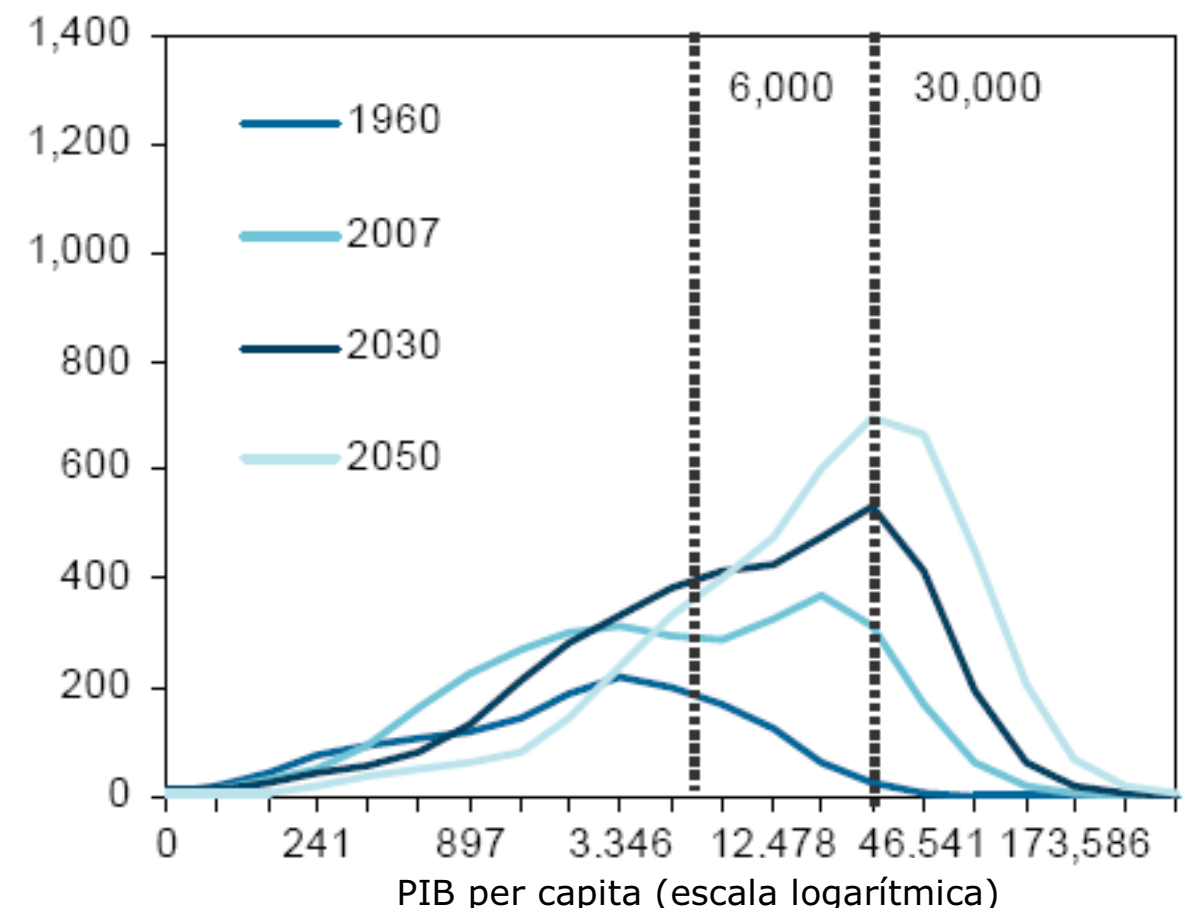

Figura 10: Previsão de distribuição mundial de renda, excluindo China e Índia Fonte: Goldman Sachs, 2008

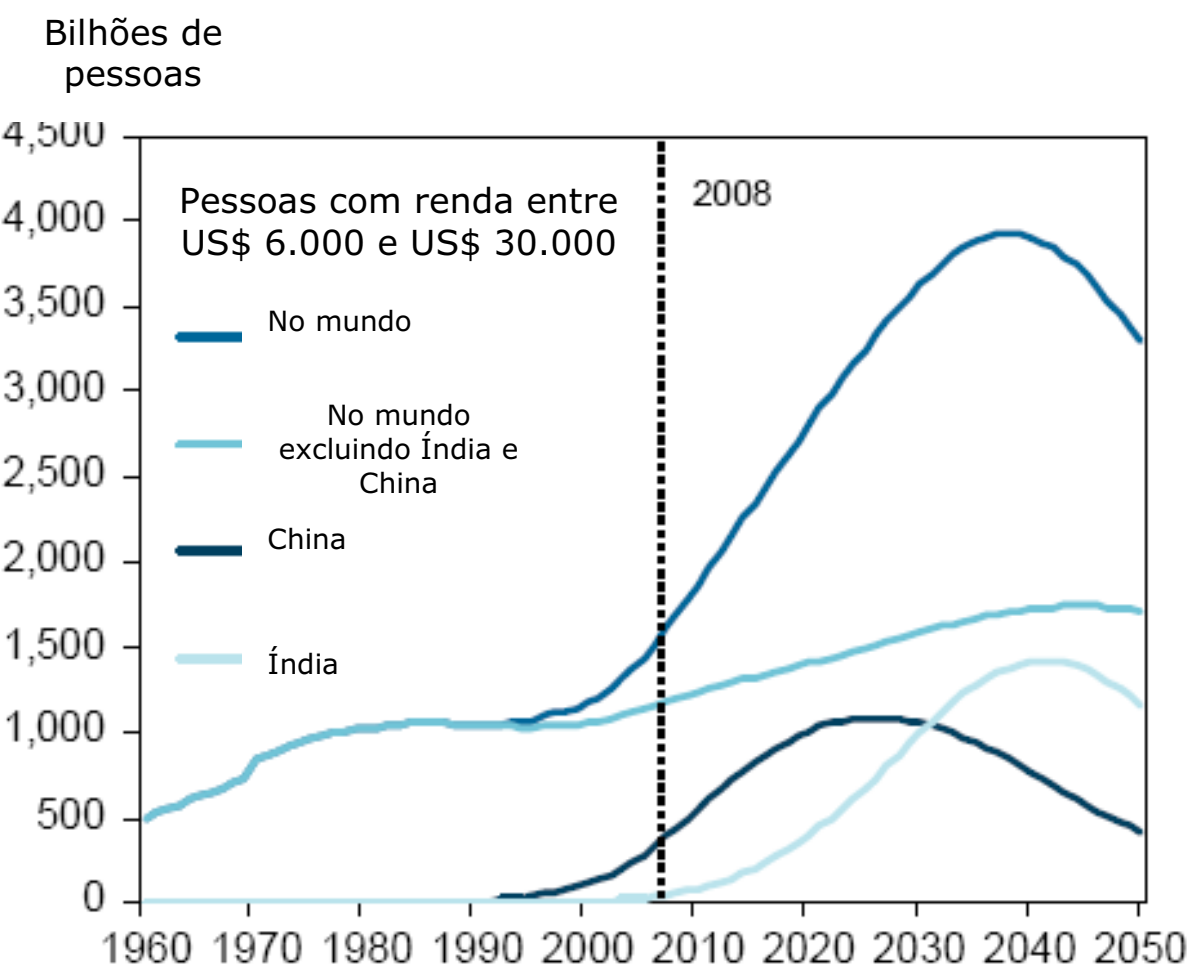

Figura 11: Previsão de expansão da classe média mundial, com efeitos separados da China e Índia 
A renda per capita também terá sensível melhora. Com foco para o Brasil, observa-se na Figura 12, que em 2007 a renda per capita brasileira representa cerca de $20 \%$ da maior renda per capita do mundo (que corresponde à renda per capita americana).

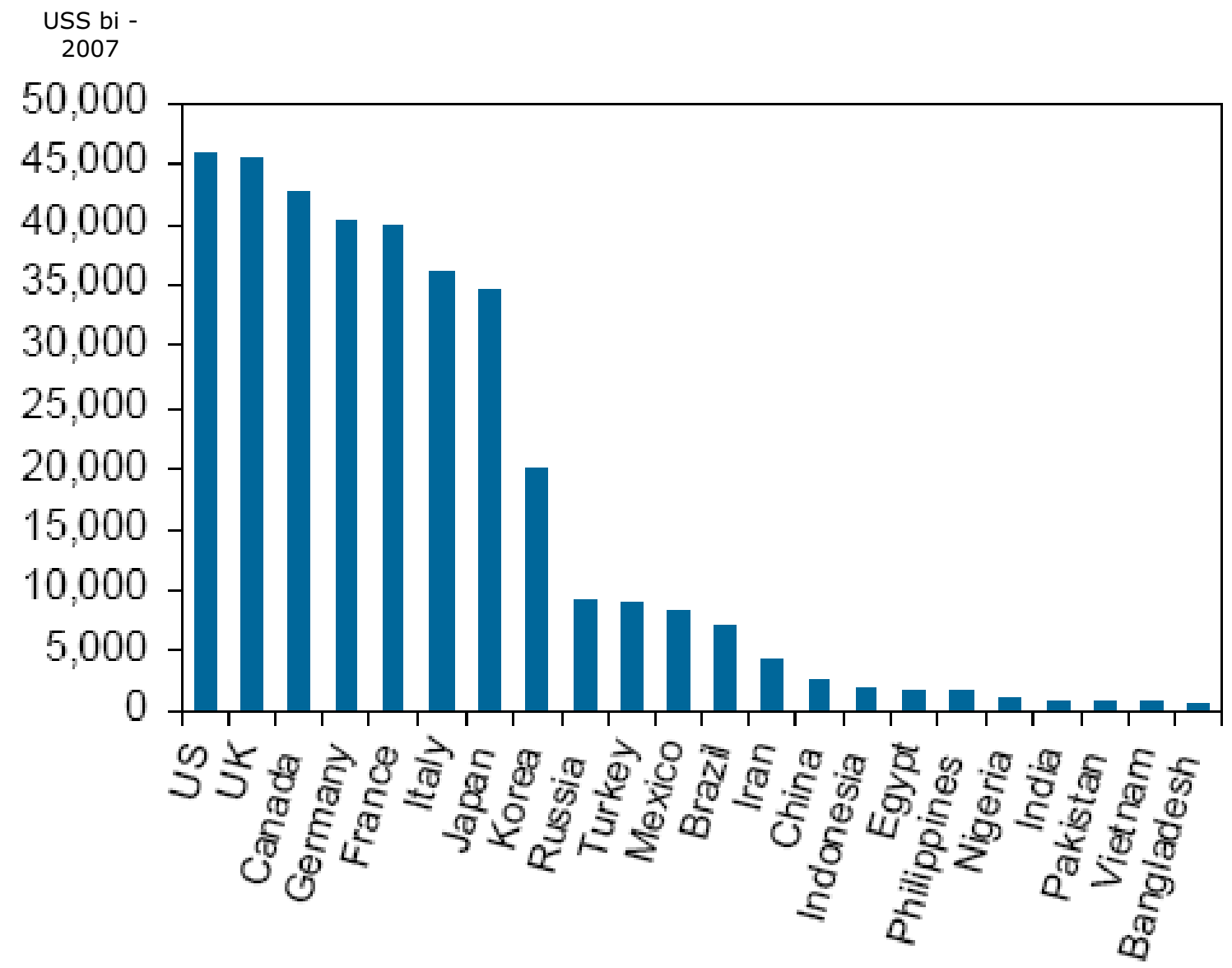

Figura 12: Renda per capita (US\$) - ano base 2007

Fonte: Goldman Sachs, 2008

Conforme a Figura 13, que apresenta a previsão de Wilson; Dragusanu (2008) para a renda per capita em 2050, o Brasil passará a ter renda per capita anual de cerca de US\$ 48 mil (valores com base em 2007), representando cerca de 50\% da maior renda per capita mundial, que continuará sendo a dos Estados Unidos. É incontestável a projeção de melhora da renda per capita.

Diante destas projeções, que configuram o cenário de referência mundial adotado, verifica-se que o Brasil tem grandes possibilidades de melhora dos indicadores de renda,com significativo crescimento da classe $\mathrm{C}$, gerando condição de consumo para bens de maior 
valor e que exigem condição de financiamento de longo prazo, tais como bens imóveis, objeto de análise deste trabalho.

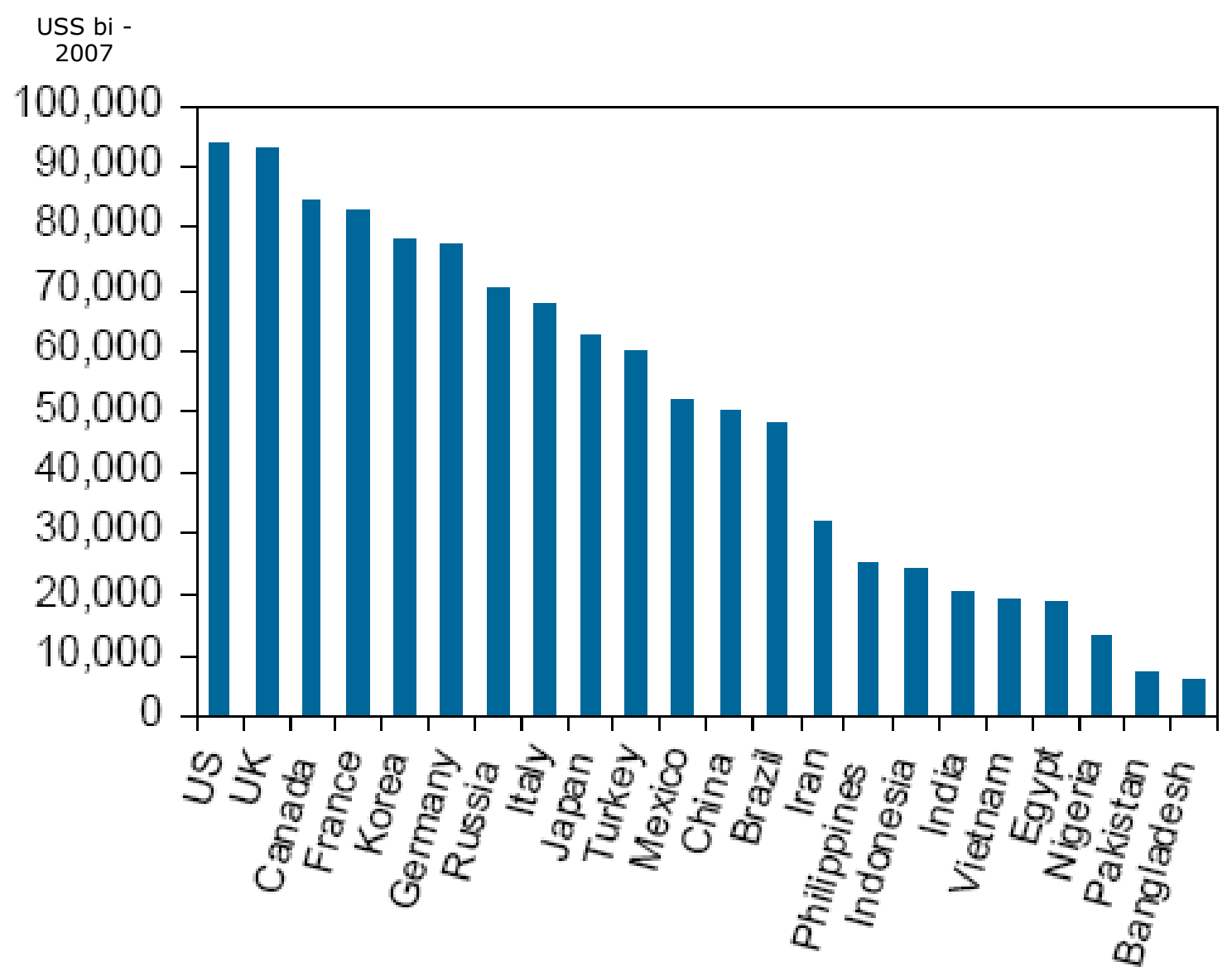

Figura 13: Previsão para 2050 da renda per capita (US\$) - valor base US\$ 2007

Fonte: Goldman Sachs, 2008

\subsection{3 - Pesquisa Nacional por Amostra de Domicílios - PNAD 2008}

Anualmente o IBGE realiza pesquisa com amostra de mais de 391 mil respostas individuais de um rico questionário com mais de uma centena de questões feito com a mesma exata estrutura a cada ano das últimas duas décadas, denominada PNAD - Pesquisa Nacional por Amostra de Domicílios.

A PNAD coleta dados demográficos e socioeconômicos da população que permitem situar o tamanho absoluto ou a posição relativa de cada grupo social. 
A análise da PNAD 2008, neste trabalho se restringirá à medir as classes econômicas, com indicadores de padrão de renda e os dados que mensuram o mercado imobiliário residencial.

Os dados da PNAD 2008, conduzida pelo IBGE, mostram que o país está em rota de crescimento, apontando sensível aumento da classe média, crescimento esse que se permanecer sustentado, efetivará o cenário previsto pela análise descrita na seção anterior.

\subsubsection{1 - As classes Econômicas}

Os microdados da PNAD, recém disponibilizados, revela entre outros indicadores a atual distribuição da população brasileira entre os diferentes estratos econômicos. A abordagem utilizada desagrega a população em quatro grupos de renda. A Tabela 3 mostra os limites das classes econômicas medidas em renda domiciliar total, por mês.

Tabela 3: Definição das Classes Econômicas

\begin{tabular}{lcc}
\hline & \multicolumn{2}{c}{ limites } \\
\cline { 2 - 3 } & Inferior & Superior \\
\hline Classe E & 0 & 804 \\
Classe D & 804 & 1.115 \\
Classe C & 1.115 & 4.807 \\
Classe AB & 4.807 & - \\
\hline Fonte: IBGE - Microdados da PNAD 2008
\end{tabular}

Neri (2009), ao organizar e comparar microdados das últimas PNADs, dos quatro grupos de renda, conclui:

Classe AB: A proporção de pessoas na classe AB (renda familiar acima de 4.807 reais) aumentou em 7\% apenas no último ano (2007-2008), o que corresponde a entrada de 1,5 milhões de pessoas no grupo mais alto de renda. Só nos últimos cinco anos, 6 milhões de pessoas ascenderam a esta classe, que em 2008 atingia 19,4 milhões de pessoas.

Classe C: Em 2003 representava 37,56\% da população, passou a 49,22\% em 2008, ou 91 milhões de brasileiros que tem renda acima de 1.115 até 4.807 reais mensais. É a classe dominante no sentido populacional. Houve crescimento de $31 \%$ no período de cinco anos. 
Traduzido em termos de população, equivale dizer que 25,9 milhões de brasileiros passaram a integrar a classe $\mathrm{C}$ nos últimos 5 anos, sendo 5,3 milhões apenas no último ano. $\mathrm{O}$ crescimento da classe $\mathrm{C}$, em termos globais e nacionais a torna o foco das estratégias de marketing e análise de mercado.

Classe D: A proporção de pessoas na classe D é $24,35 \%$ em 2008, atingindo 45,3 milhões de brasileiros com renda de 768 reais mensais até o limite da classe $\mathrm{C}$. Em termos de mobilidade houve redução de $3 \%$ ou 0,9 milhões de pessoas em um ano. Nos últimos cinco anos foi reduzida de 1,5 milhões de pessoas.

Classe E: Com redução de 12,27\% no último ano, o que corresponde à saída de 3,8 milhões de pessoas do grupo de renda familiar mais baixa. Este movimento resulta numa diminuição de $43 \%$ da pobreza, desde o fim da recessão de 2003 , ou seja, cerca de 9,4 milhões de pessoas cruzaram a linha de miséria. Em 2008, passou a ter 29,9 milhões de miseráveis (pessoas com renda inferior a R\$ 145,00 mensais (a preços médios nacionais ponderados pela população de cada estado). Os dados coletados pela PNAD 2008 permitiram concluir que este grande avanço foi efeito do programa do governo Federal denominado Bolsa Família.

A Tabela 4 demonstra a mobilidade social ocorrida nos últimos cinco anos e a Figura 14 ilustra a mobilidade das classes sociais, no período de 2003 a 2008, com destaque ao crescimento da classe $\mathrm{C}$.

Tabela 4: Classes Econômicas, população e distribuição.

\begin{tabular}{ccccc}
\hline \multirow{2}{*}{ Classe } & \multicolumn{3}{c}{ População } \\
\cline { 2 - 5 } & 2003 & 2008 & 2003 & 2008 \\
\cline { 2 - 5 } AB & 13.322 .409 & 19.418 .071 & $7,60 \%$ & $10,42 \%$ \\
C & 65.871 .283 & 91.762 .175 & $37,56 \%$ & $49,22 \%$ \\
D & 46.884 .477 & 45.399 .117 & $26,73 \%$ & $24,35 \%$ \\
E & 49.319 .851 & 29.860 .927 & $28,12 \%$ & $16,02 \%$ \\
\hline Total & 175.398 .020 & 186.440 .290 & $100,00 \%$ & $100,00 \%$
\end{tabular}

Fonte: Adaptado do IBGE - Microdados da PNAD 2008. 


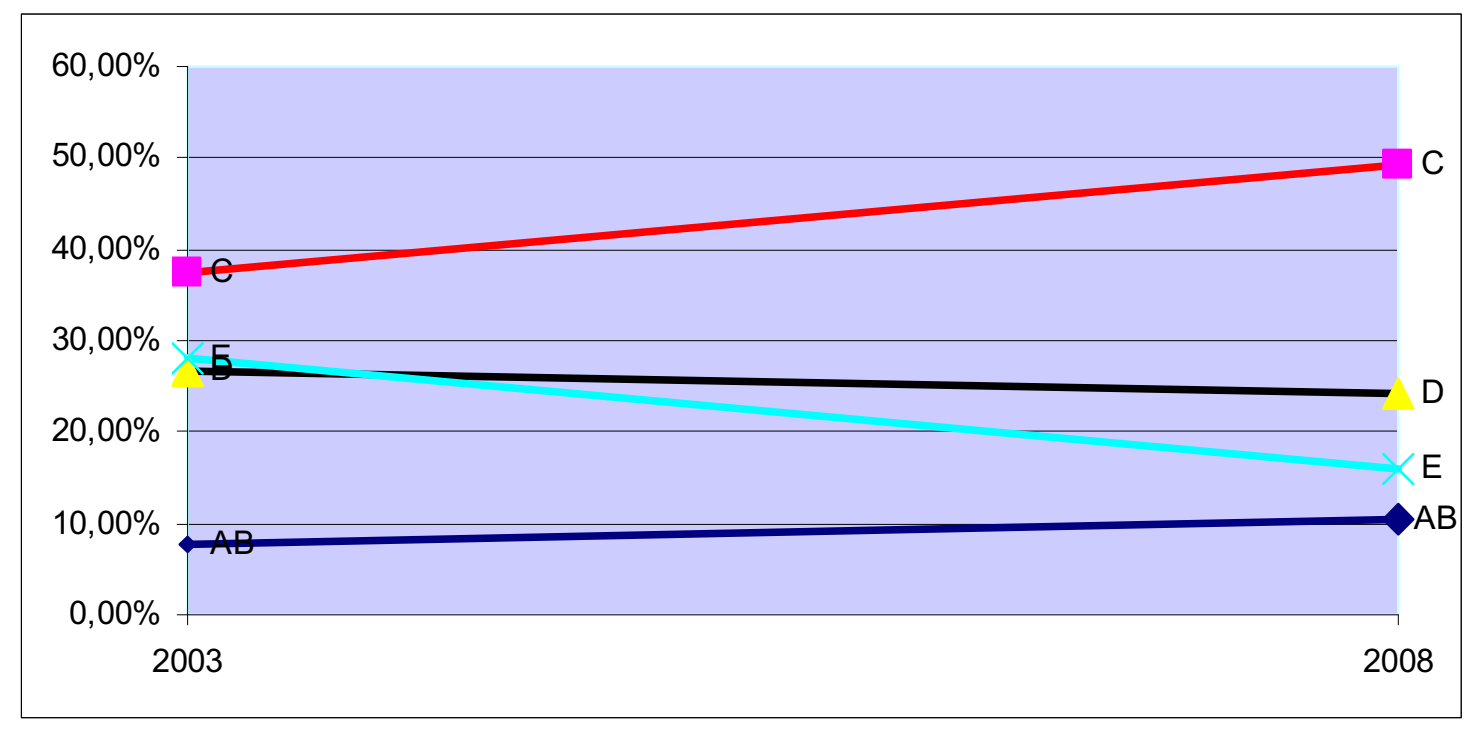

Figura 14: Mobilidade social por classes - Período 2003 / 2008

Fonte: A partir de dados do IBGE - Microdados da PNAD 2008.

\subsubsection{2 - Ano I D.C - O primeiro ano depois da crise}

Na passagem do Ano I D.C., iniciado no dia 15 de setembro de 2008, fatídica data que as bolsas de valores mundiais despencaram, fica a certeza que a crise econômica de 2008, indubitavelmente entrou para a história e resta medir suas conseqüências na composição das classes sociais brasileiras, haja vista que perdas de poder de compra influem de modo diretamente proporcional no desempenho da economia e das atividades econômicas (NERI, 2009).

Neri (2009), com base nos dados da Pesquisa Mensal do Emprego (PME/IBGE), em estudo realizado no Centro de Políticas Sociais da Fundação Getúlio Vargas (CPS/IBRE/FGV), com base nos dados de três diferentes momentos (até dezembro/2008, fevereiro/2009 e julho/2009), das seis maiores metrópoles do país obteve uma visão clara dos efeitos da crise na renda dos trabalhadores brasileiros.

\subsubsection{1 - Índice de Gini}

O matemático italiano Conrado Gini desenvolveu o coeficiente, que leva seu nome e foi adotado pela ONU, para medir a igualdade ou desigualdade dos países na distribuição de renda da população. O cálculo leva em consideração variáveis econômicas para verificar o 
grau de espalhamento da renda, em escala de zero a 1. Quanto mais próximo de zero estiver o país, mais igualitária é a sociedade. Quanto mais se aproximar de um, maior é a concentração de riqueza. $\mathrm{O}$ índice de Gini não mede riqueza ou pobreza de um país, mas a homogeneidade econômica e social de seu povo. É calculado com base na renda domiciliar per capita (incluindo os sem renda), também é o conceito mais aceito de medida de bem estar das famílias.

Durante este primeiro ano após a crise econômica mundial, a desigualdade de renda passou por forte deterioração em janeiro/2009 quando perdeu-se parte das melhoras conseguidas nos últimos anos, entretanto em julho/2009 já voltou aos níveis mais próximos do pré-crise.

Comparando-se os índices de julho/2009 com julho/2008, tem-se variação de apenas $0,3 \%$ (aumento do índice).

A Figura 15 apresenta a evolução do índice no Brasil, do período de 1992 a 2008.

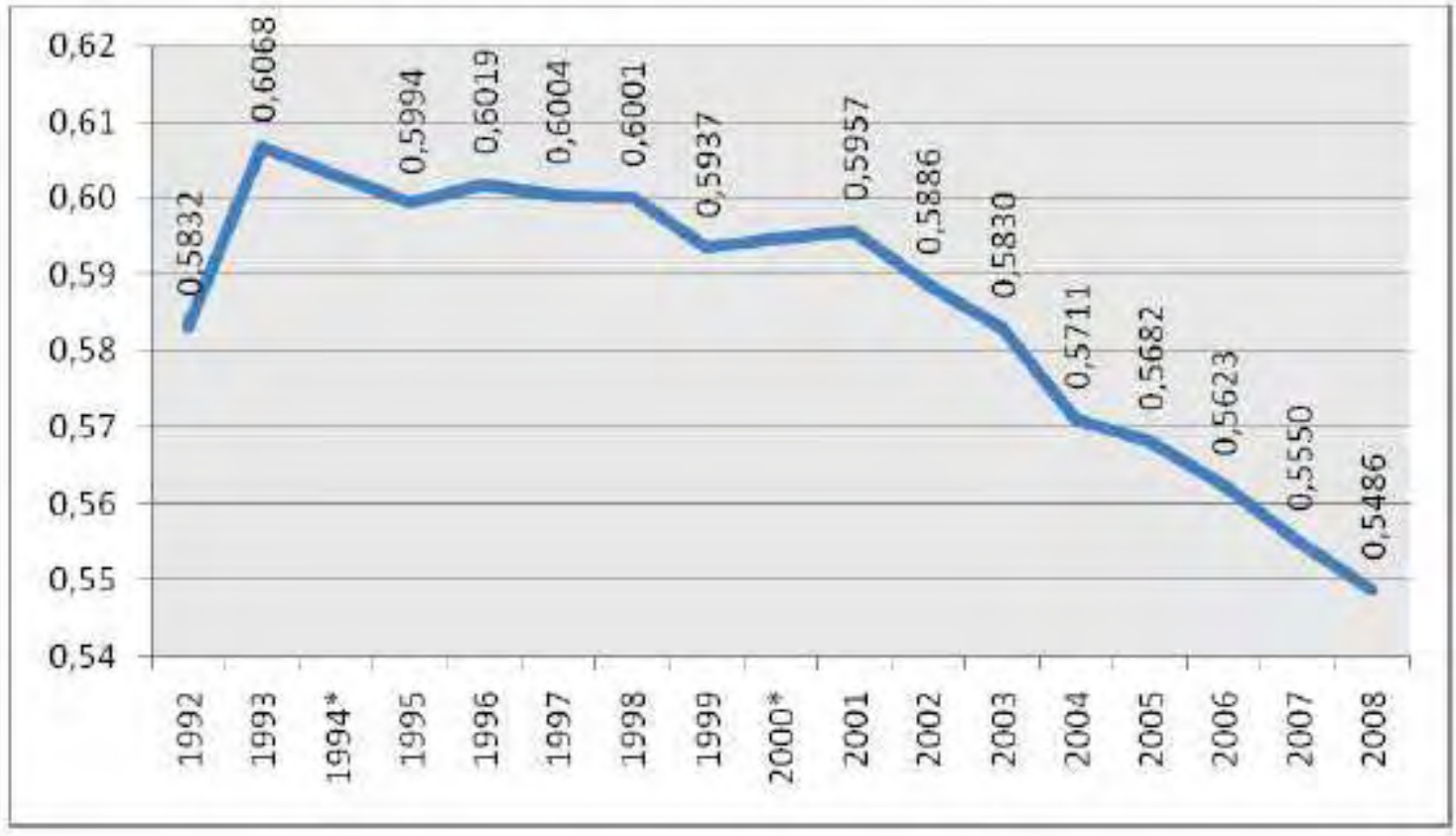

Figura 15: Índice de Gini

Fonte: CPS/FGV a partir de dados da PME/IBGE 


\subsubsection{2 - $O$ efeito da crise nas classes sociais}

A classe $\mathrm{AB}$ que tinha perdido mais com a crise (-2,7\% só em janeiro/09), em julho/09 está apenas 0,5\% abaixo dos níveis de julho/08 (pré-crise).

A classe C, dominante em termos populacionais (49,22\% da população) e motor do desenvolvimento econômico, já está com saldo positivo de $2,5 \%$, no mesmo período. A Figura 16 compara a variação das classes econômicas no período de julho/08 a julho/09.

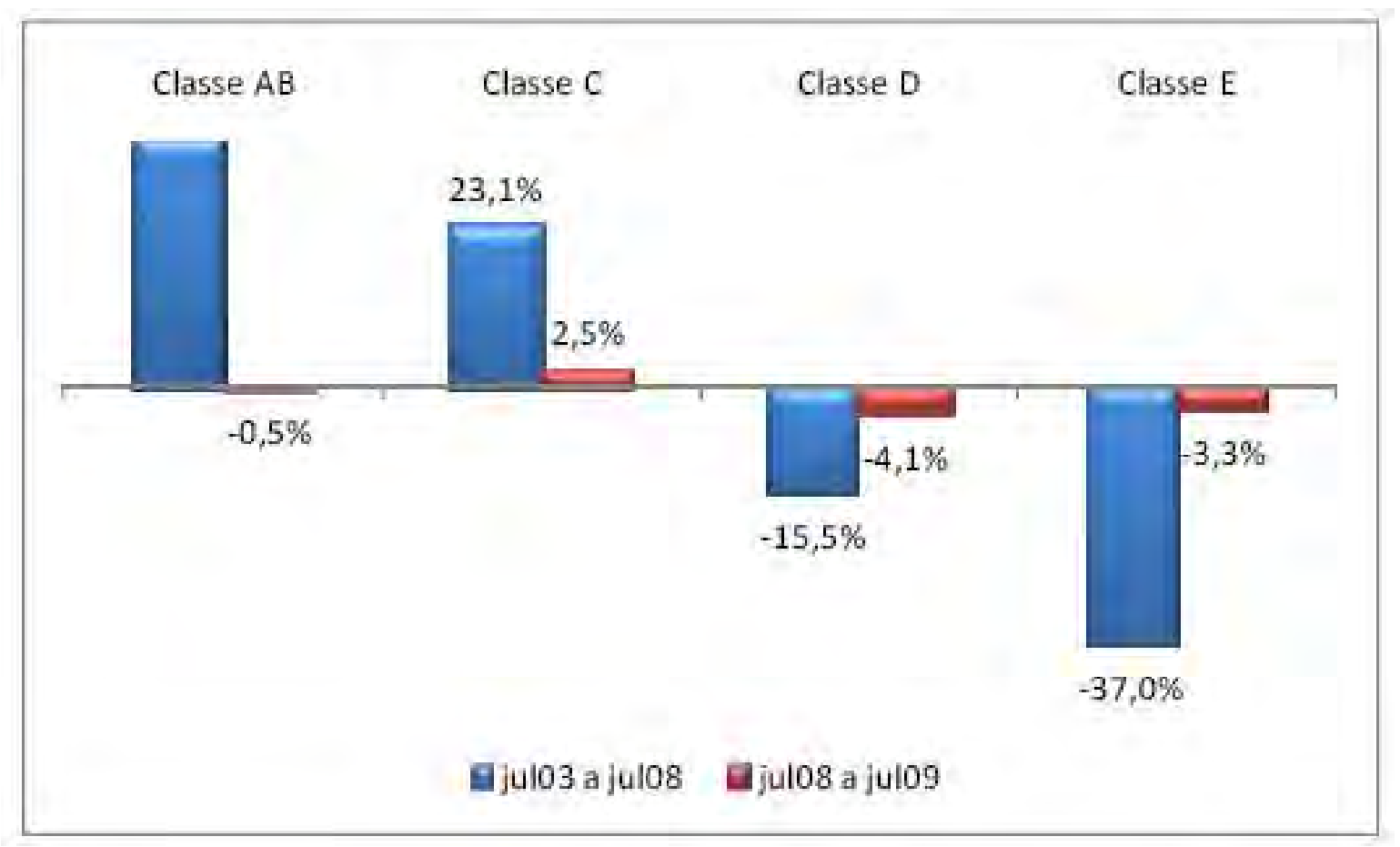

Figura 16: Variação das classes econômicas pré versus pós-crise

Fonte: CPS/FGV a partir dos microdados da PME/IBGE

\subsubsection{3 - O perfil da Moradia}

Atualmente, um indicador que demonstra relevância na avaliação de riqueza é o número de banheiros existentes nos domicílios. O critério padrão de classificação econômica Brasil elaborado pela ABEP (2008), construído por meio de análise de regressão da renda familiar em função da posse de bens e do grau de escolaridade, onde a posse de bens são incorporadas ao modelo como variáveis "dummy" e a renda como logaritmo da renda 
familiar, com base em amostra de 11.000 domicílios de 9 capitais brasileira, embasados em dados do IBOPE.

O modelo resultou que as três variáveis mais relevantes e significativas são: a quantidade de veículos, a quantidade de banheiros e o grau de escolaridade do chefe de família.

Importante ressaltar que, embora a renda tenha sido usada como um parâmetro de avaliação das variáveis e de sua pontuação, não se trata de um critério de renda. Há famílias de mesma classe com rendas diferentes; e há pessoas de mesma renda em classe diferentes.

A Tabela 05 mostra aspectos da desigualdade, com proporção 70,07\% de pessoas na classe $\mathrm{AB}$ que possuem mais de três banheiros, contra $56,02 \%$ das pessoas da classe $\mathrm{E}$ que não tem banheiros.

Tabela 05: Número de banheiros por classe social - PNAD 2008

\begin{tabular}{lcccc}
\hline \multicolumn{1}{c}{ Número de Banheiros } & Classe AB & Classe C & Classe D & Classe E \\
\hline Não tem banheiros & 0,11 & 14,21 & 29,66 & 56,02 \\
1 banheiro & 4,34 & 49,19 & 29,02 & 17,45 \\
2 banheiros & 20,42 & 62,64 & 11,96 & 4,98 \\
3 banheiros & 48,02 & 44,84 & 4,20 & 2,94 \\
Mais de 3 banheiros & 70,07 & 24,36 & 2,54 & 3,04 \\
\hline Fonte: Adaptado do CPS/FGV a partir dos microdados da PNAD/IBGE (2008)
\end{tabular}

A evolução do percentual da população que possui três ou mais banheiros, passou de 6,08\% em 2002 para 6,79\% em 2008, um crescimento de 11,7\%. A Figura 17 retrata a evolução. 


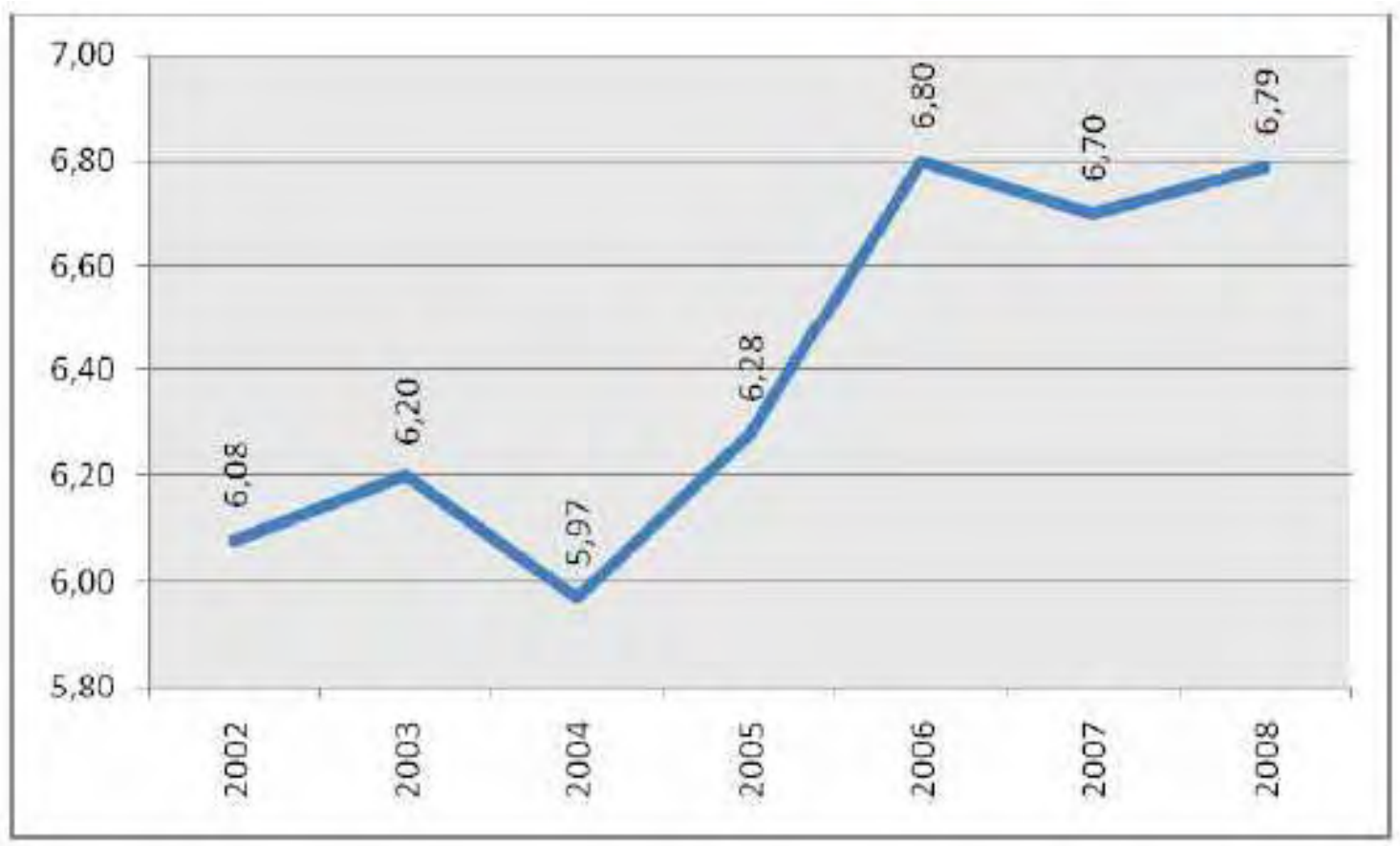

Figura 17: Evolução do percentual da população com 3 banheiros ou mais - Período 2002 a 2008 Fonte: CPS/FGV a partir dos microdados da PNAD/IBGE

Pela Tabela 06, apresenta-se, que em termos de financiamento, as classes $\mathrm{AB}$ e $\mathrm{C}$ representam juntas $77,23 \%$ dos indivíduos.

Tabela 06: Distribuição de financiamento da casa própria, por classe social (2008).

\begin{tabular}{lcccc}
\hline \multicolumn{1}{c}{ Casa Própria financiada } & Classe AB & Classe C & Classe D & Classe E \\
\hline Possui & 18,76 & 58,47 & 16,45 & 6,33 \\
Não possui & 10,04 & 48,80 & 24,71 & 16,46 \\
\hline
\end{tabular}

Fonte: Adaptado do CPS/FGV a partir dos microdados da PNAD/IBGE (2008)

Completando a análise de imóveis financiados, na Tabela 07 é indicada a distribuição da população por ocupação de domicílio. 
Tabela 07: Evolução percentual da população por condição de ocupação do domicílio - 2002 a 2008

\begin{tabular}{lccccccc}
\hline \multicolumn{1}{c}{ Tipo de domicílio } & $\mathbf{2 0 0 2}$ & $\mathbf{2 0 0 3}$ & $\mathbf{2 0 0 4}$ & $\mathbf{2 0 0 5}$ & $\mathbf{2 0 0 6}$ & $\mathbf{2 0 0 7}$ & $\mathbf{2 0 0 8}$ \\
\hline Próprio - já pago & 70,54 & 70,62 & 70,89 & 70,85 & 70,44 & 71,22 & 71,27 \\
Próprio - ainda pagando & 4,89 & 4,8 & 4,31 & 4,23 & 4,37 & 4,18 & 4,35 \\
Alugado & 13,47 & 13,42 & 14,13 & 14,61 & 14,86 & 15,27 & 15,36 \\
Cedido & 10,42 & 10,38 & 10,00 & 9,61 & 9,45 & 8,54 & 8,23 \\
Outra condição & 0,54 & 0,65 & 0,54 & 0,59 & 0,74 & 0,55 & 0,57
\end{tabular}

Fonte: Adaptado do CPS/FGV a partir dos microdados da PNAD/IBGE (2008)

O IBGE classifica como moradia cedida, na qual a característica de ocupação é a cessão gratuita por empregador do morador, instituição ou pessoa não moradora (parente ou não) ainda que mediante uma taxa de ocupação ou conservação. Verifica-se que $23,59 \%$ da população brasileira mora em residências alugadas ou cedidas, conforme os dados constantes na Tabela 07.

A Figura 18, elaborada a partir dos dados da Tabela 06, mostra que no decorrer do período a maior mobilidade ocorreu com a diminuição de $20,82 \%$ nos imóveis cedidos e aumento de $14,03 \%$ nos imóveis alugados.

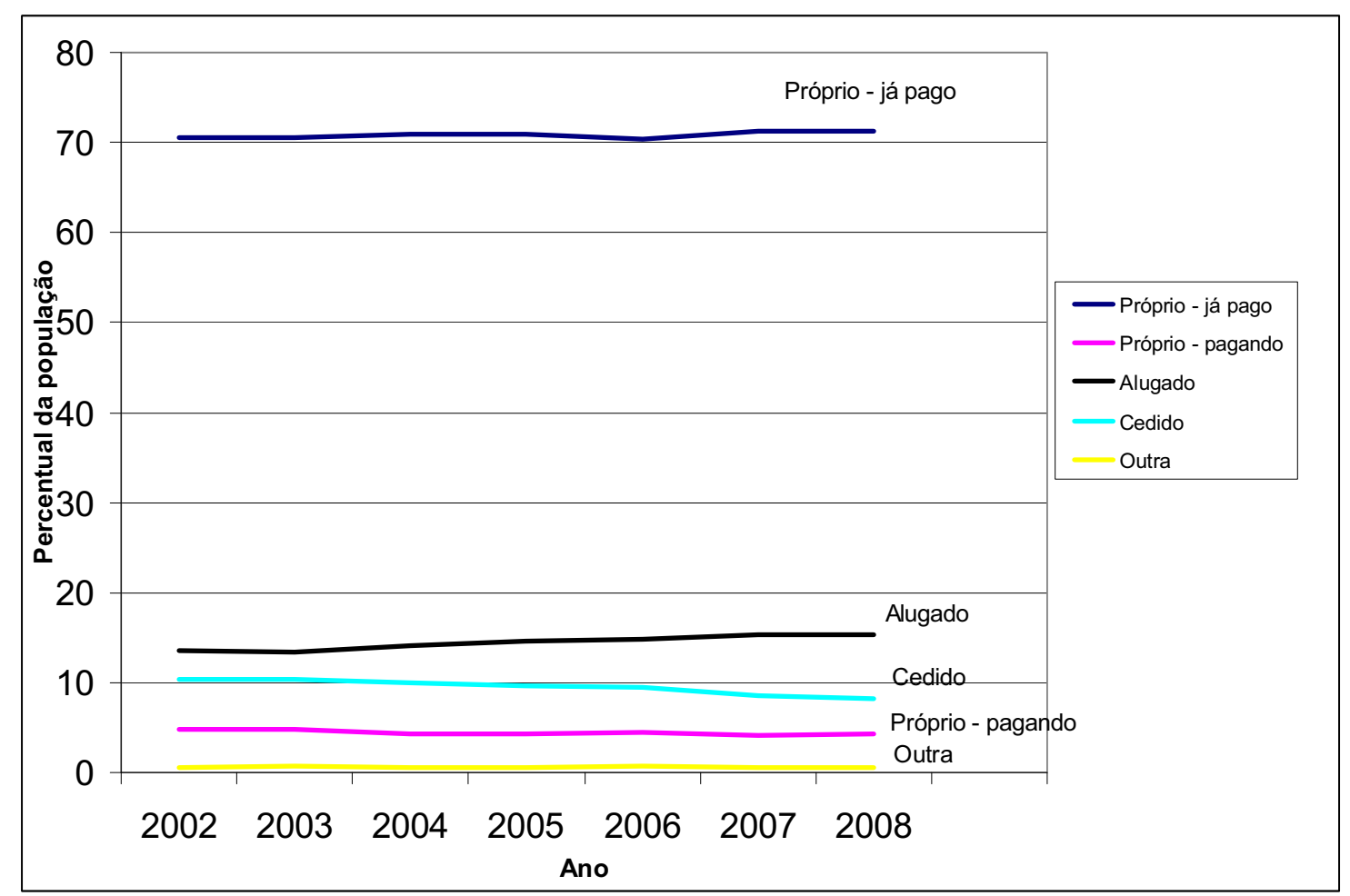

Figura 18: Evolução da população por condição de ocupação

Fonte: Adaptado de CPS/FGV a partir dos microdados da PNAD/IBGE (2008) 


\subsection{4 - Plano Minha Casa, Minha Vida}

O Governo Federal implementando o Plano Nacional de Habitação (PlanHab) elaborado pelo Ministério das Cidades, lançou em 26 de março de 2009, o Plano Minha Casa, Minha Vida (PMCMV), com início operacional em 13 de abril de 2009. O ambicioso Plano tem como meta construir 1 milhão de moradias para famílias com renda de até 10 salários mínimos (SM).

Os principais objetivos do programa, são:

- Integrar o modelo de desenvolvimento adotado pelo Governo Federal, tendo como pilares:

○ Reforço da Política de distribuição de renda e inclusão social;

- Fortalecimento da família;

- Aumento do acesso das famílias de baixa renda à casa própria;

- Geração de emprego e renda por meio do aumento de investimento na construção civil;

- Função anticíclica, ao estimular a demanda e o emprego.

O programa segmentou a classe de renda contemplada da seguinte forma:

- Famílias com renda de 0 a 3 salários mínimos: subsídio integral com isenção do seguro habitacional;

- Famílias com renda de 3 a 6 sálarios mínimos: aumento do subsídio parcial com redução dos custos de seguro e acesso ao Fundo Garantidor (casos de desemprego);

- Famílias com renda de 6 a 10 salários: estímulo á demanda com redução dos custos de seguro e acesso ao Fundo Garantidor. 
O programa também prevê a regularização fundiária de assentamentos localizados em áreas urbanas.

Linhas especiais de financiamento para obras de infraestrutura e para toda a cadeia produtiva da indústria de construção civil, também estão disponíveis, visando elevar o patamar de qualidade das construtoras, fornecedoras de materiais, componentes e sistemas construtivos, inclusive para construção industrializada, objetivando promover investimentos em alternativas construtivas de menor custo, prazo de entrega, impacto ambiental e maior qualidade construtiva. 


\section{METODOLOGIA DA PESQUISA}

Este Capítulo destaca a aplicação da metodologia proposta, tendo como objetivo a implantação de um Condomínio Residencial Horizontal, na cidade de Bauru.

\section{1 - Descrição do objeto de estudo: o Condomínio Residencial Urupês}

O Condomínio Residencial Urupês tem seu projeto de implantação, em terreno de 187.973,4534 m2, localizado na malha urbana da cidade de Bauru, próximo de Avenida de acesso da cidade (Avenida Nações Unidas), tendo ao seu entorno bairros de níveis sócioeconômicos variados e com aspectos construtivos diversos. A Figura 19 mostra a caracterização da gleba e os bairros do entorno.

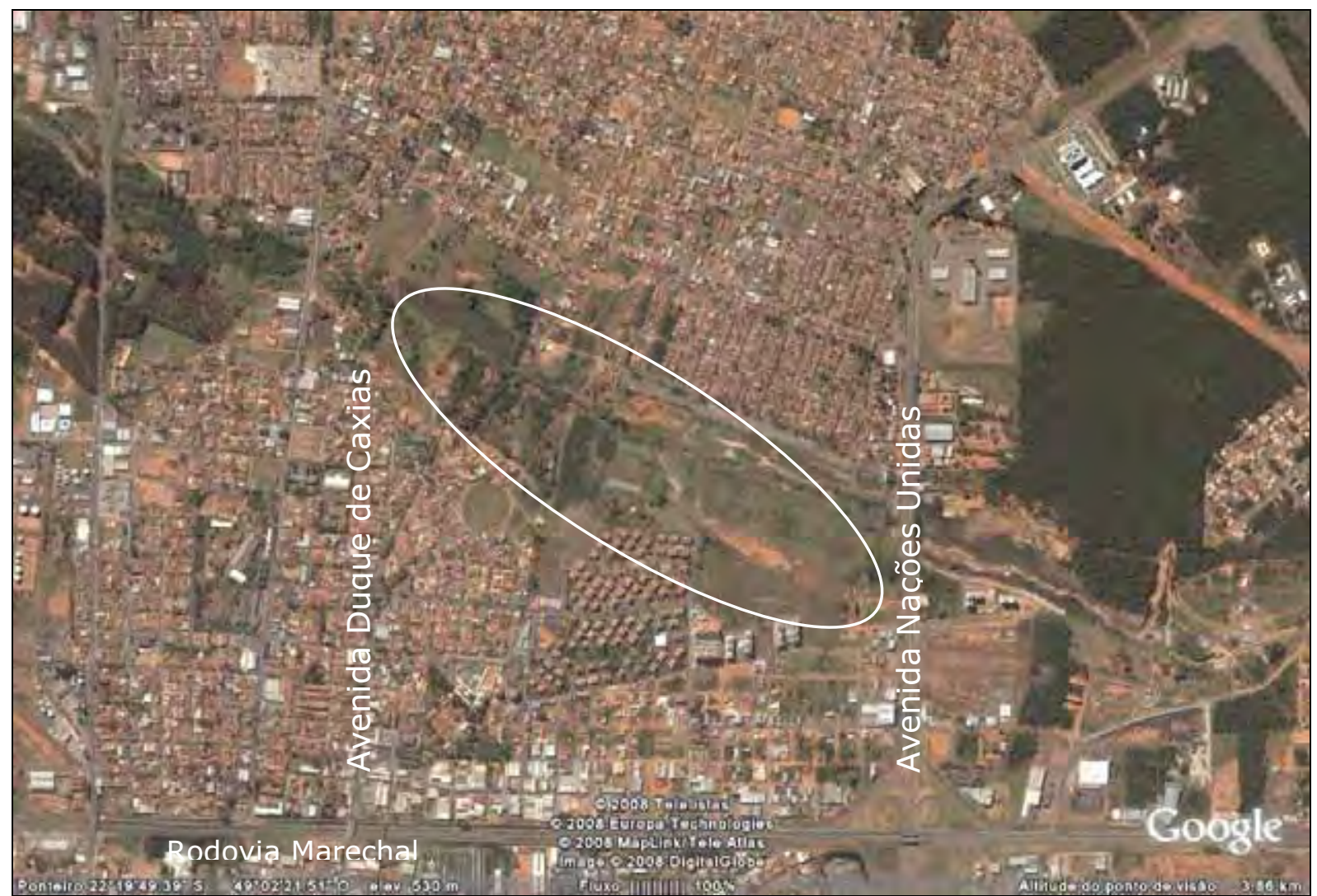

Figura 19: Vista global da região, com destaque a gleba do empreendimento em estudo. 
O município de Bauru é a sede da Região Administrativa do Estado de São Paulo, localizado na região central do estado. O município possui área total de $674 \mathrm{Km}^{2}$, segundo dados da Fundação SEADE, apresentados na Figura 20. A cidade de Bauru dista 345 Km de São Paulo, $269 \mathrm{Km}$ de Campinas e $228 \mathrm{Km}$ de Ribeirão Preto (Fundação SEADE, 2009). Embora seja considerado entroncamento rodo-ferroviário do estado, o principal acesso é pela Rodovia Marechal Rondon - SP-300. A posição geográfica central e sendo principal acesso para o Estado de Mato Grosso do Sul, tornam a cidade de Bauru ponto de convergência para novos empreendimentos imobiliários e alternativa para investimentos.

\begin{tabular}{|c|c|}
\hline População & 361.918 habitantes \\
\hline Área & $674 \mathrm{~km} 2$ \\
\hline Densidade demográfica & 537,38 habitantes por $\mathrm{km} 2$ \\
\hline Altitude & $\begin{array}{l}\text { Máxima de } 615 \text { metros } \\
\text { Mínima de } 490 \text { metros }\end{array}$ \\
\hline Clima & Tropical temperado \\
\hline Coordenadas & $\begin{array}{l}\text { Longitude: entre os meridianos } 48 \text { e } 50 \text { ao Oeste de Greenwich; } \\
\text { Latitude: entre os paralelos } 21,30 \text { e } 23 \text { ao Sul do Equador }\end{array}$ \\
\hline Solo & Afloramento Pré-cambriano; Arenito Bauru ("Terra Branca") \\
\hline Topografia & Ondulações: $64,71 \%$; Plano: $23,85 \%$ \\
\hline Municípios Limítrofes & $\begin{array}{l}\text { Reginópolis (Norte) } \\
\text { Piratininga (Sul) } \\
\text { Agudos e Pederneiras (Leste) } \\
\text { Avaí (Oeste) }\end{array}$ \\
\hline Hidrografia & Rio Batalha; Rio Bauru ("das flores") \\
\hline Vegetação & Primitiva: Floresta Tropical, Atual: Cerrado \\
\hline Precipitação & $\begin{array}{l}\text { Máxima: Janeiro } 286 \mathrm{~mm} \\
\text { Mínima: Julho } 33 \mathrm{~mm}\end{array}$ \\
\hline Temperatura & $\begin{array}{l}\text { Máxima: de } 32,2 \mathrm{C} \text {. em janeiro a } 24,9 \text { em julho } \\
\text { Mínima: de } 20,5 \mathrm{C} \text { em janeiro a } 12,9 \text { em julho } \\
\text { Média: de } 26,3 \mathrm{C} \text { em janeiro a } 19 \mathrm{em} \text { julho }\end{array}$ \\
\hline
\end{tabular}

Figura 20: Dados geográficos da cidade de Bauru (2009).

Fonte: Fundação SEADE a partir de dados do IBGE e IGC.

Segundo estudo do IBGE (2007), sobre a região de influência das cidades, a cidade de Bauru está classificada como Capital Regional - nível C, conforme mostra a Figura 21. Os níveis de hierarquia urbana estabelecem a delimitação das regiões de influência das cidades brasileiras. 
Mapa 1 - Rede urbana - Brasil - 2007

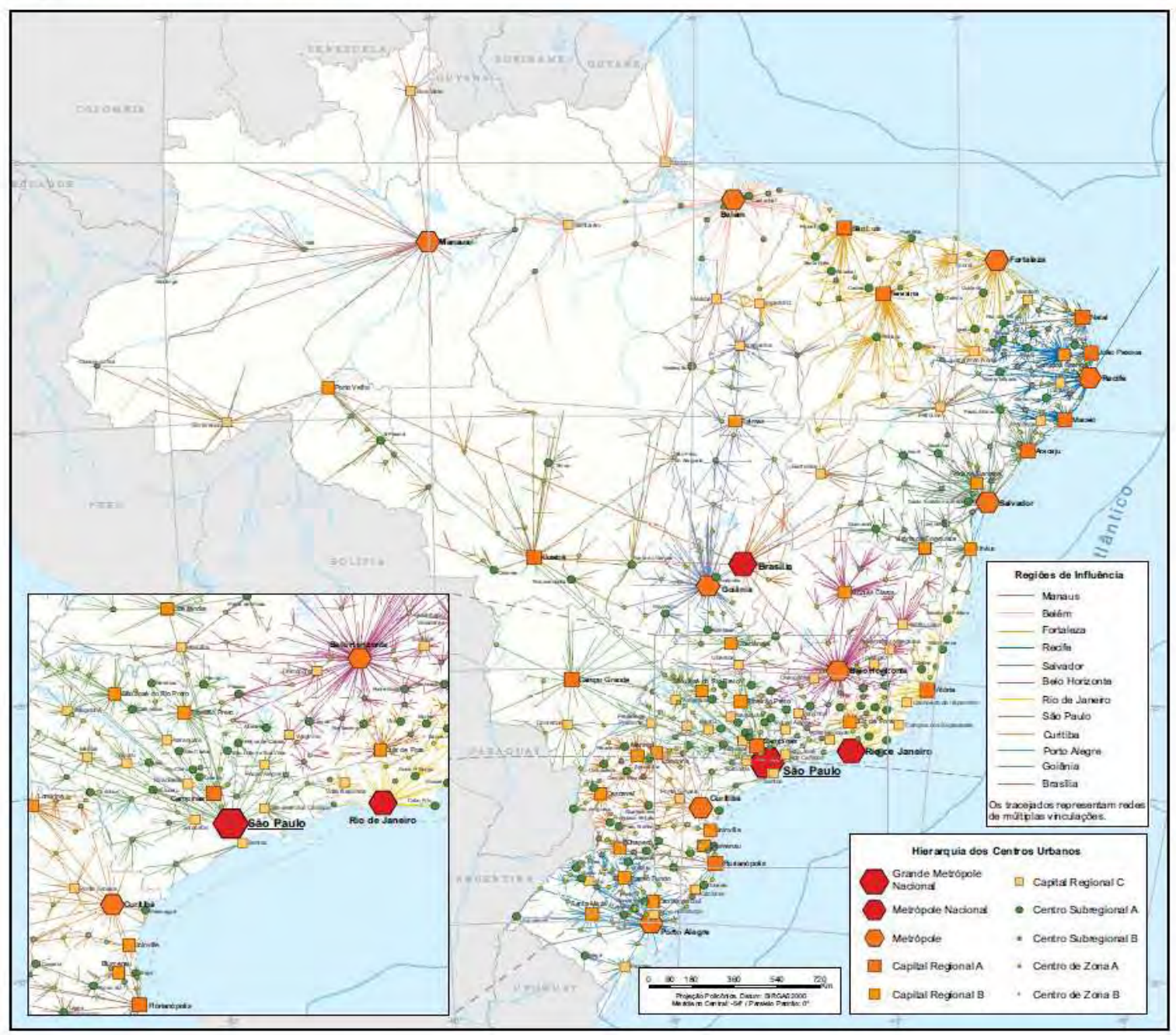

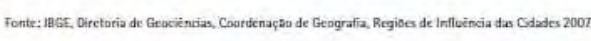

Figura 21: Região de influência das cidades - detalhe interior de São Paulo.

Fonte: IBGE (2007).

\section{2 - Amostragem}

A amostra obtida tem classificação como não-probabilística (não aleatória), efetivada por escolhas racionais por parte de especialistas.

Bêrni (2002) detalha que a amostragem por escolhas racionais, também denominada de amostragem por julgamento ou por escolha deliberada, pois as unidades selecionadas 
(indivíduos componentes da amostragem) são escolhidos por critérios de ordem prática ou técnica.

No mercado imobiliário, é opinião comum que amostras probabilísticas, colhidas ao acaso ou até as estratificadas (com potenciais compradores ou que tenham intenção de compra) têm pequena representatividade. A justificativa é que os elementos componentes de tais amostras têm pequena ou nenhuma experiência de compra no mercado, pequeno conhecimento do produto e têm sua decisão de compra mais atrelada à capacidade de pagamento que a critérios de preferência (LIMA JUNIOR, 1993).

Ainda, Lima Junior (1993) considera que apenas os profissionais que atuam diária e continuamente no mercado imobiliário é que dispõe de dados de demanda, capacidade de investimento do compradores e tendências de mercado.

Honda (2008), ao analisar e identificar atributos relevantes que condicionam o desenvolvimento de loteamentos residenciais fechados, reforça o entendimento, que em se tratando de mercado imobiliário, a amostra deve ser elaborada por conveniência, com a participação de um grupo limitado e seleto de especialistas.

Ribeiro (2005), ao elaborar matriz de atributos que configuram a qualidade de condomínios horizontais na cidade de São Paulo, também coletou dados junto a profissionais de arquitetura e engenharia, com profissionais que possuem conhecimento específico sobre o tema abordado.

Em suma, tem-se a concluir que a amostra composta por profissionais do mercado imobiliário, experientes, atuantes, com visão global do mercado, com capacidade de perceber mudança de padrões e comportamentos dos consumidores, têm relevância para demonstrar a preferência do consumidor, conferindo representatividade à amostra e ao final, conduzirão a pesquisa a resultados significativos e aderentes ao real mercado analisado.

A pesquisa de campo foi conduzida entre os dias 22 de setembro e 02 de outubro de 2009. O experimento foi administrado durante entrevista pessoal, realizada com 27 pessoas, todos profissionais ligados ao mercado imobiliário e com no mínimo 04 anos de experiência. Os respondentes atuam nas áreas de mercado imobiliário (corretores de imóveis, proprietários de imobiliárias, incorporadores, construtores, engenheiros, arquitetos e consultores) e funcionalismo público municipal (arquiteto, engenheiro e administrador). 
O procedimento de aplicação da pesquisa seguiu os seguintes passos:

- Explanação dos objetivos da pesquisa e motivo da escolha do profissional, agradecendo a atenção dispensada e reforçando a necessidade de concentração e nas ordenações dos cartões. Atenção especial foi dada ao fato de que as respostas requeridas deveriam se basear na preferência de mercado dos compradores e não na preferência pessoal do entrevistado.

- Apresentação de fotos e de tabela contendo os atributos em análise, com explicação detalhada dos fatores e níveis, que será apresentada no Capítulo 4, no item que trata da coleta de dados.

\section{3 - Técnica estatística e delineamento fatorial fracionário}

A técnica estatística multivariada adotada é a análise conjunta, cujos detalhes metodológicos acompanham os resultados no Capítulo 4. Seguiu-se o roteiro de aplicação sugerido por Hair et al (2005).

Em função do número de fatores e quantidade de níveis é possível obter 216 combinações de perfis de estímulo, produto fatorial dos níveis envolvidos na análise $(3 \times 2 \times 3 \times 2 \times 3 \times 2)$, conforme indicado na Tabela 8 .

Tabela 8: Planejamento fatorial

\begin{tabular}{lc}
\hline \multicolumn{1}{c}{ Atributos } & Planejamento fatorial \\
\cline { 2 - 2 } & Níveis \\
\hline Área da unidade & 3 \\
Tipologia & 2 \\
Equipamento de lazer & 3 \\
Localização & 2 \\
Preço & 3 \\
Área Verde & 2 \\
Total de estímulos & 216 \\
\hline
\end{tabular}


Para este trabalho, utilizando o processo de delineamento fatorial fracionário, resultou em 19 estímulos ortogonais e suficientes para a compreensão da completa estrutura de preferência dos respondentes. Desses, 3 estímulos foram reservados para a validação interna de cada amostra. Estes cartões, embora sejam apresentados aos respondentes e façam parte da ordenação dos estímulos, não foram utilizados da estimação do modelo. 


\section{UMA APLICAÇÃO NO MERCADO IMOBILIÁRIO}

O problema de pesquisa estabelecido é o planejamento do empreendimento imobiliário proposto. Com base na interpretação da função de utilidade e do recurso de simulações de produtos, orientar a elaboração do projeto de construção do empreendimento e os recursos de marketing, com reforço dos atributos mais importantes, os quais serão definidos na aplicação da técnica.

A aplicação é dividida basicamente em duas etapas:

1. Identificação e seleção dos atributos relevantes e que conferem valor ao produto habitacional em estudo, por meio de avaliação com especialistas do setor imobiliário e de pré-teste em pequena escala.

2. Modelagem da função de utilidade geral dos atributos, bem como suas utilidades parciais, por indivíduo e agregada; apresentação dos resultados do modelo conjunto; e simulação do produto imobiliário a ser implantado.

\section{1 - Diferenças jurídicas entre condomínios e loteamentos}

Há muita confusão no entendimento das expressões "loteamento fechado" e "condomínio horizontal”, que convém esclarecer, para melhor compreensão do objeto de estudo deste trabalho. Juridicamente, os loteamentos fechados são regidos pela Lei 6.766/79 e os condomínios horizontais (ou verticais) são regidos pela Lei 4.591/64.

O loteamento caracteriza-se por parcelamento de solo, onde há transferência de titularidade das áreas de uso público para a municipalidade (ruas, área verde e área 
institucional) e cada adquirente de lote (área particular e de domínio pleno do adquirente) realiza construções (benfeitorias) se e quando achar conveniente.

No condomínio, adquire-se uma unidade autônoma, seja casa ou apartamento, pronto, em construção ou à construir, resultado de uma incorporação imobiliária e inicialmente caracterizando pela transmissão da fração ideal de terreno.

Como define a NBR 12.721:2.006; Norma brasileira que atende ao prescrito à ABNT pela Lei Federal n. 4.591 e ao disposto na lei Federal n. 4.864, em seu subitem 3.5:

\begin{abstract}
Unidade autônoma: Parte da edificação vinculada a uma fração ideal de terreno, sujeitas às limitações da lei, constituída de dependências e instalações de uso privativo e de parcela das dependências e instalações de uso comum da edificação destinada a fins residenciais ou não, assinaladas por designação especial, numérica ou alfabética, para efeitos de identificação e discriminação.
\end{abstract}

Daí depreende-se que, só há unidade autônoma, se e somente se, o empreendimento for objeto de uma Incorporação Imobiliária registrada na matrícula do terreno, junto ao cartório de Registro de Imóveis.

Outras diferenças relevantes, que diferenciam-no do loteamento:

- O local de trânsito de pessoas e veículos são áreas de uso comum, porém de propriedade particular dos condôminos e não da municipalidade;

- Não há áreas públicas em um condomínio.

A Lei Federal 4.591 de 16.12.1964 define a figura de condomínio, que hoje vigora de acordo com as normas do Código Civil (Lei 10.406 de 10.01.2002) e da Lei 10.931/2004 (que institui o Patrimônio de Afetação para imóveis decorrentes de incorporação Imobiliária).

A Lei Federal 6.766, de 19.12.1979, alterada pela Lei 9.785 de 29.1.1999 regulamenta o parcelamento do solo urbano, que pode ser feito mediante loteamento ou desmembramento. Conforme o diploma legal, é considerado loteamento: 
subdivisão de gleba em lotes destinados a edificação, com abertura de novas vias de circulação, de logradouros públicos ou prolongamento, modificação ou ampliação das vias existentes, considerando-se lote o terreno servido de infraestrutura básica cujas dimensões atendam aos índices urbanísticos definidos pelo plano diretor ou lei municipal para a zona em que se situe. Considerando-se infraestrutura básica os equipamentos urbanos de escoamento das águas pluviais, iluminação pública, redes de esgoto sanitário e abastecimento de água potável, e de energia elétrica pública e domiciliar e as vias de circulação pavimentadas ou não.

Os loteamentos fechados possuem esta denominação, pois são loteamentos cercados por muros, controle de acesso de pessoas e veículos por meio de portarias e segurança 24 horas.

A confusão dos conceitos originou-se no rateio de valor necessário ao custeio de despesas de funcionários (portaria e limpeza), administradas pela associação de moradores de loteamentos fechados. Tal despesa foi alcunhada de taxa de condomínio e a partir daí surgiu a fusão (ou confusão) entre dois conceitos completamente diferentes.

$\mathrm{O}$ art. 22 da Lei Federal $n^{0}$ 6.766/79, define que " desde a data do registro do loteamento, passam a integrar o domínio do Município as vias e praças, os espaços livres e as áreas destinadas a edifícios públicos e outros equipamentos urbanos, constantes do projeto e do memorial descritivo". Portanto, o acesso limitado a um número restrito de pessoas é garantido por meio da concessão de direito real de uso das áreas públicas dos loteamentos conforme o art. $7^{\circ}$ do Decreto-lei 271, de 28.02.1967.

\section{2 - Condomínio Residencial Horizontal}

O condomínio horizontal, apesar de criado pela Lei 4.591/64, foi regulamentado pelo novo Código Civil - Lei 10.406/2002, passando a ter denominação geral de Condomínio 
edilício e disposto pelos artigos 1.331 ao 1.358. O artigo $8^{\circ}$. - itens a, c e d da citada Lei 4.591/64 define especificamente o condomínio horizontal:

\begin{abstract}
Em terreno onde não houver edificação, o proprietário, o promitente comprador, o cessionário ou promitente cessionário sobre ele desejar erigir mais de uma edificação, observar-se-á que em relação às unidades autônomas que se constituírem em casas térreas ou assobradadas, será discriminada a parte do terreno ocupada pela edificação e também aquela eventualmente reservada como de utilização exclusiva dessas casas, como jardim e quintal, bem assim a fração ideal de todo o terreno e de partes comuns, que corresponderá às unidades. Serão ainda, discriminadas as partes do total do terreno que poderão ser utilizadas em comum pelos titulares de direito sobre os vários tipos de unidades autônomas e as áreas que se constituírem em passagem comum para as vias públicas ou para as unidades entre si.
\end{abstract}

\title{
4.3 - Análise conjunta
}

A aplicação da técnica de análise conjunta, proposta na seção 3 do Capítulo 2 visou obter uma função de utilidade deste empreendimento, em relação aos atributos que o empreendimento poderá oferecer, sendo ferramenta de suporte ao processo de tomada de decisão do projeto a ser elaborado no local.

\subsection{1 - Estágio 1: Identificação e seleção das variáveis relevantes}

O ponto de partida da aplicação do método é a identificação e seleção das variáveis ou atributos relevantes que o empreendimento deverá conter.

Pascale (2005), utilizando o método Delphi, identifica e hierarquiza o conjunto de atributos que configuram qualidade a uma localização residencial para os potenciais compradores, indicando a preferência dos mesmos e apontando aos empreendedores critério de escolha de terreno para futuros lançamentos. 
O trabalho analisa a questão da localização, na definição de mercados alvo, na fase de planejamento do produto residencial (ciclo de formatação).

A pesquisa se concentra no conjunto de atributos que compõe as localizações e em como a qualidade destes influencia as escolhas residenciais tanto para os potenciais compradores quanto a seleção de terrenos para os empreendedores. Os atributos analisados referem-se a qualidade ambiental, infra-estrutura, comércio e serviços, acessibilidade e questões econômico-sociais.

Ribeiro (2005), utilizando o método AHP (Analytic Hierarchy Process - Análise Hierárquica de atributos) identifica os atributos físicos e de vizinhança e seus graus relativos de importância aplicado em condomínio horizontais fechados.

Honda (2008), também utilizando o método AHP, elabora e hierarquiza os atributos que mais influenciam o consumidor a abrir mão do conceito de centralidade e passar a residir em loteamentos residenciais fechados, nos arredores da capital.

Lima Júnior (1993), destaca que fatores econômicos e financeiros influenciam a tomada de decisão do consumidor ao adquirir um produto residencial.

A compilação das características mencionadas nos trabalhos de Lima Junior (1993), Pascale (2005), Ribeiro (2005) e Honda (2008), resultou num quadro de características relevantes, retratadas na Tabela 9 e que serviram de base para a análise e seleção das variáveis que compõem o presente trabalho. 
Tabela 9: Características preselecionadas e base para definição dos atributos do experimento.

\begin{tabular}{|cl|}
\hline CARACTERISTICAS & \\
\hline & - Renda / estrato de renda \\
& - Renda familiar \\
ECONÔMICAS & - Densidade populacional (m2/hab) \\
& - Preço produto \\
& - Capacidade pagamento e endividamento (valor prestação) \\
\hline & - Status da vizinhança \\
& - Local próximo a bairros valorizados \\
& - Ciclo de vida familiar (solteiro, casado, número e idade dos filhos) \\
& - Perfil etário \\
& - Escolaridade \\
\hline SOCIAIS & - Distância centro cidade (centralidade) \\
& - Acesso a Avenidas \\
& - Distância a escolas \\
& - Distância a conveniências (farmácias, academias, lavanderias) e \\
comércio pequeno e médio portes
\end{tabular}

Fonte: Compilado de Lima Junior (1993), Pascale (2005), Ribeiro (2005) e Honda (2208).

Para a determinação das variáveis, foi composto um grupo exploratório, composto de quatro profissionais (que atuam como incorporador, construtor, corretor de imóveis e funcionário da Prefeitura Municipal de Bauru da Secretaria de Planejamento) além do pesquisador, atuantes e com ampla experiência no mercado imobiliário. 
Após a exposição das características do empreendimento, as características preselecionadas (Tabela 9) foram discutidas, tomando-se por base os seguintes critérios:

- Exclusão das variáveis não mensuráveis na pesquisa (capacidade de pagamento, renda familiar, escolaridade, etc...);

- Junção das variáveis que explicam a mesma característica ou agregam demais características.

- Seleção final com as variáveis relevantes ao empreendimento em estudo e permitiam amplitude suficiente para suportar o estudo.

Dessa forma, após 3 rodadas, concluiu-se as variáveis determinantes e relevantes para a definição do produto imobiliário estudado, partindo para o pré-teste, com a utilização do software SPSS - módulo conjoint - versão 17.0, respondido apenas pelos componentes do grupo exploratório, para avaliação dos resultados. Ajustes nos níveis e em algumas variáveis foram procedidos, novo teste elaborado com o mesmo grupo, desta feita tendo apresentado resultados consistentes.

Dentre as características coletadas, após processo de agrupamento, escalonamento por relevância econômica, adequação ao produto a ser analisado (condomínio horizontal) e prétestes com o uso do software, houve a seleção das seguintes variáveis:

- Área da unidade

Com o objetivo de condensar os atributos físicos da unidade, quantidade e tamanho de dormitórios, número de banheiros (inclusive lavabo), julgou-se ser a área da unidade o atributo mensurável que reúne estas características;

- Tipologia

Uma das características do empreendimento, que notadamente os especialistas apontaram como de suma importância para a aceitação do consumidor é o fato 
das unidades serem isoladas ou geminadas. Há consciência comum no mercado que unidades geminadas apresentam grande rejeição na preferência do consumidor. Dessa forma, imprescindível que esteja presente no modelo;

- Equipamentos de Lazer

Outra característica do empreendimento que o diferencia de unidades construídas em loteamentos comuns (sem controle de acesso tampouco área de lazer de uso privativo dos condôminos);

- Localização

Em se tratando de empreendimentos imobiliários esta característica é indispensável. No caso do produto em estudo, que está localizado em vazio urbano da cidade, com presença de comércio local (padaria, mercado, lotérica, farmácia e diversas lojas, além de estabelecimentos de serviço tais como escola, clínicas médicas e odontológicas), porém com bairros do entorno de diferentes níveis sociais, julgou-se fundamental a inclusão desta variável como uma dicotômica. O contra-ponto da localização do empreendimento em análise são áreas de expansão urbana, onde não há comércio nem serviços locais, com maiores distâncias do centro da cidade, porém com nível sócio-econômico alto nos bairros do entorno. Esta variável reúne todas as características de localização, além de parte das variáveis sociais;

- Área Verde

Outra característica do empreendimento, alinhada à movimentos ecológicos que eclodem no país inteiro, onde pretende-se medir se a atratividade da área verde reverte em aumento de preço do empreendimento;

- Preço da unidade

Esta variável é complexa e seu uso requer extremo cuidado, mas do modo que o experimento foi planejado, a ausência da variável preço no modelo resultaria inexpressiva a contribuição deste trabalho. O acréscimo de variáveis, sem a contrapartida de preço não permite conclusão sobre a estrutura de preferência de 
compra do consumidor de imóveis. Se os níveis de preço forem muito baixos a variável deixa de ser significativa.

De outro modo, se forem muito altos, conferirá à variável preço importância demasiada, ofuscando e mascarando a importância relativa das demais variáveis. Produtos onde a variável de maior importância é o preço resultam em movimento de concorrência, onde a elasticidade de preço é que vai determinar a velocidade de venda e a margem de lucro do empreendimento fica comprometida, além de não atingir o objetivo da pesquisa, que é entender a preferência de compra do consumidor.

Os procedimentos descritos permitiram definir os fatores e níveis relevantes para a pesquisa, como mostrados na Tabela 10. 
Tabela 10: Atributos selecionados e níveis do experimento

\begin{tabular}{|c|c|c|}
\hline ATRIBUTOS & NÍVEIS & DESCRIÇÃO \\
\hline \multirow{3}{*}{ Área da unidade } & $A$ & $\begin{array}{c}\text { Área privativa de } 70 \mathrm{~m}^{2}=\text { sobrado com sala } \\
\text { estar/jantar, lavabo, cozinha "americana", } 2 \\
\text { dormitórios, banheiro, área serviço, garagem } \\
\text { descoberta para } 2 \text { carros e quintal. }\end{array}$ \\
\hline & B & $\begin{array}{c}\text { Área privativa de } 85 \mathrm{~m}^{2}=\text { sobrado com sala } \\
\text { estar/jantar, lavabo, cozinha, área serviço, } \\
\text { suíte, } 2 \text { dorm, banheiro, garagem descoberta } \\
\text { para } 2 \text { carros e quintal. }\end{array}$ \\
\hline & $\mathrm{C}$ & $\begin{array}{l}\text { Área privativa de } 95 \mathrm{~m}^{2}=\text { sobrado com sala } \\
\text { estar/jantar/varanda, lavabo, cozinha, área } \\
\text { serviço, suite c/closet, } 2 \text { dorm e banheiro, } \\
\text { garagem descoberta para } 2 \text { carros e quintal. }\end{array}$ \\
\hline \multirow{2}{*}{ Tipologia } & $A$ & geminado \\
\hline & $\mathrm{B}$ & isolado \\
\hline \multirow[b]{3}{*}{ Equipamentos de lazer } & A & Quadra poliesportiva e piscina \\
\hline & B & $\begin{array}{c}\text { Quadra poliesportiva, piscina, academia de } \\
\text { ginástica, espaço gourmet (churrasqueira e } \\
\text { cozinha com galadeira, fogão, freezer e mesas, } \\
\text { ambiente climatizado). }\end{array}$ \\
\hline & $\mathrm{C}$ & $\begin{array}{c}\text { Quadra poliesportiva, piscina, academia de } \\
\text { ginástica, espaço gourmet (churrasqueira e } \\
\text { cozinha com geladeira, fogão, freezer e } \\
\text { mesas), ambiente climatizado) e estrutura de } \\
\text { Lazer Infantil completa: Composta de } 3 \\
\text { pequenos espaços de lazer [1] - Praça infantil } \\
\text { (bebês); [2] - Play-ground para crianças de } 2 \text { a } \\
6 \text { anos, e; [3] Praça de esportes - crianças de } 6 \\
\text { a } 12 \text { anos) }\end{array}$ \\
\hline \multirow[t]{2}{*}{ Localização } & A & $\begin{array}{c}\text { Inserido na malha urbana e presença de } \\
\text { comércio e serviços (mercado, escola e lojas } \\
\text { de conveniência). Nível sócio-econômico } \\
\text { médio. }\end{array}$ \\
\hline & $\mathrm{B}$ & $\begin{array}{l}\text { Área de expansão urbana, com ausência de } \\
\text { comércio local. Nível sócio-econômico alto. }\end{array}$ \\
\hline \multirow{3}{*}{ Preço } & $A$ & $\$ 160 \mathrm{mil}$ \\
\hline & $\mathrm{B}$ & $\$ 180 \mathrm{mil}$ \\
\hline & $\mathrm{C}$ & $\$ 200$ mil \\
\hline \multirow{2}{*}{ Área Verde } & $A$ & $\begin{array}{c}\text { Área verde mínima - Praça arborizada, } \\
\text { gramada e com bancos. }\end{array}$ \\
\hline & B & $\begin{array}{l}\text { Ampla área Verde - Praça arborizada, gramada } \\
\text { e com bancos. Bosque com trilha para } \\
\text { caminhada e quiosques com churrasqueiras. }\end{array}$ \\
\hline
\end{tabular}




\subsection{2 - Estágio 2: Estruturação do experimento}

Definidos os atributos relevantes e determinantes, efetua-se a escolha da abordagem conjunta apropriada, o planejamento dos estímulos e a coleta de dados.

\subsubsection{1 - Seleção da abordagem}

Devem ser consideradas na definição da abordagem da técnica, três características, como segue:

- O número de atributos: De acordo com o definido no subitem anterior, o número de atributos especificados para o estudo é seis (6).

- O nível de análise: Há dois tipos de níveis de análise, a individual e a agregada. Neste caso, optou-se pela análise em nível individual, com posterior agregação das utilidades parciais dos respondentes, na elaboração do modelo.

- A forma do modelo: Há a opção da forma aditiva, onde a utilidade geral é a soma das utilidades parciais dos fatores e com efeitos de interação.

Deste modo, a abordagem adotada foi o método conjunto tradicional. Além dos motivos expostos, demais ponderações levaram a escolha do método tradicional, quais sejam:

- Dado o número de atributos selecionados (seis), as três metodologias seriam adequadas;

- As estimativas em nível individual, com posterior agregação, permitem resultados mais generalizáveis;

- Apesar de pesquisas e evidências mostrarem que frequentemente o preço tem interações com outros fatores, foi verificado no pré-teste que os outros fatores eram ortogonais e que não eram necessários termos de interação;

- A ênfase da pesquisa é a compreensão direta da estrutura de preferência dos respondentes; 
- Considerando a carga de resposta e informação a ser colocada ao respondente, aliada à profundidade da informação representada, selecionou-se a metodologia tradicional.

\subsubsection{2 - Planejamento dos estímulos}

O método adotado para elaboração dos cartões de estímulo é o de perfil completo, com delineamento fatorial fracionário, por meio do qual busca-se o menor número de cartões possível e suficiente para o completo entendimento da estrutura de preferência do respondente.

O comando de elaboração de desenho ortogonal do programa SPSS - versão 17.0, ressaltou a necessidade de no mínimo 16 cartões, para que o delineamento fatorial fracionário fosse executado. Definiu-se também a construção de três cartões retidos (amostras holdout), que serão utilizados para a validação interna da amostra e que será informada no modelo como coeficiente $\tau$ de Kendall da amostra retida.

\subsubsection{3 - Coleta de dados}

A abordagem adotada na pesquisa, para coletar os dados de preferência dos respondentes, foi o de ordenação dos cartões de estímulos, sendo o primeiro cartão apresentado após a ordenação, aquele que apresenta maior preferência e obviamente o último cartão o que demonstra a menor preferência.

A Tabela 11 foi apresentada aos respondentes contendo a descrição dos fatores, descrição detalhada de cada um de seus níveis e descrição resumida (da mesma forma que se encontra disposta nos cartões, para que haja melhor entendimento no momento da execução da pesquisa). 
Tabela 11: Informação prévia aos respondentes, com descrição detalhada dos atributos e níveis.

\begin{tabular}{|c|c|c|c|}
\hline ATRIBUTOS & NÍVEIS & DESCRIÇÃO & DESCRIÇÃO RESUMIDA - CARTÕES \\
\hline \multirow{3}{*}{$\begin{array}{l}\text { Área da } \\
\text { unidade }\end{array}$} & 1 & $\begin{array}{c}\text { Área privativa de } 70 \mathrm{~m}^{2}= \\
\text { sobrado com sala estarljantar, } \\
\text { lavabo, cozinha "americana", } 2 \\
\text { dormitórios, banheiro, área } \\
\text { serviço, garagem descoberta } \\
\text { para } 2 \text { carros e quintal. }\end{array}$ & 2 dorm. - $70 \mathrm{~m} 2$ \\
\hline & 2 & $\begin{array}{c}\text { Área privativa de } 85 \mathrm{~m}^{2}= \\
\text { sobrado com sala estarljantar, } \\
\text { lavabo, cozinha, área serviço, } \\
\text { suíte, } 2 \text { dorm, banheiro, } \\
\text { garagem descoberta para } 2 \\
\text { carros e quintal. } \\
\end{array}$ & 3 dorm. (suíte) - 85 m2 \\
\hline & 3 & $\begin{array}{c}\text { Área privativa de } 95 \mathrm{~m}^{2}= \\
\text { sobrado com sala } \\
\text { estar/jantar/varanda, lavabo, } \\
\text { cozinha, área serviço, suite } \\
\text { c/closet, } 2 \text { dorm e banheiro, } \\
\text { garagem descoberta para } 2 \\
\text { carros e quintal. } \\
\end{array}$ & $\begin{array}{l}3 \text { dorm. (suíte com closet e sala mais ampla) - } \\
95 \mathrm{~m} 2\end{array}$ \\
\hline \multirow{2}{*}{ Tipologia } & 1 & geminado & geminado \\
\hline & 2 & isolado & isolado \\
\hline \multirow[b]{3}{*}{$\begin{array}{l}\text { Equipamentos } \\
\text { de lazer }\end{array}$} & 1 & Quadra poliesportiva e piscina & Qda e pisc \\
\hline & 2 & $\begin{array}{c}\text { Quadra poliesportiva, piscina, } \\
\text { academia de ginástica, espaço } \\
\text { gourmet (churrasqueira e } \\
\text { cozinha com galadeira, fogão, } \\
\text { freezer e mesas, ambiente } \\
\text { climatizado). }\end{array}$ & Qda, pisc, academia e esp. gourmet \\
\hline & 3 & $\begin{array}{l}\text { Quadra poliesportiva, piscina, } \\
\text { academia de ginástica, espaço } \\
\text { gourmet (churrasqueira e } \\
\text { cozinha com geladeira, fogão, } \\
\text { freezer e mesas), ambiente } \\
\text { climatizado) e estrutura de Lazer } \\
\text { Infantil completa: Composta de } 3 \\
\text { pequenos espaços de lazer [1] - } \\
\text { Praça infantil (bebês); [2] - Play- } \\
\text { ground para crianças de } 2 \text { a } 6 \\
\text { anos, e; [3] Praça de esportes - } \\
\text { crianças de } 6 \text { a } 12 \text { anos) } \\
\end{array}$ & $\begin{array}{l}\text { Qda, pisc, academia, esp. gmet e lazer infantil } \\
\text { comp }\end{array}$ \\
\hline \multirow[t]{2}{*}{ Localização } & 1 & $\begin{array}{l}\text { Inserido na malha urbana e } \\
\text { presença de comércio e serviços } \\
\text { (mercado, escola e lojas de } \\
\text { conveniência). Nível sócio- } \\
\text { econômico médio. }\end{array}$ & malha urbana, comércio local, nível médio \\
\hline & 2 & $\begin{array}{l}\text { Área de expansão urbana, com } \\
\text { ausência de comércio local. } \\
\text { Nível sócio-econômico alto. }\end{array}$ & exp urbana, sem comércio local, nível alto \\
\hline \multirow{3}{*}{ Preço } & 1 & $\$ 160$ mil & $\$ 160 \mathrm{mil}$ \\
\hline & 2 & $\$ 180 \mathrm{mil}$ & $\$ 180 \mathrm{mil}$ \\
\hline & 3 & $\$ 200 \mathrm{mil}$ & $\$ 200$ mil \\
\hline \multirow[t]{2}{*}{ Área Verde } & 1 & $\begin{array}{l}\text { Área verde mínima - Praça } \\
\text { arborizada, gramada e com } \\
\text { bancos. }\end{array}$ & Praça arborizada, gramada e com bancos. \\
\hline & 2 & $\begin{array}{c}\text { Ampla área Verde - Praça } \\
\text { arborizada, gramada e com } \\
\text { bancos. Bosque com trilha para } \\
\text { caminhada e quiosques com } \\
\text { churrasqueiras. }\end{array}$ & $\begin{array}{c}\text { Praça arborizada, gramada, Bosque, trilha e } \\
\text { quiosques }\end{array}$ \\
\hline
\end{tabular}


Para melhorar o entendimento do nível 3 da variável Equipamentos de Lazer, foram mostradas aos respondentes, fotografias de um empreendimento habitacional existente, com detalhes das praças de lazer infantil, conforme ilustra a Figura 22.
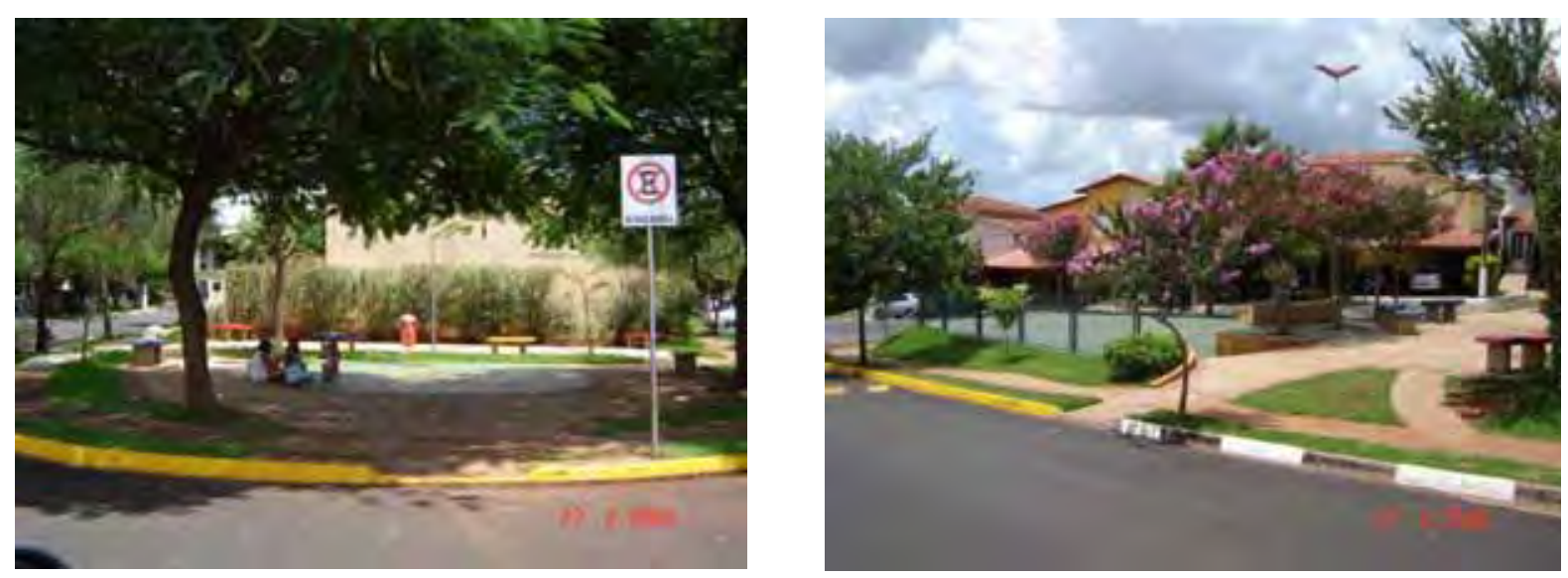

Figura 22: Exemplos das fotografias apresentadas aos respondentes.

As alternativas foram apresentadas aos respondentes, no formato de cartões com exemplo mostrado na Figura 23.

\begin{tabular}{|ccccccc|}
\hline \multicolumn{7}{c|}{ Perfil 8} \\
\hline Cartão & $\begin{array}{c}\text { Area da } \\
\text { unidade }\end{array}$ & Tipologia & $\begin{array}{c}\text { Equipamentos } \\
\text { de Lazer }\end{array}$ & Localização & Preço & Área Verde \\
8 & $\begin{array}{c}2 \text { dorm }-70 \\
\mathrm{~m} 2\end{array}$ & isolado & $\begin{array}{c}\text { Qda, pisc, } \\
\text { academia e esp } \\
\text { gourmet }\end{array}$ & $\begin{array}{c}\text { malha urbana, } \\
\text { comércio local, } \\
\text { nível médio }\end{array}$ & $\$ 180$ mil & $\begin{array}{c}\text { Pça arborizada, } \\
\text { gramada e com } \\
\text { bancos }\end{array}$ \\
\hline
\end{tabular}

Figura 23: Exemplo do formato de cartão apresentado aos respondentes.

Os dados coletados, na forma de ordenação dos cartões de estímulos são apresentados na Tabela 12, na qual as linhas indicam o respondente e as colunas o número dos cartões ordenados, por ordem decrescente (da maior preferência para a menor preferência). 


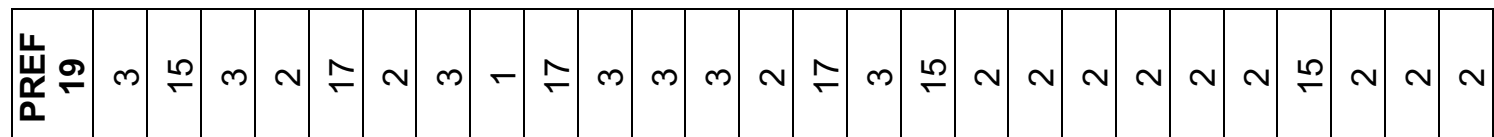

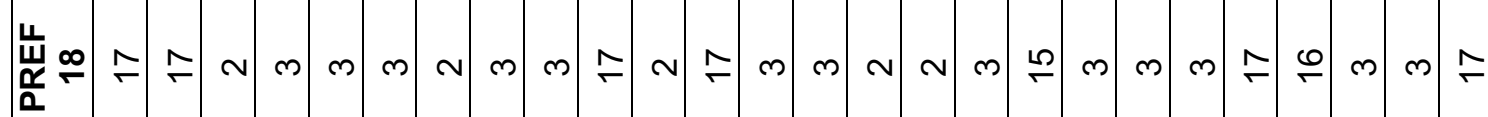
炭々

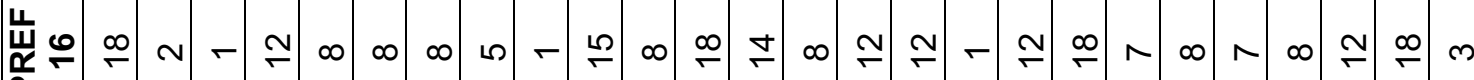
a

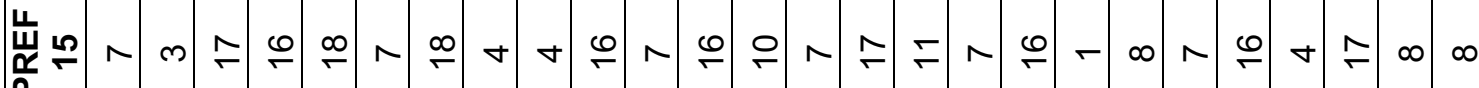
a

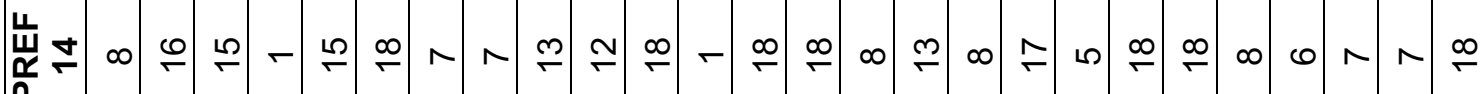
$\frac{\pi}{a}$

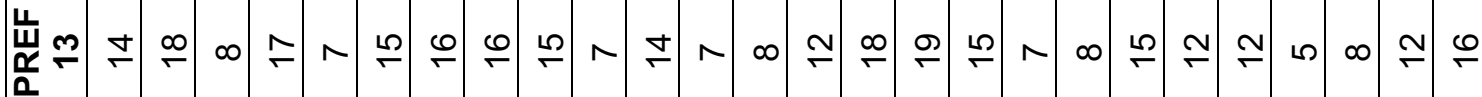

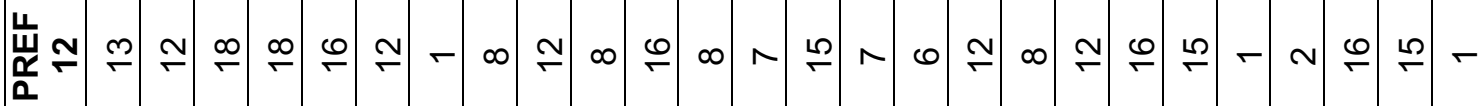

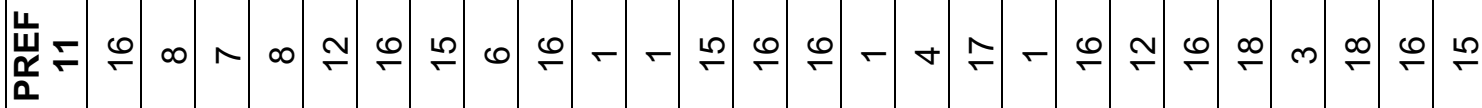

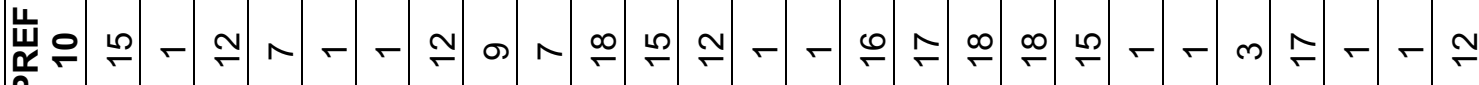
魚

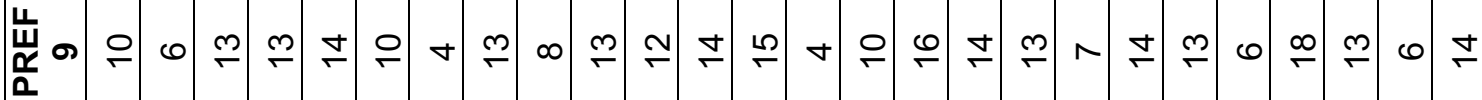
宸 $\infty$ $\frac{\pi}{a}$

崫

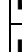

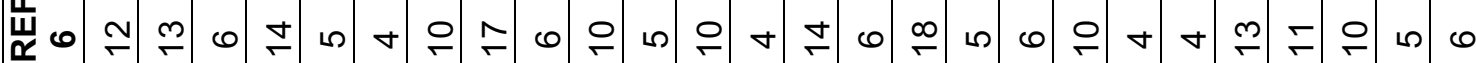

㟓几 然

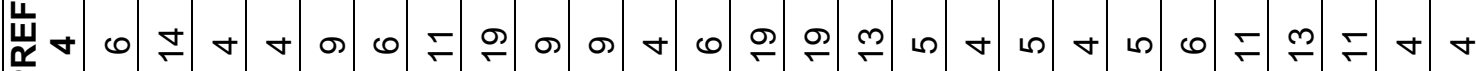

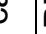

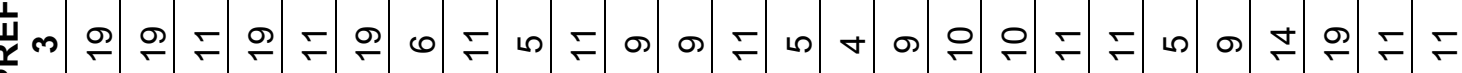
这

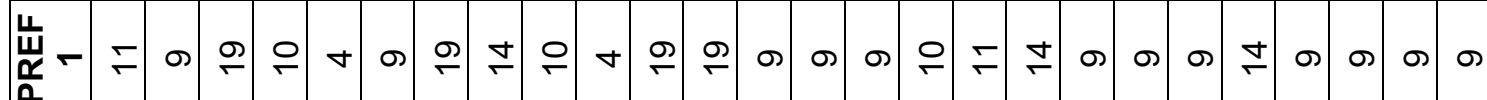
$-$

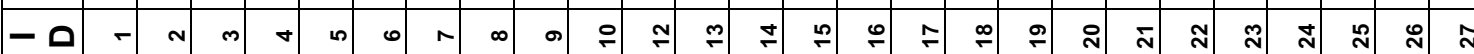




\subsection{3 - Estágio 3: pressupostos da análise conjunta}

A análise conjunta tem menor conjunto restritivo de pressupostos. Os testes de normalidade e homocedasticidade são desnecessários. O pressuposto de independência das variáveis, em função do critério, ao efetuar a especificação destas, aliado ao delineamento fatorial fracionário, garante ortogonalidade ao modelo. A construção dos estímulos, por meio do delineamento fatorial fracionário, fornece a correta estimação dos efeitos principais (objetivo maior da análise).

Os dezenove (19) estímulos gerados, incluindo as amostras retidas (amostras de validação - em número de três) são apresentados na Tabela A1.02 do Anexo 01.

\subsection{4 - Estágio 4: estimação do modelo de análise conjunta}

Para a estimação do modelo conjunto é necessário selecionar a relação de utilidades parciais, ou seja, para cada atributo deve-se especificar o modelo de como os níveis de um fator estão relacionados.

Há um antagonismo entre optar-se por modelos mais aderentes ao mercado real e menos significativos estatisticamente, ao utilizar-se a forma de utilidades parciais separadas ou adotar formas mais restritas (linear ou ideal) obtendo modelos estatísticos mais eficientes, porém representando o mercado - a preferência do consumidor de forma menos precisa.

É admissível e talvez necessário especificar a forma de relação de utilidades parciais, separadamente para cada fator e uma mistura de forma é recomendável, sempre observando a dicotomia entre correlação estatística do modelo e retratação do real mercado analisado.

Na primeira rodada do programa computacional de análise conjunta (módulo acessório “conjoint” do programa estatístico SPSS - versão 17.0), especificou-se a forma de utilidades parciais separadas para todas as variáveis. Este procedimento resultará em melhor retratação do mercado, com maior poder de predição do modelo, embora com alto termo de erro. $\mathrm{O}$ resultado obtido é mostrado nas Tabelas 13 e 14. 
Tabela 13: Utilidades parciais estimadas pelo modelo

\begin{tabular}{|c|c|c|c|}
\hline & & Utilidade Estimada & Erro Padrão \\
\hline \multirow[t]{3}{*}{ Area } & 2 dormitórios - 70 m2 & $-4,488$ & 177 \\
\hline & 3 dormitórios com suíte - 85 m2 & 1,147 & ,208 \\
\hline & 3 dormitórios, suite $\mathrm{c} /$ closet $-95 \mathrm{~m} 2$ & 3,341 & ,208 \\
\hline \multirow[t]{2}{*}{ Tipo } & geminado &,- 704 & 133 \\
\hline & isolado &, 704 & ,133 \\
\hline \multirow[t]{5}{*}{ Lazer } & Quadra e piscina &,- 438 & 177 \\
\hline & Quadra, piscina, academia e espaço &,- 054 & ,208 \\
\hline & gourmet & & \\
\hline & Quadra, piscina, academia, espaço & 492 & 208 \\
\hline & gourmet e lazer infantil & & \\
\hline \multirow[t]{3}{*}{ Local } & Malha urbana, comércio local, nível médio & ,356 & 133 \\
\hline & expansão urbana, sem comércio local, nível &,- 356 & 133 \\
\hline & alto & & \\
\hline \multirow[t]{3}{*}{ Preço } & \$160 mil & 1,340 & 177 \\
\hline & $\$ 180 \mathrm{mil}$ &,- 073 & 208 \\
\hline & $\$ 200$ mil & $-1,267$ & ,208 \\
\hline \multirow[t]{4}{*}{ A.Verde } & Praça arborizada, grama e bancos &,- 139 & ,133 \\
\hline & Praça, grama, bancos, bosque, trilha e & 139 & ,133 \\
\hline & quiosques & & \\
\hline & Constante & 9,397 & 154 \\
\hline
\end{tabular}

Tabela 14: Coeficientes de correlação do modelo

\begin{tabular}{|l|c|c|}
\hline & Valor & Significância \\
\hline$\rho$ de Pearson &, 996 &, 000 \\
$\tau$ de Kendall &, 996 &, 000 \\
$\tau$ de Kendall para holdouts & 1,000 &, 059 \\
\hline
\end{tabular}


Com os dados obtidos, efetua-se análise gráfica do comportamento dos fatores e níveis, conforme mostra a Figura 24.

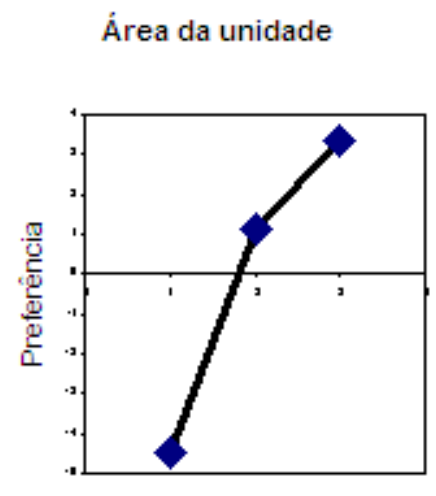

Nivel

Localização

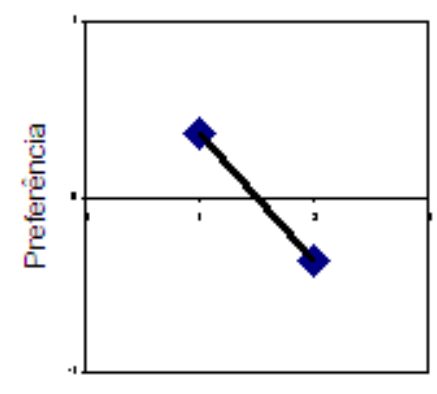

Nivel
Tipologia

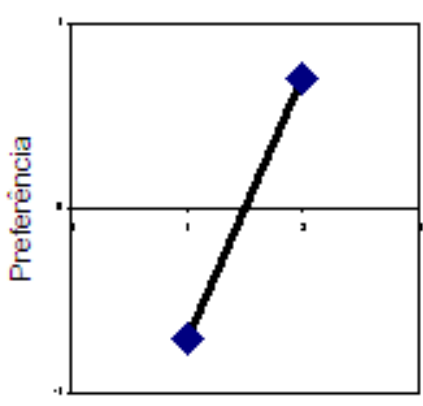

Nivel

Preço

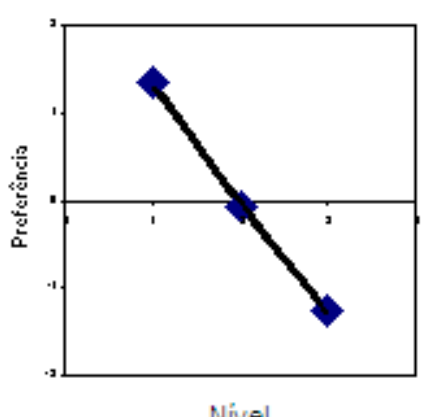

Nivel
Lazer

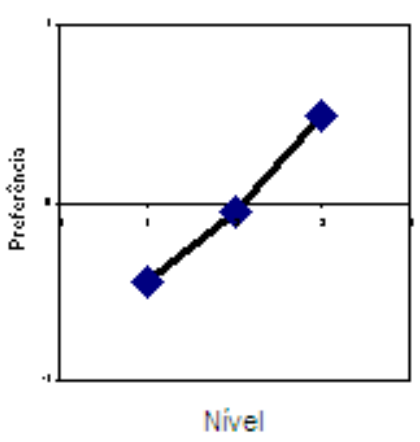

Área Verde

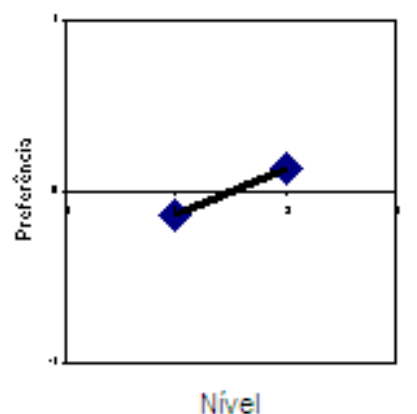

Figura 24: Comportamento dos fatores - relação entre níveis de utilidades parciais separadas.

A depuração do modelo, visando atender os requisitos de aderência aos valores observados no mercado (real preferência do consumidor), capacidade de predição do modelo, expresso pelos coeficientes de correlação de $\rho$ de Pearson e $\tau$ de kendall, e minimização do termo de erro, conduz ao ajuste das relações de utilidades parciais dos níveis dos fatores para relações mais restritivas (forma linear ou quadrática).

Inicialmente, a medida é linearizar os fatores que têm menor importância relativa, já que seus efeitos sobre o modelo também são menores, o que resulta em redução do erro da estimação para 7,232, conforme indicação do modelo 1 mostrado na Tabela 15. Interessante observar que nenhuma das variáveis apresentou comportamento de ponto ótimo (relação quadrática). 
Tabela 15: Forma de relação entre os níveis e efeito no termo de erro.

\begin{tabular}{|c|c|c|c|c|c|c|c|c|}
\hline Fator & $\begin{array}{c}\text { modelo } \\
\text { inicial }\end{array}$ & $\begin{array}{c}\text { modelo } \\
1\end{array}$ & $\begin{array}{c}\text { modelo } \\
2\end{array}$ & $\begin{array}{c}\text { modelo } \\
3\end{array}$ & $\begin{array}{c}\text { modelo } \\
4\end{array}$ & $\begin{array}{c}\text { modelo } \\
5\end{array}$ & $\begin{array}{c}\text { modelo } \\
6\end{array}$ & $\begin{array}{c}\text { modelo } \\
7\end{array}$ \\
\hline Área da unidade & $\begin{array}{l}\text { Util. } \\
\text { Parcial }\end{array}$ & $\begin{array}{l}\text { Util. } \\
\text { Parcial }\end{array}$ & $\begin{array}{c}\text { Util. } \\
\text { Parcial }\end{array}$ & Linear + & Linear + & Linear + & Linear + & Linear + \\
\hline Tipologia & $\begin{array}{l}\text { Util. } \\
\text { Parcial }\end{array}$ & Linear + & Linear + & Linear + & $\begin{array}{l}\text { Util. } \\
\text { Parcial }\end{array}$ & Linear + & Linear + & Linear + \\
\hline $\begin{array}{l}\text { Equipamento de } \\
\text { lazer }\end{array}$ & $\begin{array}{c}\text { Util. } \\
\text { Parcial }\end{array}$ & Linear + & Linear + & Linear + & Linear + & $\begin{array}{l}\text { Util. } \\
\text { Parcial }\end{array}$ & Linear + & Linear + \\
\hline Localização & $\begin{array}{c}\text { Util. } \\
\text { Parcial }\end{array}$ & Linear - & Linear - & Linear - & Linear - & Linear - & $\begin{array}{l}\text { Util. } \\
\text { Parcial }\end{array}$ & Linear - \\
\hline Preço & $\begin{array}{l}\text { Util. } \\
\text { Parcial }\end{array}$ & $\begin{array}{l}\text { Util. } \\
\text { Parcial }\end{array}$ & Linear - & $\begin{array}{l}\text { Util. } \\
\text { Parcial }\end{array}$ & $\begin{array}{l}\text { Util. } \\
\text { Parcial }\end{array}$ & $\begin{array}{l}\text { Util. } \\
\text { Parcial }\end{array}$ & $\begin{array}{l}\text { Util. } \\
\text { Parcial }\end{array}$ & $\begin{array}{c}\text { Util. } \\
\text { Parcial }\end{array}$ \\
\hline Área Verde & $\begin{array}{l}\text { Util. } \\
\text { Parcial }\end{array}$ & Linear + & Linear + & Linear + & Linear + & Linear + & Linear + & $\begin{array}{l}\text { Util. } \\
\text { Parcial }\end{array}$ \\
\hline Termo de erro & 9,397 & 7,232 & 9,851 & $-1,545$ & 0,374 & $-0,677$ & $-2,655$ & $-0,997$ \\
\hline
\end{tabular}

No modelo 2 , ao adotar a relação linear negativa para o fator preço, o erro ao invés de diminuir aumenta para 9,851. Portanto, o fator preço continua com relação de utilidade parcial.

No caso do fator Área da unidade, ao adotar a relação linear positiva - modelo 3, o erro passa para $-1,545$.

Mantido o fator preço com relação de utilidade parcial, os demais com relação linear e testando um fator por vez com a relação de utilidade parcial - modelos 4 a 7, os efeitos sobre o termo de erro são mostrados na Tabela 15.

Portanto, o menor termo de erro é obtido com a relação de utilidade parcial para o fator Tipologia. Importante lembrar que estas depurações e minimizações do termo de erro não influem no poder de predição do modelo, tampouco no nível de significância. A Tabela 16 apresenta as relações entre níveis que conduzem ao menor termo de erro, obtidas conforme o procedimento detalhado acima e que serão especificadas no modelo de estimação. 
Tabela 16: Relação entre níveis para os atributos.

\begin{tabular}{lc}
\hline \multicolumn{1}{c}{ Atributos } & Relação \\
\hline Área da unidade & Linear positiva \\
Tipologia & Utilidade parcial \\
Equipamento de lazer & Linear positiva \\
Localização & Linear negativa \\
Preço & Utilidade parcial \\
Área Verde & Linear positiva \\
\hline
\end{tabular}

\subsection{5 - Estágio 5: interpretação dos resultados}

Para melhor entendimento do comportamento dos respondentes ao analisar os atributos, definiu-se que primeiramente cada respondente foi analisado individualmente, obtendo-se a estimação de utilidades parciais para cada um e a importância relativa de cada atributo. $\mathrm{Na}$ sequencia foram agregados os respondentes, para obtenção do resultado e do modelo geral.

Executou-se o aplicativo e os resultados obtidos são apresentados na Tabela 17. 
Tabela 17: Resumo dos resultados da estimação do modelo

\begin{tabular}{|c|c|c|c|c|}
\hline Atributo & Nível & Descrição & Utilidade & Importância medida \\
\hline & $A$ & $\begin{array}{c}\text { Área privativa de } 70 \mathrm{~m}^{2} \text { = sobrado com sala estar/jantar, lavabo, } \\
\text { cozinha "americana", } 2 \text { dormitórios, banheiro, área serviço, } \\
\text { garagem descoberta para } 2 \text { carros e quintal. }\end{array}$ & 4,3322 & \\
\hline \multirow[t]{2}{*}{$\begin{array}{l}\text { Área da } \\
\text { unidade }\end{array}$} & $\mathrm{B}$ & $\begin{array}{c}\text { Área privativa de } 85 \mathrm{~m}^{2} \text { = sobrado com sala estar/jantar, lavabo, } \\
\text { cozinha, área serviço, suíte, } 2 \text { dorm, banheiro, garagem } \\
\text { descoberta para } 2 \text { carros e quintal. }\end{array}$ & 8,6643 & $51,85 \%$ \\
\hline & C & $\begin{array}{c}\text { Área privativa de } 95 \mathrm{~m}^{2}=\text { sobrado com sala estar/jantar/varanda, } \\
\text { lavabo, cozinha, área serviço, suite c/closet, } 2 \text { dorm e banheiro, } \\
\text { garagem descoberta para } 2 \text { carros e quintal. }\end{array}$ & 12,9965 & \\
\hline \multirow[t]{3}{*}{ Tipologia } & $\begin{array}{l}\text { A } \\
B\end{array}$ & $\begin{array}{l}\text { geminado } \\
\text { isolado }\end{array}$ & $\begin{array}{l}-0,1154 \\
-1,2308\end{array}$ & $9,89 \%$ \\
\hline & $A$ & Quadra poliesportiva e piscina & 0,4406 & \\
\hline & $\mathrm{B}$ & $\begin{array}{c}\text { Quadra poliesportiva, piscina, academia de ginástica, espaço } \\
\text { gourmet (churrasqueira e cozinha com galadeira, fogão, freezer } \\
\text { e mesas, ambiente climatizado). }\end{array}$ & 0,8811 & \\
\hline $\begin{array}{l}\text { Equipamentos } \\
\text { de lazer }\end{array}$ & C & $\begin{array}{l}\text { Quadra poliesportiva, piscina, academia de ginástica, espaço } \\
\text { gourmet (churrasqueira e cozinha com geladeira, fogão, freezer } \\
\text { e mesas), ambiente climatizado) e estrutura de Lazer Infantil } \\
\text { completa: Composta de } 3 \text { pequenos espaços de lazer [1] - } \\
\text { Praça infantil (bebês); [2] - Play-ground para crianças de } 2 \text { a } 6 \\
\text { anos, e; [3] Praça de esportes - crianças de } 6 \text { a } 12 \text { anos) }\end{array}$ & 1,3217 & $6,51 \%$ \\
\hline \multirow[t]{2}{*}{ Localização } & $A$ & $\begin{array}{l}\text { Inserido na malha urbana e presença de comércio e serviços } \\
\text { (mercado, escola e lojas de conveniência). Nível sócio- } \\
\text { econômico médio. }\end{array}$ & $-0,7404$ & $8,21 \%$ \\
\hline & B & $\begin{array}{c}\text { Área de expansão urbana, com ausência de comércio local. } \\
\text { Nível sócio-econômico alto. }\end{array}$ & $-1,4808$ & \\
\hline \multirow{3}{*}{ Preço } & $A$ & $\$ 160 \mathrm{mil}$ & 1,3462 & \\
\hline & B & $\$ 180 \mathrm{mil}$ & $-0,1154$ & $20,30 \%$ \\
\hline & $\mathrm{C}$ & $\$ 200 \mathrm{mil}$ & $-1,2308$ & \\
\hline \multirow[b]{2}{*}{ Área Verde } & $A$ & Área verde mínima - Praça arborizada, gramada e com bancos. & 0,3654 & \\
\hline & B & $\begin{array}{c}\text { Ampla área Verde - Praça arborizada, gramada e com bancos. } \\
\text { Bosque com trilha para caminhada e quiosques com } \\
\text { churrasqueiras. }\end{array}$ & 0,7308 & $3,24 \%$ \\
\hline
\end{tabular}




\subsubsection{1 - Análise agregada - Importância dos atributos e utilidade parciais}

A Figura 25 apresenta o gráfico das importâncias relativas, por fator, também expressas na Tabela 17, obtidos para cada fator, para os resultados agregados. Os resultados demonstram que o atributo área da unidade é considerado como sendo o de maior importância, quando comparado com os demais atributos do experimento.

Por ordem de importância relativa, os atributos estão classificados: preço, tipo, localização, equipamentos de lazer e área verde.

Os valores indicados, de importância relativa, são determinados em função da amplitude de variação de preferência de cada atributo.

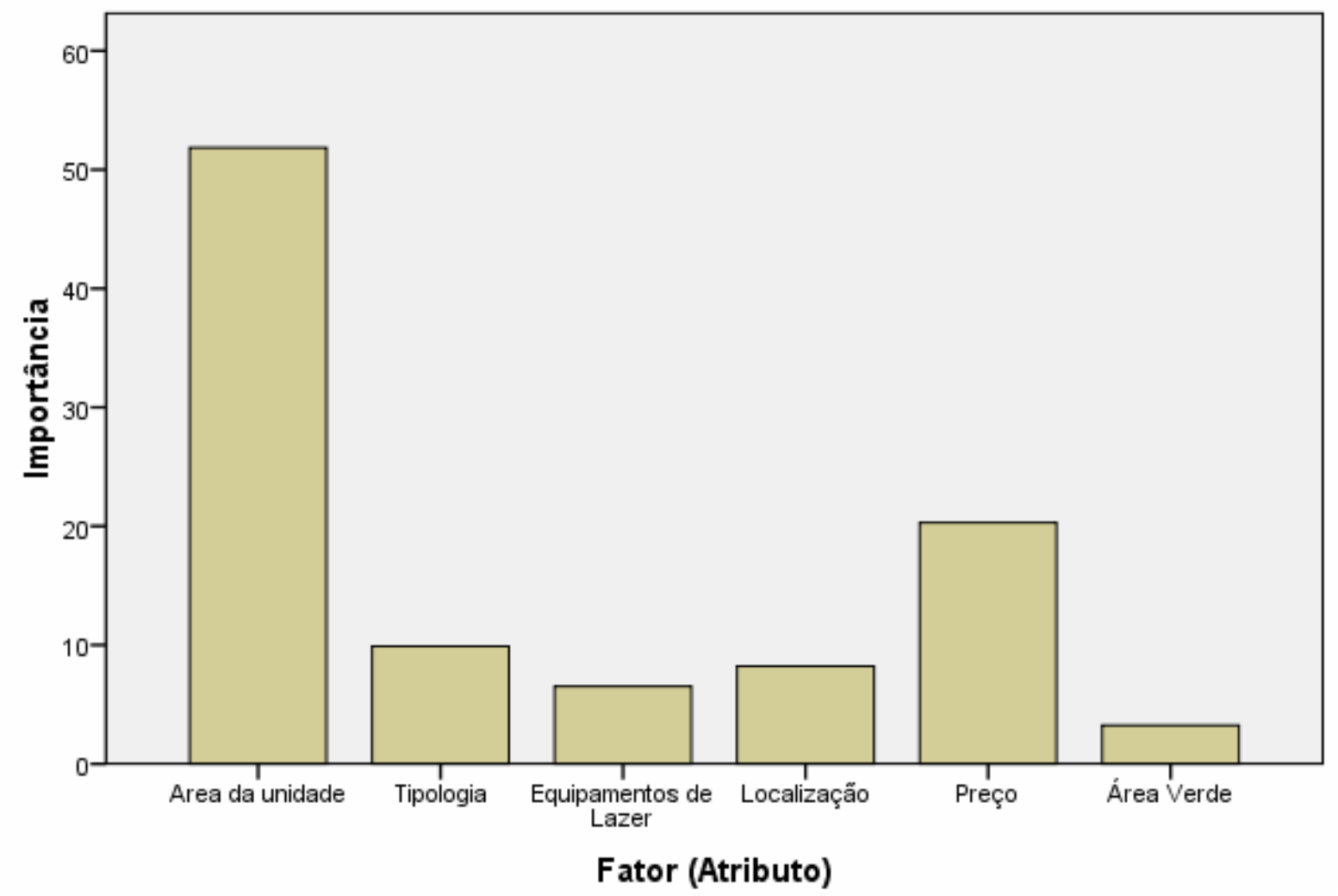

Figura 25: Importância relativa dos atributos - análise agregada 


\subsubsection{2 - Análise desagregada - Importância dos atributos e utilidade parciais}

Apesar de observar-se uma consistência com os resultados desagregados, cada respondente possui aspectos únicos e distintos dos demais e diferem dos resultados agregados.

Como exemplo da importância relativa dos atributos em nível individual, tomou-se de forma aleatória, os dados individuais para os respondentes 7 e 25, consolidados, respectivamente nas Tabelas 18 e 19, para efeito de comparação com os dados agregados do modelo.

Tabela 18: Tabela de resumo dos resultados da estimação do respondente 7 .

\begin{tabular}{|c|c|c|c|c|}
\hline Atributo & Nível & Descrição & Utilidade & Importância medida \\
\hline \multirow{3}{*}{ Área da unidade } & $A$ & 2 dorm - $70 \mathrm{~m} 2$ & 4,455 & \multirow{3}{*}{$54,52 \%$} \\
\hline & B & 3 dorm (suíte) - 85 m2 & 8,909 & \\
\hline & $\mathrm{C}$ & 3 dorm (suíte com closet) - 95 m2 & 13,364 & \\
\hline \multirow{2}{*}{ Tipologia } & A & geminado & $-0,125$ & \multirow{2}{*}{$1,53 \%$} \\
\hline & B & isolado & 0,125 & \\
\hline \multirow{3}{*}{ Equipamentos de lazer } & A & Quadra e piscina & $-0,091$ & \multirow{3}{*}{$1,11 \%$} \\
\hline & B & Quadra, academia e espaço gourmet & $-0,182$ & \\
\hline & $\mathrm{C}$ & Quadra, acad, gourmet e Lazer Infantil & $-0,273$ & \\
\hline \multirow[b]{2}{*}{ Localização } & $A$ & malha urbana. Nível sócio-econômico médio & $-1,250$ & \multirow[b]{2}{*}{$7,65 \%$} \\
\hline & B & expansão urbana. Nível sócio-econ alto & $-2,500$ & \\
\hline \multirow{3}{*}{ Preço } & $A$ & $\$ 160 \mathrm{mil}$ & 2,667 & \multirow{3}{*}{$26,01 \%$} \\
\hline & B & $\$ 180 \mathrm{mil}$ & $-1,083$ & \\
\hline & $\mathrm{C}$ & $\$ 200 \mathrm{mil}$ & $-1,583$ & \\
\hline \multirow{3}{*}{ Área Verde } & $A$ & Área verde mínima - Praça. & 1,5000 & \multirow{3}{*}{$9,18 \%$} \\
\hline & $\mathrm{B}$ & Ampla área Verde. Bosque, trilha e quiosques & 3,0000 & \\
\hline & & constante & $-0,178$ & \\
\hline
\end{tabular}


Tabela 19: Tabela de resumo dos resultados da estimação do respondente 25.

\begin{tabular}{|c|c|c|c|c|}
\hline Atributo & Nível & Descrição & Utilidade & Importância medida \\
\hline \multirow{3}{*}{ Área da unidade } & A & 2 dorm - $70 \mathrm{~m} 2$ & 4,818 & \multirow{3}{*}{$53,57 \%$} \\
\hline & B & 3 dorm (suíte) - 85 m2 & 9,636 & \\
\hline & $\mathrm{C}$ & 3 dorm (suíte com closet) - 95 m2 & 14,455 & \\
\hline \multirow{2}{*}{ Tipologia } & $A$ & geminado & $-1,500$ & \multirow{2}{*}{$16,68 \%$} \\
\hline & $\mathrm{B}$ & isolado & 1,500 & \\
\hline \multirow{3}{*}{$\begin{array}{l}\text { Equipamentos de } \\
\text { lazer }\end{array}$} & $A$ & Quadra e piscina & 0,364 & \multirow{3}{*}{$4,04 \%$} \\
\hline & $\mathrm{B}$ & Quadra, academia e espaço gourmet & 0,727 & \\
\hline & C & Quadra, acad, gourmet e Lazer Infantil & 1,091 & \\
\hline \multirow[b]{2}{*}{ Localização } & $A$ & malha urbana. Nível sócio-econômico médio & 0,750 & \multirow[b]{2}{*}{$4,17 \%$} \\
\hline & $\mathrm{B}$ & expansão urbana. Nível sócio-econômico alto & 1,500 & \\
\hline \multirow{3}{*}{ Preço } & $A$ & $\$ 160 \mathrm{mil}$ & 1,500 & \multirow{3}{*}{$17,37 \%$} \\
\hline & B & $\$ 180 \mathrm{mil}$ & 0,125 & \\
\hline & $\mathrm{C}$ & $\$ 200 \mathrm{mil}$ & $-1,625$ & \\
\hline \multirow{3}{*}{ Área Verde } & $A$ & Área verde mínima - Praça. & $-0,750$ & \multirow{3}{*}{$4,17 \%$} \\
\hline & $\mathrm{B}$ & Ampla área Verde. Bosque, trilha e quiosques. & $-1,500$ & \\
\hline & & constante & $-0,943$ & \\
\hline
\end{tabular}

A Figura 26 ilustra os Resultados desagregados dos respondentes 7 e 25 e mostra claramente a unicidade e diferença nas avaliações de preferência. $\mathrm{O}$ atributo área da unidade foi o único que apresentou o mesmo comportamento em todos os respondentes. Comparando as respostas, o indivíduo 25 , em termos de preferência, apresentou forte aderência com a análise agregada, enquanto o indivíduo 7 apresentou uma função de utilidade diferente do modelo agregado.

Estes dois exemplos, foram escolhidos dentre os respondentes para ilustrar que, embora haja notórias diferenças entre os indivíduos, este aspecto não invalida o modelo, pois no nível agregado a indicação da qualidade do ajuste do modelo deve resultar níveis de correlações altos ( $\rho$ de Pearson e $\tau$ de Kendall ao nível de significância determinado para a análise). 


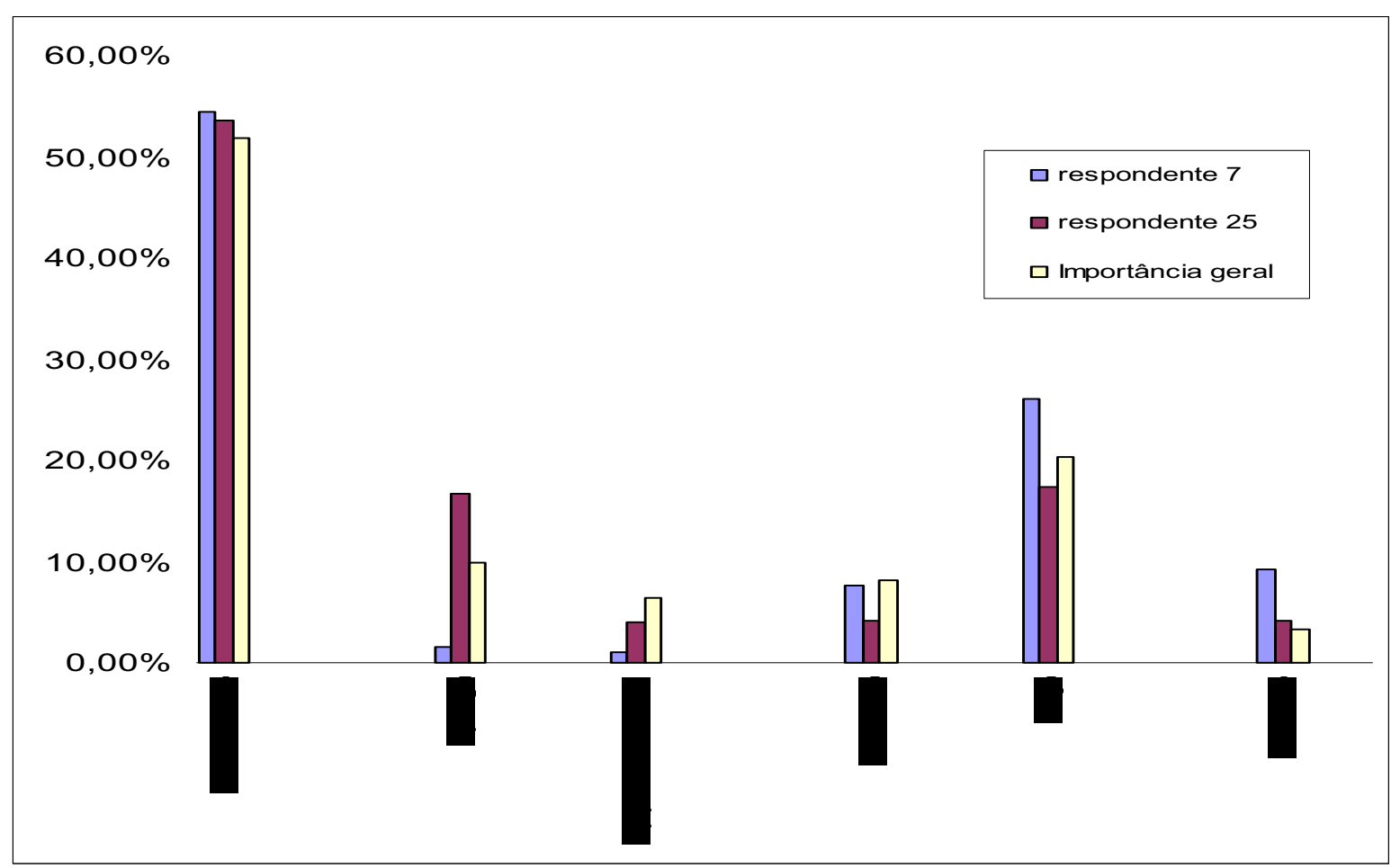

Figura 26: Comparativo de importâncias relativas entre respondentes

\subsubsection{3 - A função de utilidade estimada}

A partir dos dados das utilidades parciais apresentadas na Tabela 17, o modelo aditivo simples representativo da estrutura de preferência do produto habitacional residencial em estudo, com base nos seis atributos de valor (área da unidade, tipologia, equipamentos de lazer, localização, preço a área verde) é definido pela função de utilidade da expressão (2) (considerando um nível de significância $\alpha=0,05$ ) .

$$
\begin{aligned}
U= & (4,332) \cdot X_{\text {area }}^{A}+(8,664) \cdot X_{\text {area }}^{B}+(12,997) \cdot X_{\text {area }}^{C}+(-0,639) \cdot X_{\text {tipo }}^{A}+ \\
& (0,639) \cdot X_{\text {tipo }}^{B}+(0,441) \cdot X_{\text {lazer }}^{A}+(0,881) \cdot X_{\text {lazer }}^{B}+(1,322) \cdot X_{\text {lazer }}^{C}+(- \\
& \text { 0,740). } X_{\text {local }}^{A}+(-1,481) \cdot X_{\text {local }}^{D}+(1,346) \cdot X_{\text {preco }}^{A}+(-0,115) \cdot X_{\text {preco }}^{D}+ \\
& (-1,231) \cdot X_{\text {preqo }}^{C}+(0,365) \cdot X_{\text {area verde }}^{A}+(0,731) \cdot X_{\text {area verde }}^{D}+0,374
\end{aligned}
$$


em que,

$U$ representa a utilidade total do condomínio residencial horizontal;

$X_{i}^{a}$ representa os níveis dos atributos, em que $a$ representa o nível (A, B ou C) e $i$ representa o atributo (área da unidade, tipo, equipamentos de lazer, localização, preço e área verde).

No Anexo-01 deste trabalho são apresentadas as utilidades parciais dos atributos por indivíduo (Figuras A1.09 a A1.14) e as utilidades agregadas (Figuras A1.15 a A1.20).

Do modelo obtido, tem-se que o resíduo é igual a 0,374. Este valor representa o termo de erro do modelo, que pode ser explicado:

- variáveis relevantes e não incluídas no modelo;

- efeitos de interação entre as variáveis;

- $\quad$ erro de predição do modelo - variâncias não explicadas;

- $\quad$ erros na medição dos atributos, feitos pelo pesquisador;

- erros de percepção, ocasionados pelos respondentes.

\subsection{6 - Estágio 6: validação dos resultados}

A validação dos resultados da análise conjunta é definida pelos coeficientes $\rho$ (rô) de Pearson e $\tau$ (tau) de Kendall, conforme indicações na Tabela 20. 
Tabela 20: Validação dos resultados da análise conjunta

\begin{tabular}{lcc}
\hline \multicolumn{1}{c}{ Coeficientes } & Valor & Significância. \\
\hline$\rho$ de Pearson &, 976 &, 000 \\
$\tau$ de Kendall &, 950 &, 000 \\
$\tau$ de Kendall para as amostras retidas & 1,000 &, 059 \\
\hline
\end{tabular}

Estes coeficientes indicam a correlação entre as preferências observadas e as medidas e fornecem o poder de predição e o grau de ajustamento do modelo comparando-se os valores calculados com os valores observados. Em toda análise estatística espera-se altos valores de correlação.

No caso deste estudo em que a variável de resposta é não métrica, ou seja, os dados não pertencem a uma escala de medida métrica, mas seguem uma ordenação clara, os coeficientes representam a correlação entre os postos previstos e os postos observados.

O teste de hipóteses do modelo, é estabelecido para a hipótese nula $H_{0}$ que supõe que a correlação entre os postos observados e previstos seja igual a zero, e a hipótese alternativa $H_{1}$, na qual a correlação entre os postos é diferente de zero, a um nível de significância do modelo de 0,05 ou $5 \%$.

$$
\begin{aligned}
& H_{0} \text { : correlação entre os postos }=0 ; \\
& H_{1} \text { : correlação entre os postos } \neq 0 ; \\
& \text { para } \alpha=0,05 \text { (nível de significância } 5 \% \text { ). }
\end{aligned}
$$

Dos resultados do experimento conjunto, obteve-se o valor do $\rho$ de Pearson de 0,976 , um valor excelente, considerando que, a significância obtida pelo modelo é de menor que 0,001 $(0,1 \%)$ podemos rejeitar a hipótese nula $\left(H_{0}\right)$.

O coeficiente de Kendall também apresenta valores desejáveis. No experimento, o resultado do coeficiente $\tau$ de Kendall apresentou um valor de 0,950 para o conjunto de estímulos do experimento, com significância também menor que $0,001(0,1 \%)$, portanto 
rejeitando-se também a hipótese nula e afirmar que ao nível de significância menor que $0,1 \%$ há correlação entre os postos observados e os postos medidos.

No caso da amostra de validação interna (amostra “holdout”), observaram-se valores ainda melhores para o modelo de correlação, onde o coeficiente $\tau$ de Kendall apresentou valor igual a 1,000, com significância igual a 0,059, num nível aceitável de até 0,100 $(10,0 \%)$ para o caso de amostras de validação.

A diferença entre os níveis de significância do modelo e da amostra de validação, devese ao fato que a validação interna é realizada com apenas três elementos, enquanto que para a estimação do modelo é utilizado 16 elementos, os quais foram obtidos por meio de delineamento fatorial fracionário e têm efeito equivalente aos 216 elementos possíveis (fatorial completo).

Portanto, o modelo experimental obtido para aplicação no mercado imobiliário, na definição do projeto de implantação de um condomínio residencial horizontal na cidade de Bauru, apresenta-se estatisticamente significativo.

Desta forma, na definição dos atributos que o condomínio deve oferecer, quando apresentado ao mercado, os atributos área da unidade $(51,85 \%)$, preço $(20,30 \%)$ e tipo (9,89\%), representando juntos $82,04 \%$ da função de utilidade do produto residencial, devem merecer destaque, conforme se observa na Figura 27.

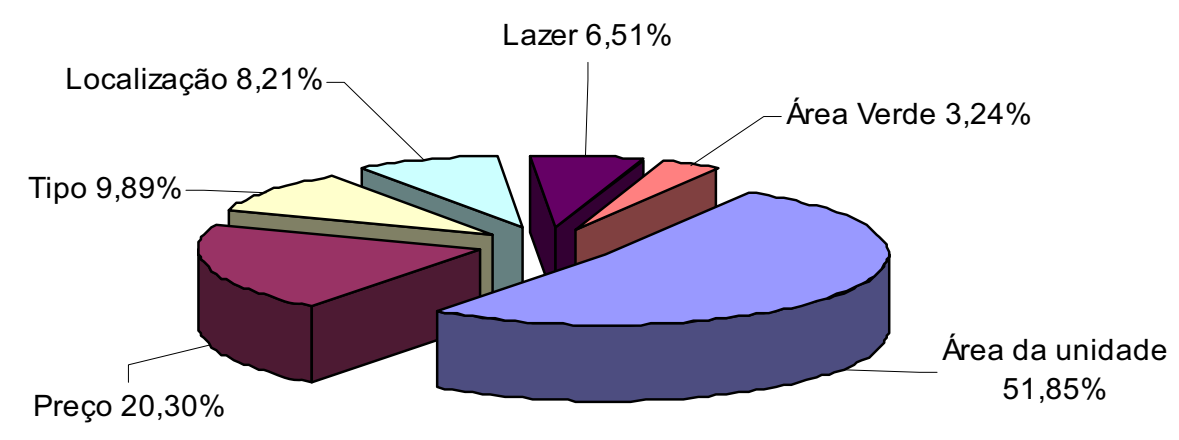

Figura 27: Resumo da importância relativa dos atributos. 


\subsection{7 - Aplicação dos resultados da análise conjunta - Simulador de escolha}

Obtidos os resultados têm-se a importância relativa dos atributos e o impacto de seus níveis, mas a força desta técnica reside na previsão da participação de preferências que um estímulo (real ou hipotético) está apto a capturar em vários cenários de interesse do pesquisador.

No caso será fornecido um conjunto de estímulos (produtos) e realizada a simulação de escolhas dos clientes, para prever a participação de mercado e desta forma orientar a formatação do empreendimento imobiliário em análise.

Conforme já exposto na fundamentação do método, os simuladores de escolha, normalmente, usam dois tipos de regras para prever a escolha de um estímulo:

- Utilidade máxima, onde o modelo assume que o cliente escolhe o produto que apresentar maior escore de utilidade previsto;

- Probabilidade de compra, usualmente com base nos modelos BTL (BradleyTerry-Luce) e Logit, que indicam a escolha com base em uma distribuição de probabilidade.

No estudo em curso, far-se-á a simulação em duas fases:

\section{Fase 1: Determinação da proporção de produtos que o empreendimento imobiliário deve conter.}

Tendo em vista que o atributo área da unidade foi o mais importante, a simulação envolverá os três possíveis produtos (com áreas de 70, 85 e $95 \mathrm{~m}^{2}$ ) e o resultado embasará o mix de produtos que o empreendimento deverá conter. Com relação aos demais atributos, o critério será: 
- Preço: Com base em valores factíveis de mercado, o produto de $70 \mathrm{~m}^{2}$ terá preço simulado de R $\$ 160$ mil, o de $85 \mathrm{~m}^{2}$ preço de $\mathrm{R} \$ 180$ mil e o de $95 \mathrm{~m}^{2}$ preço de R\$ 200 mil;

- Tipo: A simulação adotará unidades geminadas, que é a pretensão de implantação;

- Localização: Inserido na malha urbana, em função da característica real da área em análise;

- Equipamento de Lazer: Será adotado nível mínimo;

- Área Verde: Também será adotado nível mínimo, nos moldes do atributo equipamento de lazer.

Os perfis de simulação estão apresentados na Tabela 21.

Tabela 21: Perfis da simulação - Fase 1

\begin{tabular}{ccccccc}
\hline $\begin{array}{c}\text { Produto } \\
\text { simulado }\end{array}$ & Área & Tipo & Lazer & Localização & Preço & Área Verde \\
\hline 1 & 2 dorm $-70 \mathrm{~m} 2$ & geminado & $\begin{array}{c}\text { Qda e } \\
\text { pisc }\end{array}$ & $\begin{array}{c}\text { malha urbana, comérc } \\
\text { local, nivel médio }\end{array}$ & $\begin{array}{c}\$ 160 \\
\text { mil }\end{array}$ & $\begin{array}{c}\text { Pça arboriz, } \\
\text { grama e bancos }\end{array}$ \\
2 & $\begin{array}{c}3 \text { dorm (suite) - } \\
85 \mathrm{~m} 2\end{array}$ & geminado & $\begin{array}{c}\text { Qda e } \\
\text { pisc }\end{array}$ & $\begin{array}{c}\text { malha urbana, comérc } \\
\text { local, nivel médio }\end{array}$ & $\begin{array}{c}\$ 180 \\
\text { mil }\end{array}$ & $\begin{array}{c}\text { Pça arboriz, } \\
\text { grama e bancos }\end{array}$ \\
3 & $\begin{array}{c}3 \text { dorm (suite } \mathrm{c} / \\
\text { closet) }-95 \mathrm{~m} 2\end{array}$ & geminado & $\begin{array}{c}\text { Qda e } \\
\text { pisc }\end{array}$ & $\begin{array}{c}\text { malha urbana, comérc } \\
\text { local, nivel médio }\end{array}$ & $\begin{array}{c}\$ 200 \\
\text { mil }\end{array}$ & $\begin{array}{c}\text { Pça arboriz, } \\
\text { grama e bancos }\end{array}$ \\
\hline
\end{tabular}

Foram submetidos à análise três produtos com seus respectivos preços ajustados ao mercado. As simulações permitem estimar a probabilidade de preferência dos produtos propostos, por meio de três critérios diferentes.

O critério de utilidade máxima conta o número de vezes que cada um dos três produtos teve a mais alta utilidade no conjunto de respondentes e é o critério de análise eleito para esta 
situação (comportamento de compra complexa, com alto envolvimento e compra esporádica não-rotineira).

Os modelos de simulação BTL e Logit, que envolvem distribuição de probabilidade, avaliam a preferência relativa de cada produto e estimam a proporção de vezes que o conjunto de respondentes irá comprar cada produto.

Na Tabela 22 apresenta-se o resultado da simulação, com indicação unânime pelas três regras de preferência pelo produto 3 (que contém 3 dormitórios com suíte e closet $-95 \mathrm{~m}^{2} \mathrm{e}$ preço de R $\$ 200$ mil).

Tabela 22: Simulação de probabilidade de preferência - Fase 1

\section{Produto simulado}

\begin{tabular}{|c|c|c|c|c|}
\hline Identificação & Área e Preço & & Bradley-Terry-Luce & Logit \\
\hline 1 & $70 \mathrm{~m} 2-\$ 160 \mathrm{mil}$ & $7,7 \%$ & $21,0 \%$ & $4,8 \%$ \\
\hline 2 & $85 \mathrm{~m} 2-\$ 180 \mathrm{mil}$ & $0,0 \%$ & $32,8 \%$ & $7,7 \%$ \\
\hline 3 & $95 \mathrm{~m} 2-\$ 200 \mathrm{mil}$ & $92,3 \%$ & $46,2 \%$ & $87,5 \%$ \\
\hline
\end{tabular}

No aspecto de definição do produto imobiliário, a simulação realizada indica que o imóvel com área de $95 \mathrm{~m} 2$, apesar do preço de R\$ 200 mil, deteve a preferência de 92,3\% dos respondentes.

Análise complementar quanto à participação de mercado dos produtos $1 \mathrm{e} 2$, em função da dissonância dos resultados entre os métodos adotados, justificam oferta ao mercado em quantidades conservadoras.

Adicionalmente, realizou-se simulação apenas entre os produtos de 3 dormitórios e os resultados confirmaram a preferência pelo produto de $95 \mathrm{~m} 2$, conforme mostrada na Tabela 23. 
Tabela 23: Simulação de probabilidade de preferência, entre produtos de 3 dormitórios

\begin{tabular}{ccccc}
\hline \multicolumn{2}{c}{ Produto simulado } & $\begin{array}{c}\text { Utilidade } \\
\text { Máxima }\end{array}$ & $\begin{array}{c}\text { Bradley-Terry- } \\
\text { Luce }\end{array}$ & Logit \\
\hline Identificação & Área e Preço & & & \\
\hline 1 & $85 \mathrm{~m} 2-\$ 180 \mathrm{mil}$ & $0,0 \%$ & $39,5 \%$ & $2,0 \%$ \\
2 & $95 \mathrm{~m} 2-\$ 200 \mathrm{mil}$ & $100,0 \%$ & $60,5 \%$ & $98,0 \%$ \\
\hline
\end{tabular}

Fase 2: Influência da variável localização na participação de mercado.

Nesta fase, a simulação analisa a influência da variável localização, visando estimar os efeitos da concorrência. Mantidas as características do empreendimento, inclusive área e preço, verificar-se-á a influência da variável localização, desta vez, com atenção às distribuições de probabilidade alternativas (BTL e Logit). Na Tabela 24 é mostrado que o empreendimento em análise apresenta vantagem de mercado, em virtude da localização.

Tabela 24: Simulação de probabilidade de preferência - Participação de mercado

\begin{tabular}{ccccc}
\hline \multicolumn{2}{c}{ Produto simulado } & Utilidade & $\begin{array}{c}\text { Bradley-Terry- } \\
\text { Luce }\end{array}$ & Logit \\
\hline Identificação & Localização & Máxima & $51,5 \%$ & $59,1 \%$ \\
\hline 1 & malha urbana & $59,6 \%$ & $40 \%$ & $40,9 \%$ \\
\hline
\end{tabular}

\subsection{8 - Considerações finais}

Este estudo apresentou o cenário que se desenha no mercado imobiliário e uma breve revisão da literatura sobre comportamento do consumidor e do método utilizado no experimento, a técnica estatística multivariada de análise conjunta. 
Com base nos dados e projeções apresentadas, que configuram o cenário econômico mundial, aliada às transformações econômicas e sociais brasileiras, notadamente aquelas relativas à queda do juro interno, alongamento do prazo de pagamento, expansão da oferta de crédito, melhora dos indicadores de emprego e renda e significativo crescimento da classe C.

Com o objetivo de medir a estrutura de preferência do consumidor de unidade habitacional em condomínio residencial horizontal. Com base em discussões com especialistas do setor imobiliário, operadores do mercado e pré-teste, foram determinados seis atributos relevantes para o estudo: área da unidade, tipologia (isolado ou geminado), equipamentos de lazer, localização, preço e área verde. Também foram selecionados os níveis para cada atributo, o que gerou 15 parâmetros estimados no modelo.

A aplicação do método foi orientada à implantação de um empreendimento habitacional na cidade de Bauru. O modelo gerado apresentou excelente nível de significância estatística, o que conduz à adequada capacidade de previsão da preferência do consumidor. 


\section{CONCLUSÕES}

Os resultados obtidos mostraram que as principais variáveis da função de utilidade, como medida de preferência do consumidor, na aquisição da unidade habitacional, são: área da unidade com 51,85\% de importância, seguida do preço do imóvel, com 20,30\% de importância, tipologia de construção (isolado ou geminado) com 9,89\% de importância, localização do empreendimento com $8,21 \%$, equipamentos de lazer do condomínio com $6,51 \%$ de e área verde com $3,24 \%$ de importância.

As conclusões se revelam bastante interessantes. Houve supremacia da variável área, representando mais de 50\% da preferência do consumidor, superando o fator preço. Este fato leva a conclusão que o produto possui alto nível de aceitação e que a elasticidade do fator preço não é preponderante. Em toda situação que o preço não é o fator mais importante há espaço para praticar melhores margens de lucro e obter maiores taxas de retorno do investimento.

Outra conclusão que o estudo permitiu diz respeito à tipologia, na qual está sendo medida a preferência por unidades isoladas ou geminadas. Que há uma rejeição do mercado para unidades geminadas, isto é incontestável, porém há a necessidade de medi-la, para saber se o fator tem importância relativa alta. Os resultados levam a crer que no conjunto das variáveis medidas, este atributo não tem grande relevância.

A existência de ampla área verde, com bosque e trilha para caminhada, ao contrário do pressuposto inicial, também demonstrou pequena relevância na preferência do consumidor, resultando em importância relativa de apenas 3,24\%.

Como sugestão para trabalhos futuros, tendo como linha de pesquisa o mercado imobiliário, recomenda-se aplicação de técnica de análise conjunta que aborde o efeito da interação entre as variáveis.

Esta pesquisa também pode ser aplicada a um grupo de consumidores finais compradores de imóveis e seus resultados comparados com os obtidos apenas por especialistas. A conclusão deste estudo pode levar à mudança de conceito, na elaboração de pesquisas de marketing. 
A aplicação da pesquisa, nos mesmos moldes, em outras regiões também possibilitará comparações e conclusões a respeito de similaridades e tendências de mercado.

E, por final, recomenda-se estudo, na mesma linha de pesquisa, sem a utilização do preço como fator, dado sua alta correlação interatributos. A comparação dos estudos pode levar a conclusões sobre a influência do preço na importância relativa dos atributos. 


\section{REFERÊNCIAS BIBLIOGRÁFICAS}

ABEP - Associação Brasileira de Empresas de Pesquisa. Critério padrão de classificação econômica Brasil - 2008. Disponível em <www.abep.org/codigosguias/CCEB2008Base2006e2007.pdf> Acesso em 28 dez. 2009.

BÊRNI, Dúlio de Avila. Técnicas de pesquisa em economia: transformando curiosidade em conhecimento. São Paulo: Saraiva, 2002.

BRASIL. Decreto Lei 271, de 20 de fevereiro de 1967. Dispõe sobre loteamento urbano, responsabilidade do loteador concessão de uso e espaço aéreo e dá outras providências. Disponível em: < http://www.planalto.gov.br/ccivil/Decreto-Lei/Del0271.htm>. Acesso em: 26 set. 2009.

.Lei 4.591, de 16 de dezembro de 1964. Dispõe sobre o condomínio em edificações e as incorporações imobiliárias. Diário Oficial da União, Brasília, DF, 21 dez. 1964. Disponível em: < http://www.planalto.gov.br/ccivil/Leis/L4591.htm>. Acesso em: 26 set. 2009.

. Lei 6.766/79, de 19 de dezembro de 1979. Dispõe sobre o Parcelamento do Solo Urbano e dá outras Providências. Disponível em: < http://www.planalto.gov.br/ ccivil/Leis/L6766.htm>. Acesso em: 26 set. 2009.

. Lei 9.785, de 29 de janeiro de 1999. Altera o Decreto-Lei no 3.365, de 21 de junho de 1941 (desapropriação por utilidade pública) e as Leis $\mathrm{n}^{\underline{\mathrm{os}}}$ 6.015, de 31 de dezembro de 
1973 (registros públicos) e 6.766, de 19 de dezembro de 1979 (parcelamento do solo urbano). Diário Oficial da União, Brasília, DF, 01 fev. 1999. Disponível em: < http://www.planalto.gov.br/ccivil_03/Leis/L9785.htm>. Acesso em: 26 set. 2009.

. Lei 10.406, de 10 de janeiro de 2002. Institui o Código Civil. Diário Oficial da

União, Brasília, DF, 11 jan. 2002. Disponível em: < http://www.planalto.gov.br/CCIVIL/LEIS/2002/L10406.htm>. Acesso em: 26 set. 2009.

. Lei no 11.274, de 6 de fevereiro de 2006. Altera a redação dos artigos 29, 30, 32 e 87 da Lei no 9.394, de 20 de dezembro de 1996, que estabelece as diretrizes e bases da educação nacional, dispondo sobre a duração de 9 (nove) anos para o ensino fundamental, com matrícula obrigatória a partir dos 6 (seis) anos de idade. Diário Oficial da República Federativa do Brasil, Brasília, DF, 7 fev. 2006. p.1, col.3. Disponível em: $<$ http://www.senado.gov.br/sicon/ PreparaPesquisa-Legislacao.action>. Acesso em: 26 set. 2009.

. Lei no 11.977, de 7 de julho de 2009. Dispõe sobre o Programa Minha Casa, Minha Vida - PMCMV e a regularização fundiária de assentamentos localizados em áreas. Diário Oficial da República Federativa do Brasil, Brasília, DF, 8 jul. 2009. Disponível em: http://www.planalto.gov.br/ccivil_03/_ato2007-2010/2009/1ei/111977.htm. Acesso em: 26 set. 2009.

CASTRO, L. R. K. Valor percebido como ferramenta para tomada de decisão: Uma aplicação na indústria hoteleira utilizando a análise conjunta. 2006. Dissertação (Mestrado em Engenharia de Produção) - Escola de Engenharia de São Carlos, USP, São Carlos. 
. Marketing Básico: uma perspectiva brasileira. São Paulo: Atlas, 1997.

ENGEL, James F.; BLACKWELL, Roger D.; Miniard, Paul W. Comportamento do Consumidor. Rio de Janeiro: Livros Técnicos e Científicos Editora S.A, 2000.

FÁVERO, Luiz P. L. Modelos de preços hedônicos aplicados a imóveis residenciais em lançamento no município de São Paulo. 2003. Dissertação (Mestrado em Administração) Faculdade de Economia, Administração e Contabilidade, USP, São Paulo.

. Mercado Imobiliário: técnicas de precificação e comercialização. São Paulo: Saint Paul Editora, 2007.

FINKELSTEIN, J. Diagrama da Hierarquia das necessidades de Maslow. Disponível em < http://en.wikipedia.org/wiki/Image:Maslow\%27s_hierarchy_of_needs.svg>.Acesso em 27 dez. 2009.

GADE, Christiane. Psicologia do Consumidor. São Paulo: EPU, 1980.

GOLDMAN SACHS - WILSON, Dominic; DRAGUSANU, Raluca. The expanding middle class and falling global inequality. Goldman Sachs Economic Research / Global Economics Paper n. 170, jul. 2008.

GREEN, P. E.; SRINIVASAN, V. Conjoint Analysis in Consumer Research: Issues and Outlook. The Journal of Consumer Research, v. 5, n. 2, p. 103-123, set. 1978. 
; SRINIVASAN, V. Conjoint Analysis in Marketing: New Developments with Implications for Research and Practice. The Journal of Marketing, v. 54, n. 4, p. 3-19, out. 1990.

GUJARATI, Damodar N.. Econometria Básica. Rio de Janeiro: Elsevier, 2006.

HAIR JR, J. F.; ANDERSON, R. E.; TATHAM, R. L.; BLACK, W. C. Análise multivariada de dados. Porto Alegre: Bookman, 2005.

HONDA, Wilson S. Atributos que condicionam o desenvolvimento de loteamento residenciais fechados. 2008. Dissertação (Mestrado em Engenharia de Construção Civil)Programa de Pós-Graduação da Escola Politécnica, USP, São Paulo.

IBGE - Instituto Brasileiro de Geografia e Estatística. PNAD 2008 - Pesquisa Nacional por Amostras de Domicílio. Disponível em http://www.ibge.gov.br/home/estatistica/ populacao/trabalhoerendimento/pnad2008/brasilpnad2008.pdf. Acesso em 27 set. 2009.

. Região de Influência das Cidades. Disponível em http://www.ibge.gov.br/. Acesso em 27 set. 2009

KARSAKLIAN, Eliane. Comportamento do Consumidor. São Paulo: Atlas, 2004.

KOTLER, Philip. Administração de Marketing: análise, planejamento, implantação e controle. São Paulo: Atlas, 1998. 
; ARMSTRONG, Gary. Princípios de Marketing. Rio de Janeiro: Livros Técnicos e Científicos Editora, 1999.

. Administração de Marketing. São Paulo: Prentice Hall, 2000.

LIMA JÚNIOR, João da R. Evolução e Inovação - Reflexões para Empresas de Real Estate. Carta do NRE-POLI, São Paulo, n. 9-07, p. 3-4, out./dez. 2007.

LIMA JÚNIOR, João da R. Planejamento do produto no mercado habitacional. Boletim Técnico da Escola Politécnica da USP. São Paulo: EPUSP, 1993.

MALHOTRA, Naresh. Escalonamento multidimensional e Análise Conjunta. In: Pesquisa de Marketing: Uma orientação aplicada. Porto Alegre: Bookman, 2001. cap. 21, p. 543-573.

NERI, Marcelo C. Consumidores, Produtores e a Nova Classe Média: Miséria, Desigualdade e Determinantes das Classes. Rio de Janeiro: FGV/IBRE, CPS, 2009.

PASCALE, Andréa. Atributos que configuram qualidade às localizações residenciais: Uma matriz para clientes de mercado na cidade de São Paulo. 2005. Dissertação (Mestrado em Engenharia de Construção Civil)- Programa de Pós-Graduação da Escola Politécnica, USP, São Paulo. 
PLANHAB - Plano Nacional de habitação. Secretaria Nacional de Habitação do Ministério das Cidades. Governo Federal. Disponível em: http://www.cidades.gov.br/secretariasnacionais/secretaria-de-habitacao/planhab/biblioteca/biblioteca-1. acesso em: 18 mar. 2009.

PROJEÇÃO da população do Brasil por sexo e idade 1980-2050: revisão 2008. Rio de Janeiro: IBGE, 2008. Disponível em: $\underline{\text { http://www.ibge.gov.br/ }}$ home/estatistica/populacao/projecao_da_populacao/2008/default.shtm>. Acesso em: 18 mar. 2009.

RIBEIRO, Renata C. S. Proposta para matriz de atributos que configuram qualidade de Condomínios Horizontais na cidade de São Paulo. São Paulo, 2005. Monografia (MBA). Programa de Educação Continuada, Escola Politécnica, USP, São Paulo.

SOLOMON, Michael R. O Comportamento do Consumidor: comprando, possuindo e sendo. Porto Alegre: Bookman, 2002.

SPSS Conjoint, Version 17.0.0. [S.I.]: SPSS Inc., 2009. Software

YANAZE, Mitsuro H. Gestão de marketing: avanços e aplicações. São Paulo: Saraiva, 2007.

WILSON, Dominic; DRAGUSANU, Raluca. The expanding middle class and falling global inequality. Goldman Sachs Economic Research / Global Economics Paper n. 170, jul. 2008. 


\section{ANEXO-01}

\section{RESULTADOS}

\section{DA ANÁLISE CONJUNTA}


FATOR: AREA

\begin{tabular}{|c|c|c|c|}
\hline VARIÁVEL & NÍVEL & DESCRIÇÃO DETALHADA & DESCRIÇÃO RESUMIDA - CARTÕES \\
\hline \multirow{3}{*}{$\begin{array}{l}\text { Área da } \\
\text { unidade }\end{array}$} & 1 & $\begin{array}{l}\text { - com } 70 \mathrm{~m}^{2}=\text { sobrado com } \\
\text { sala estar/jantar, lavabo, } \\
\text { cozinha "americana", } 2 \\
\text { dormitórios, banheiro, área } \\
\text { serviço, garagem descoberta } \\
\text { p/ 2carros e quintal. }\end{array}$ & 2 dorm. - $70 \mathrm{~m} 2$ \\
\hline & 2 & $\begin{array}{l}\text { - com } 85 \mathrm{~m}^{2}=\text { sobrado com } \\
\text { sala estar/jantar, lavabo, } \\
\text { cozinha, área serviço, suíte, } 2 \\
\text { dorm, banheiro, quintal e } \\
\text { garagem descoberta p/ } \\
\text { 2carros }\end{array}$ & 3 dorm. (suíte) - 85 m2 \\
\hline & 3 & $\begin{array}{l}\text { - com } 95 \mathrm{~m}^{2}=\text { sobrado com } \\
\text { sala estar/jantar/varanda, } \\
\text { lavabo, cozinha, área serviço, } \\
\text { suite c/closet, } 2 \text { dorm e } \\
\text { banheiro, quintal e garagem } \\
\text { descoberta p/ 2carros }\end{array}$ & 3 dorm. (suíte com closet e sala mais ampla) - $95 \mathrm{~m} 2$ \\
\hline
\end{tabular}

Fi Generate Design: Define Values

Values and Labels for Area

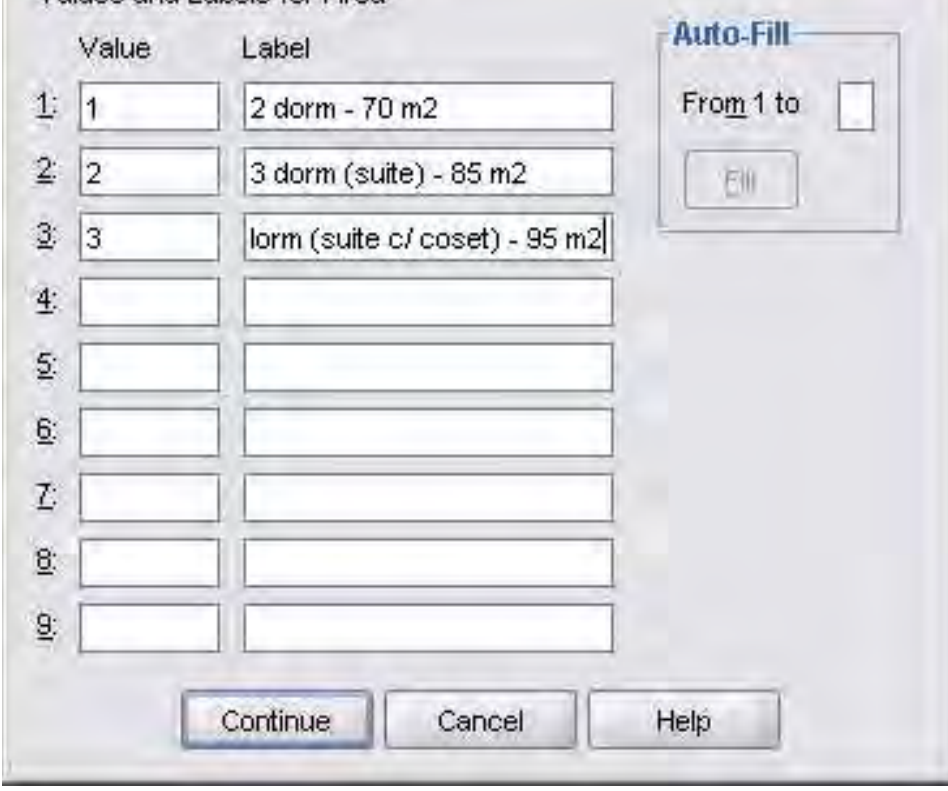

FIGURA A1.01: Geração desenho ortogonal - Fator Área e Níveis.

Fonte: Pesquisa de campo 
FATOR: TIPO

\begin{tabular}{|c|c|c|c|}
\hline VARIÁVEL & NÍVEL & DESCRIÇÃO DETALHADA & DESCRIÇÃO RESUMIDA - CARTÕES \\
\hline \multirow{3}{*}{ Tipologia } & 1 & geminado & geminado \\
\cline { 2 - 4 } & 2 & isolado & isolado \\
\hline
\end{tabular}

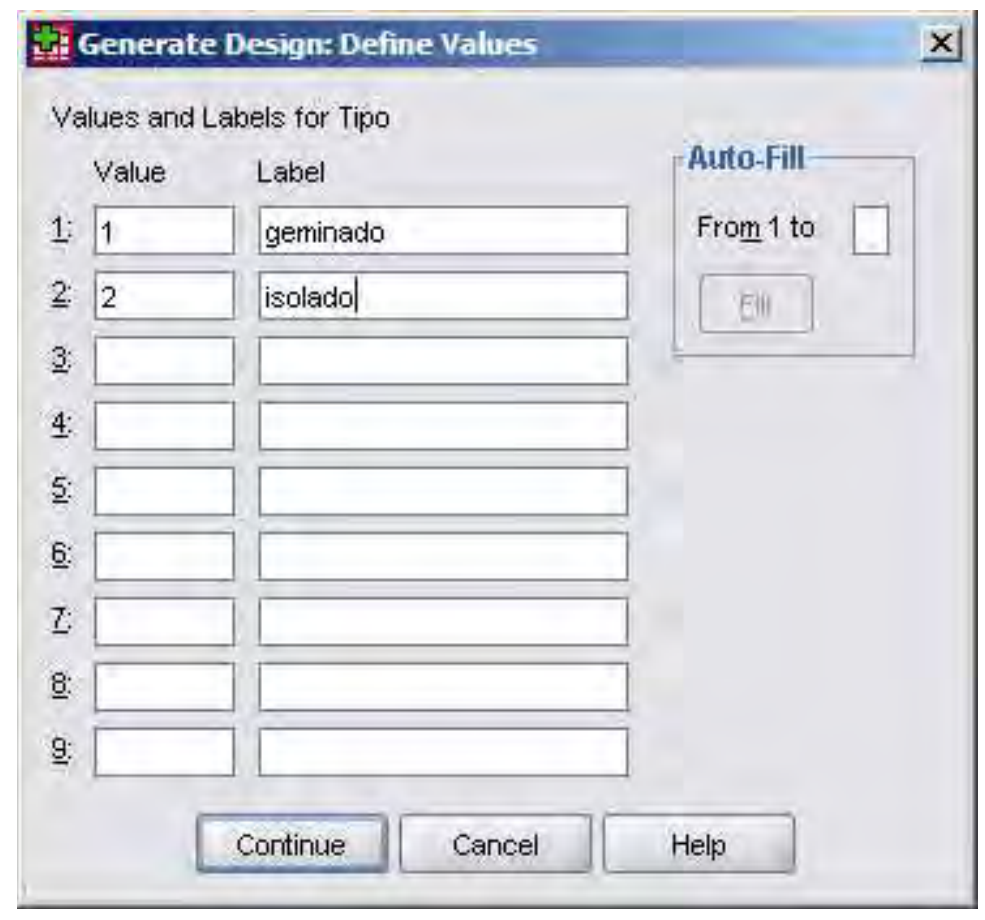

FIGURA A1.02: Geração desenho ortogonal - Fator Tipo e Níveis.

Fonte: Pesquisa de campo 
FATOR: LAZER

\begin{tabular}{|c|c|c|l|}
\hline VARIÁVEL & NÍVEL & $\begin{array}{c}\text { DESCRIÇÃO } \\
\text { DETALHADA }\end{array}$ & DESCRIÇÃO RESUMIDA - CARTÕES \\
\hline & 1 & $\begin{array}{c}\text { Quadra poliesportiva e } \\
\text { piscina }\end{array}$ & Qda e pisc \\
\cline { 2 - 5 } Equipament & 2 & $\begin{array}{c}\text { Quadra poliesportiva, } \\
\text { piscina, academia de } \\
\text { ginástica, espaço gourmet } \\
\text { (churrasqueira e cozinha } \\
\text { com galadeira, fogão, } \\
\text { freezer e mesas, ambiente } \\
\text { climatizado). }\end{array}$ & Qda, pisc, academia e esp. gourmet \\
\cline { 2 - 5 } & & $\begin{array}{c}\text { Quadra poliesportiva, } \\
\text { piscina, academia de } \\
\text { ginástica, espaço gourmet } \\
\text { (churrasqueira e cozinha } \\
\text { com geladeira, fogão, } \\
\text { freezer e mesas), ambiente } \\
\text { climatizado) e estrutura de } \\
\text { Lazer Infantil completa: } \\
\text { Composta de 3 pequenos } \\
\text { espaços de lazer [1] - Praça } \\
\text { infantil (bebês); [2] - Play- } \\
\text { ground para crianças de 2 a } \\
\text { 6 anos, e; [3] Praça de } \\
\text { esportes - crianças de 6 a } \\
12 \text { anos) }\end{array}$ & $\begin{array}{l}\text { Qda, pisc, academia, esp. gmet e lazer } \\
\text { infantil comp }\end{array}$ \\
\hline
\end{tabular}

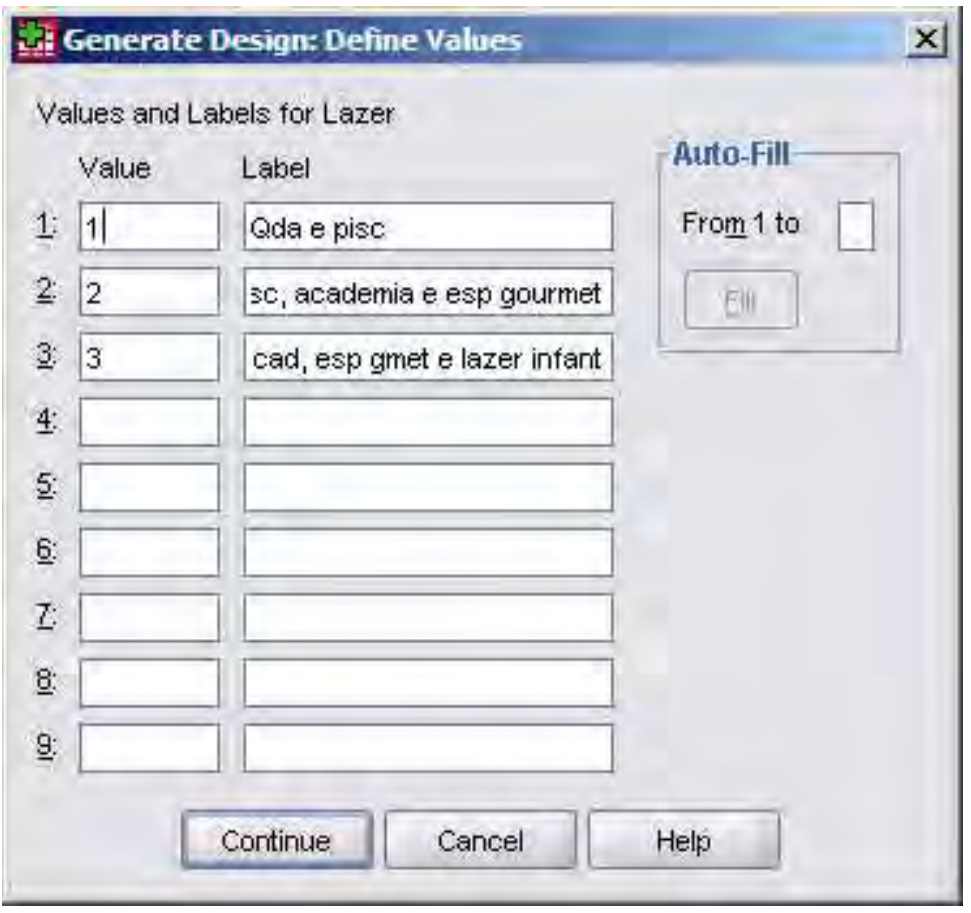

FIGURA A1.03: Geração desenho ortogonal - Fator Lazer e Níveis.

Fonte: Pesquisa de campo 
FATOR: LOCAL

\begin{tabular}{|c|c|c|c|}
\hline VARIÁVEL & NÍVEL & DESCRIÇÃO DETALHADA & DESCRIÇÃO RESUMIDA - CARTÕES \\
\hline \multirow{1}{*}{ Localização } & 1 & $\begin{array}{c}\text { Inserido na malha urbana e } \\
\text { presença de comércio e } \\
\text { serviços (mercado, escola e } \\
\text { lojas de conveniência). Nível } \\
\text { sócio-econômico médio. }\end{array}$ & malha urbana, com. Local, nível médio \\
\cline { 2 - 5 } & 2 & $\begin{array}{c}\text { Área de expansão urbana, } \\
\text { com ausência de comércio } \\
\text { local. Nível sócio-econômico } \\
\text { alto. }\end{array}$ & exp urbana, sem comércio local, nível alto \\
\hline
\end{tabular}

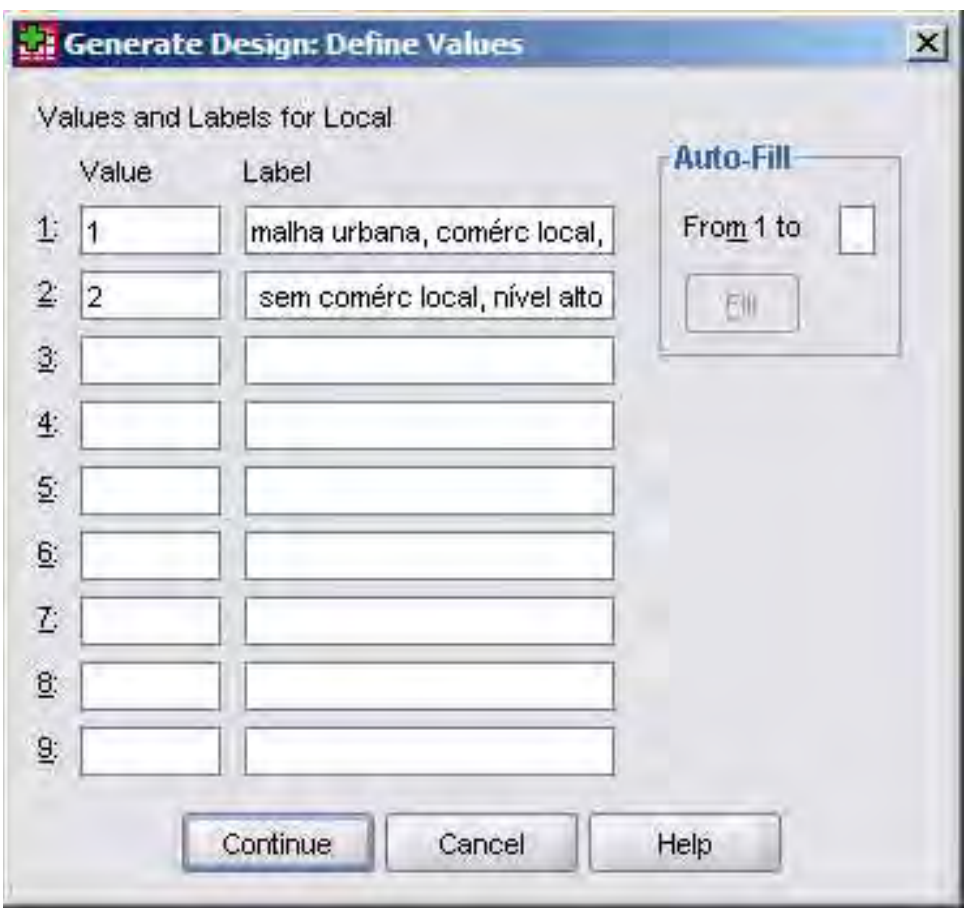

FIGURA A1.04: Geração desenho ortogonal - Fator Local e Níveis.

Fonte: Pesquisa de campo 
FATOR: PREÇO

\begin{tabular}{|c|c|c|c|}
\hline VARIÁVEL & NÍVEL & DESCRIÇÃO DETALHADA & DESCRIÇÃO RESUMIDA - CARTÕES \\
\hline \multirow{2}{*}{ Preço } & 1 & $\$ 160 \mathrm{mil}$ & $\$ 160 \mathrm{mil}$ \\
\cline { 2 - 4 } & 2 & $\$ 180 \mathrm{mil}$ & $\$ 180 \mathrm{mil}$ \\
\cline { 2 - 4 } & 3 & $\$ 200 \mathrm{mil}$ & $\$ 200 \mathrm{mil}$ \\
\hline
\end{tabular}

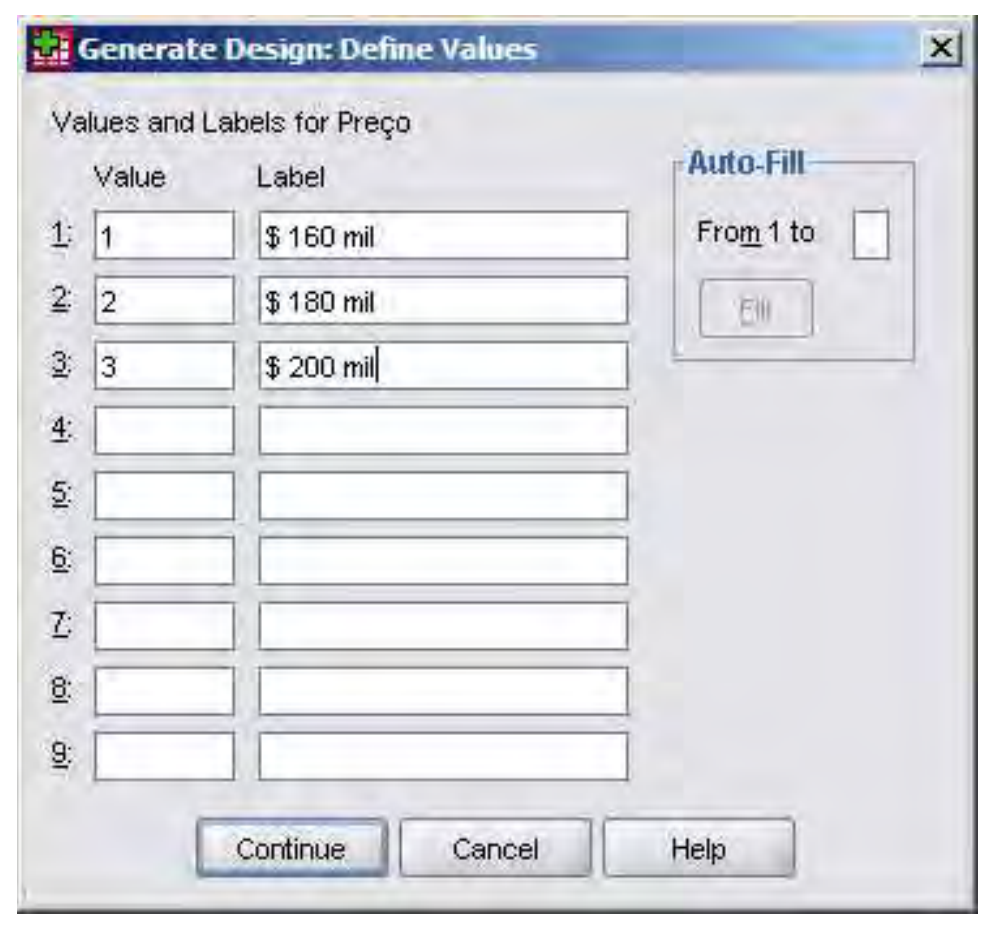

FIGURA A1.05: Geração desenho ortogonal - Fator Preço e Níveis.

Fonte: Pesquisa de campo 
FATOR: A.VERDE

\begin{tabular}{|c|c|c|c|}
\hline VARIÁVEL & NÍVEL & DESCRIÇÃO DETALHADA & DESCRIÇÃO RESUMIDA - CARTÕES \\
\hline & 1 & $\begin{array}{c}\text { Área verde mínima - Praça } \\
\text { arborizada, gramada e com } \\
\text { bancos. }\end{array}$ & Praça arborizada, gramada e com bancos. \\
\cline { 2 - 4 } Área Verde & 2 & $\begin{array}{c}\text { Ampla área Verde - Praça } \\
\text { arborizada, gramada e com } \\
\text { bancos. Bosque com trilha } \\
\text { para caminhada e quiosques } \\
\text { com churrasqueiras. }\end{array}$ & Bosque, trilha e quiosques \\
\hline
\end{tabular}

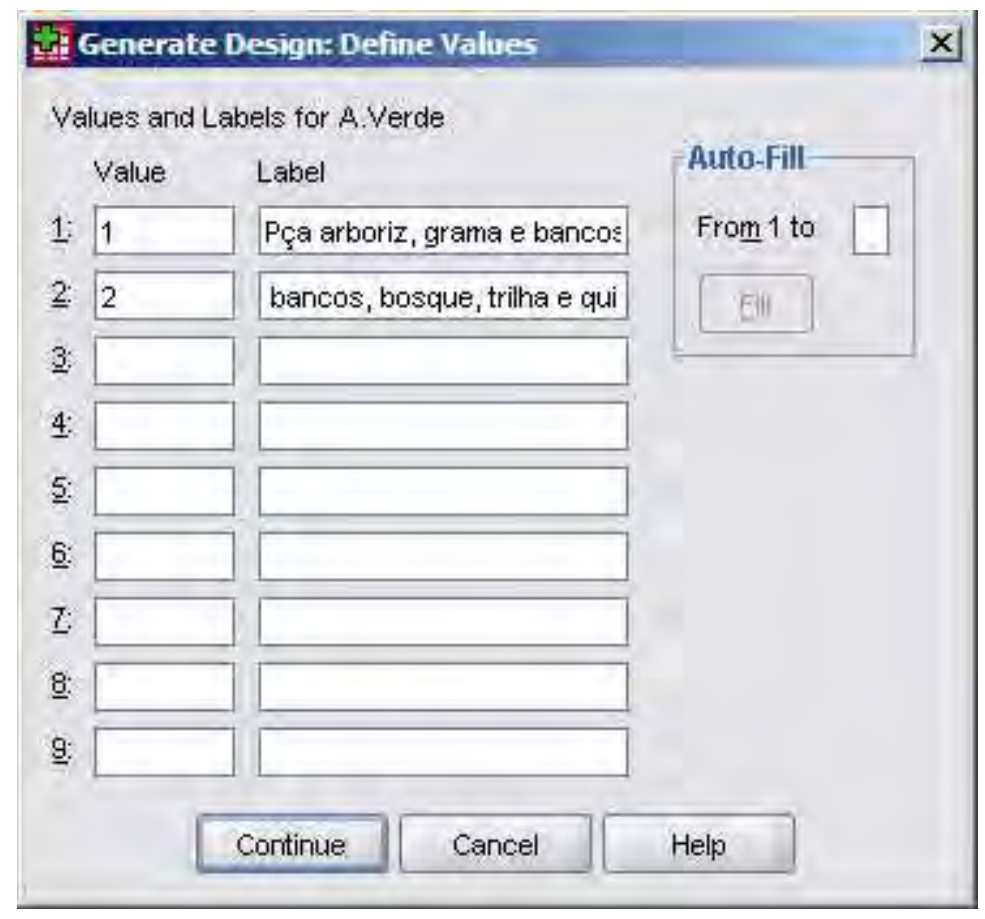

FIGURA A1.06: Geração desenho ortogonal - Fator A.Verde e Níveis.

Fonte: Pesquisa de campo 


\section{DESENHO ORTOGONAL}

1-) Definição dos fatores e níveis

2-) Criação do arquivo de dados, contendo o delineamento fatorial fracionário G: $:$ Mestrado SPSS $\backslash$ Ortho $30 \_08$ 09 LFP.sav

3-) Definição da amostra hold-out (cartões retidos)
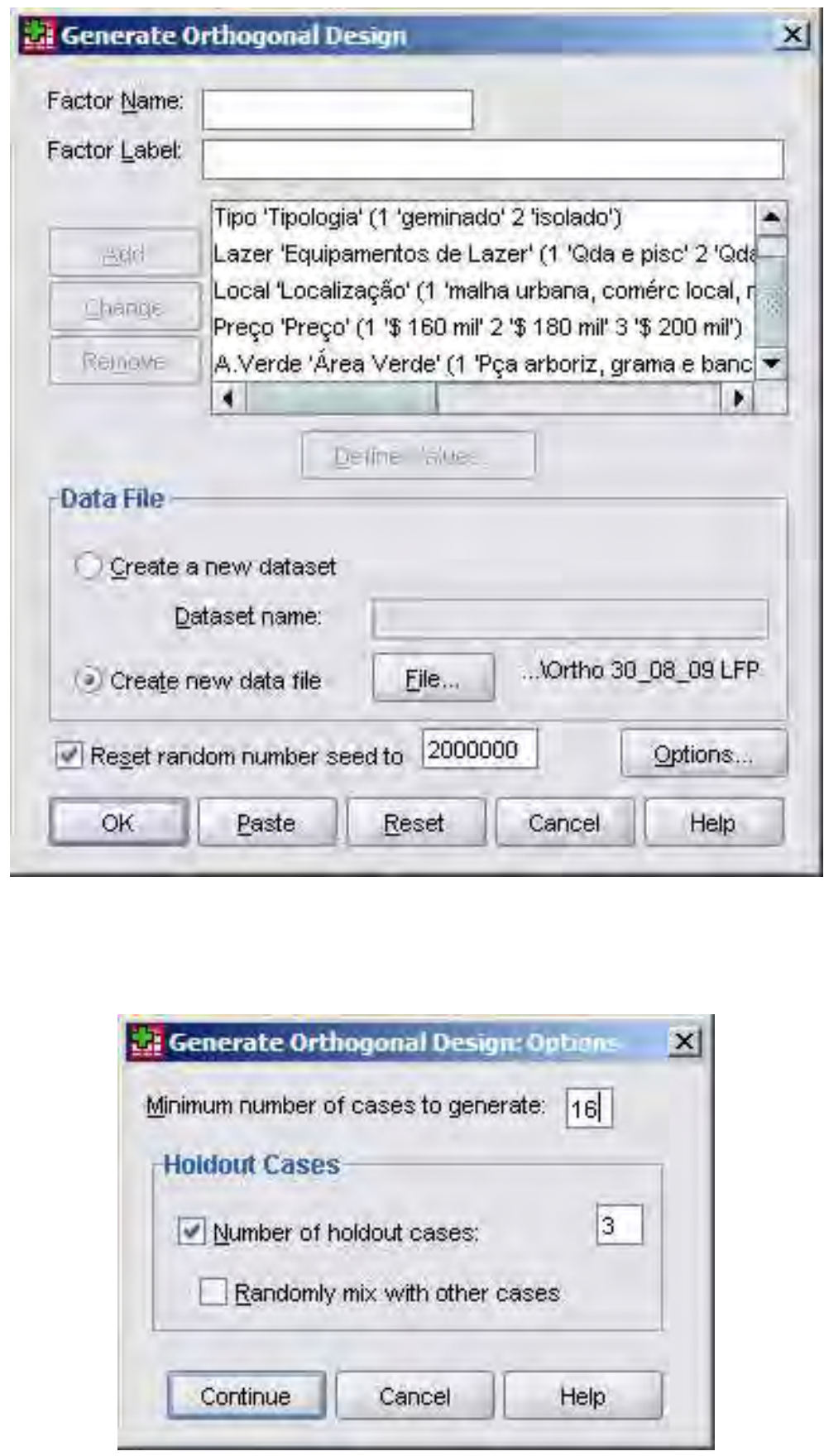

FIGURA A1.07: Delineamento fatorial fracionário, com estímulos de validação. Fonte: Pesquisa de campo 
DESENHO ORTOGONAL

TABELA A1.01: Sintaxe do comando Orthoplan, no SPSS 17.0

*Generate Orthogonal Design.

SET SEED 2000000. ORTHOPLAN

/FACTORS=Area 'Area da unidade' (1 '2 dorm - 70 m2' 2 '3 dorm (suite) - 85 m2' 3 '3 dorm (suite c/ coset) - 95 m2')

Tipo 'Tipologia' (1 'geminado' 2 'isolado')

Lazer 'Equipamentos de Lazer' (1 'Qda e pisc' 2 'Qda, pisc, academia e esp gourmet' 3 'Qda, pisc, acad, esp gmet e lazer infant')

Local 'Localização' (1 'malha urbana, comérc local, nível médio' 2 'exp urbana, sem comérc local, nível alto')

Preço 'Preço' (1 '\$ 160 mil' 2 '\$ 180 mil' 3 '\$ 200 mil')

A.Verde 'Área Verde' (1 'Pça arboriz, '+ 'grama e bancos' 2 'Pça, grama, bancos, bosque, trilha e qui')

IOUTFILE='G:IMestrado SPSSIOrtho 30_08_09 LFP.sav'

/MINIMUM 16

/HOLDOUT 3

/MIXHOLD NO. 


\section{DESENHO ORTOGONAL}

\begin{tabular}{|c|c|c|c|c|c|c|c|c|}
\hline & Area & Tipo & Lazer & Local & Preço & A. Verde & STATUS_ & CARD_ \\
\hline 1 & 2 dorm $-70 \mathrm{~m} 2$ & isolado & Qda, pisc, ac... & exp urbana, s... & $\$ 160 \mathrm{mil}$ & Pça, grama, b... & Design & 1 \\
\hline 2 & 2 dorm $-70 \mathrm{~m} 2$ & geminado & Qda e pisc & exp urbana, s... & $\$ 200 \mathrm{mil}$ & Pça, grama, b... & Design & 2 \\
\hline 3 & 2 dorm $-70 \mathrm{~m} 2$ & geminado & Qda, pisc, ac... & exp urbana, s... & $\$ 200 \mathrm{mil}$ & Pça arboriz, g... & Design & 3 \\
\hline 4 & 3 dorm (suite ... & geminado & Qda, pisc, ac... & exp urbana, s... & $\$ 180 \mathrm{mil}$ & Pça arboriz, g... & Design & 4 \\
\hline 5 & 3 dorm (suite)... & isolado & Qda e pisc & exp urbana, s... & $\$ 160 \mathrm{mil}$ & Pça arboriz, g... & Design & 5 \\
\hline 6 & 3 dorm (suite)... & geminado & Qda, pisc, ac... & malha urbana,... & $\$ 160 \mathrm{mil}$ & Pça, grama, b... & Design & 6 \\
\hline 7 & 2 dorm $-70 \mathrm{~m} 2$ & isolado & Qda e pisc & malha urbana,... & $\$ 180 \mathrm{mil}$ & Pça, grama, b... & Design & 7 \\
\hline 8 & 2 dorm - $70 \mathrm{~m} 2$ & isolado & Qda, pisc, ac... & malha urbana,... & $\$ 180 \mathrm{mil}$ & Pça arboriz, g... & Design & 8 \\
\hline 9 & 3 dorm (suite ... & isolado & Qda, pisc, ac... & exp urbana, s... & $\$ 160 \mathrm{mil}$ & Pça, grama, b... & Design & 9 \\
\hline 10 & 3 dorm (suite ... & isolado & Qda e pisc & malha urbana,... & $\$ 200 \mathrm{mil}$ & Pça, grama, b... & Design & 10 \\
\hline 11 & 3 dorm (suite ... & geminado & Qda e pisc & malha urbana,... & $\$ 160 \mathrm{mil}$ & Pça arboriz, g... & Design & 11 \\
\hline 12 & 2 dorm $-70 \mathrm{~m} 2$ & geminado & Qda, pisc, ac... & malha urbana,... & $\$ 160 \mathrm{mil}$ & Pça, grama, b... & Design & 12 \\
\hline 13 & 3 dorm (suite)... & geminado & Qda e pisc & exp urbana, s... & $\$ 180 \mathrm{mil}$ & Pça, grama, b... & Design & 13 \\
\hline 14 & 3 dorm (suite)... & isolado & Qda, pisc, ac... & malha urbana,... & $\$ 200 \mathrm{mil}$ & Pça arboriz, g... & Design & 14 \\
\hline 15 & 2 dorm $-70 \mathrm{~m} 2$ & geminado & Qda e pisc & malha urbana,... & $\$ 160 \mathrm{mil}$ & Pça arboriz, g... & Design & 15 \\
\hline 16 & 2 dorm $-70 \mathrm{~m} 2$ & isolado & Qda e pisc & exp urbana, s... & $\$ 160 \mathrm{mil}$ & Pça arboriz, g... & Design & 16 \\
\hline 17 & 2 dorm $-70 \mathrm{~m} 2$ & isolado & Qda e pisc & malha urbana,... & $\$ 200 \mathrm{mil}$ & Pça arboriz, g... & Holdout & 17 \\
\hline 18 & 2 dorm $-70 \mathrm{~m} 2$ & isolado & Qda, pisc, ac... & malha urbana,... & $\$ 180 \mathrm{mil}$ & Pça arboriz, g... & Holdout & 18 \\
\hline 19 & 3 dorm (suite ... & geminado & Qda e pisc & malha urbana,... & $\$ 160 \mathrm{mil}$ & Pça, grama, b... & Holdout & 19 \\
\hline
\end{tabular}

FIGURA A1.08: Resultado do delineamento fatorial fracionário no SPSS 17.0.

Fonte: Pesquisa de campo 
DESENHO ORTOGONAL

TABELA A1.02: Cartões de estímulo gerados - opção de visualização.

\begin{tabular}{|c|c|c|c|c|c|c|}
\hline Card ID & $\begin{array}{l}\text { Area da } \\
\text { unidade }\end{array}$ & Tipologia & $\begin{array}{c}\text { Equipamentos } \\
\text { de Lazer }\end{array}$ & Localização & Preço & Área Verde \\
\hline 1 & 2 dorm - $70 \mathrm{~m} 2$ & isolado & $\begin{array}{c}\text { Qda, pisc, } \\
\text { acad, esp gmet } \\
\text { e lazer infant }\end{array}$ & $\begin{array}{c}\text { exp urbana, } \\
\text { sem comérc } \\
\text { local, nível alto }\end{array}$ & $\$ 160 \mathrm{mil}$ & $\begin{array}{c}\text { Pça, grama, } \\
\text { bancos, } \\
\text { bosque, trilha } \\
\text { e qui }\end{array}$ \\
\hline 2 & 2 dorm - $70 \mathrm{~m} 2$ & geminado & Qda e pisc & $\begin{array}{c}\text { exp urbana, } \\
\text { sem comérc } \\
\text { local, nível alto }\end{array}$ & $\$ 200 \mathrm{mil}$ & $\begin{array}{l}\text { Pça, grama, } \\
\text { bancos, } \\
\text { bosque, trilha } \\
\text { e qui }\end{array}$ \\
\hline 3 & 2 dorm - $70 \mathrm{~m} 2$ & geminado & $\begin{array}{l}\text { Qda, pisc, } \\
\text { academia e } \\
\text { esp gourmet }\end{array}$ & $\begin{array}{c}\text { exp urbana, } \\
\text { sem comérc } \\
\text { local, nível alto }\end{array}$ & $\$ 200 \mathrm{mil}$ & $\begin{array}{c}\text { Pça arboriz, } \\
\text { grama e } \\
\text { bancos }\end{array}$ \\
\hline 4 & $\begin{array}{c}3 \text { dorm (suite } \\
\text { c/ coset) - } 95 \\
\text { m2 }\end{array}$ & geminado & $\begin{array}{c}\text { Qda, pisc, } \\
\text { acad, esp gmet } \\
\text { e lazer infant }\end{array}$ & $\begin{array}{c}\text { exp urbana, } \\
\text { sem comérc } \\
\text { local, nível alto }\end{array}$ & $\$ 180 \mathrm{mil}$ & $\begin{array}{c}\text { Pça arboriz, } \\
\text { grama e } \\
\text { bancos }\end{array}$ \\
\hline 5 & $\begin{array}{c}3 \text { dorm (suite) - } \\
85 \mathrm{~m} 2\end{array}$ & isolado & Qda e pisc & $\begin{array}{c}\text { exp urbana, } \\
\text { sem comérc } \\
\text { local, nível alto }\end{array}$ & $\$ 160 \mathrm{mil}$ & $\begin{array}{c}\text { Pça arboriz, } \\
\text { grama e } \\
\text { bancos }\end{array}$ \\
\hline 6 & $\begin{array}{c}3 \text { dorm (suite) - } \\
85 \mathrm{~m} 2\end{array}$ & geminado & $\begin{array}{c}\text { Qda, pisc, } \\
\text { academia e } \\
\text { esp gourmet }\end{array}$ & $\begin{array}{c}\text { malha urbana, } \\
\text { comérc local, } \\
\text { nível médio }\end{array}$ & $\$ 160 \mathrm{mil}$ & $\begin{array}{l}\text { Pça, grama, } \\
\text { bancos, } \\
\text { bosque, trilha } \\
\text { e qui }\end{array}$ \\
\hline 7 & 2 dorm - $70 \mathrm{~m} 2$ & isolado & Qda e pisc & $\begin{array}{c}\text { malha urbana, } \\
\text { comérc local, } \\
\text { nível médio }\end{array}$ & $\$ 180 \mathrm{mil}$ & $\begin{array}{l}\text { Pça, grama, } \\
\text { bancos, } \\
\text { bosque, trilha } \\
\text { e qui }\end{array}$ \\
\hline 8 & 2 dorm - $70 \mathrm{~m} 2$ & isolado & $\begin{array}{c}\text { Qda, pisc, } \\
\text { academia e } \\
\text { esp gourmet }\end{array}$ & $\begin{array}{c}\text { malha urbana, } \\
\text { comérc local, } \\
\text { nível médio }\end{array}$ & $\$ 180 \mathrm{mil}$ & $\begin{array}{c}\text { Pça arboriz, } \\
\text { grama e } \\
\text { bancos }\end{array}$ \\
\hline 9 & $\begin{array}{c}3 \text { dorm (suite } \\
\text { c/ coset) - } 95 \\
\text { m2 }\end{array}$ & isolado & $\begin{array}{c}\text { Qda, pisc, } \\
\text { academia e } \\
\text { esp gourmet }\end{array}$ & $\begin{array}{c}\text { exp urbana, } \\
\text { sem comérc } \\
\text { local, nível alto }\end{array}$ & $\$ 160 \mathrm{mil}$ & $\begin{array}{c}\text { Pça, grama, } \\
\text { bancos, } \\
\text { bosque, trilha } \\
\text { e qui }\end{array}$ \\
\hline
\end{tabular}




\begin{tabular}{|c|c|c|c|c|c|c|}
\hline 10 & $\begin{array}{c}3 \text { dorm (suite } \\
\text { c/ coset) - } 95 \\
\text { m2 }\end{array}$ & isolado & Qda e pisc & $\begin{array}{c}\text { malha urbana, } \\
\text { comérc local, } \\
\text { nível médio }\end{array}$ & \$ $200 \mathrm{mil}$ & $\begin{array}{l}\text { Pça, grama, } \\
\text { bancos, } \\
\text { bosque, trilha } \\
\text { e qui }\end{array}$ \\
\hline 11 & $\begin{array}{c}3 \text { dorm (suite } \\
\text { c/ coset) - } 95 \\
\text { m2 }\end{array}$ & geminado & Qda e pisc & $\begin{array}{c}\text { malha urbana, } \\
\text { comérc local, } \\
\text { nível médio }\end{array}$ & \$ $160 \mathrm{mil}$ & $\begin{array}{l}\text { Pça arboriz, } \\
\text { grama e } \\
\text { bancos }\end{array}$ \\
\hline 12 & 2 dorm - $70 \mathrm{~m} 2$ & geminado & $\begin{array}{c}\text { Qda, pisc, } \\
\text { acad, esp gmet } \\
\text { e lazer infant }\end{array}$ & $\begin{array}{c}\text { malha urbana, } \\
\text { comérc local, } \\
\text { nível médio }\end{array}$ & \$ $160 \mathrm{mil}$ & $\begin{array}{c}\text { Pça, grama, } \\
\text { bancos, } \\
\text { bosque, trilha } \\
\text { e qui }\end{array}$ \\
\hline 13 & $\begin{array}{c}3 \text { dorm (suite) - } \\
85 \mathrm{~m} 2\end{array}$ & geminado & Qda e pisc & $\begin{array}{c}\text { exp urbana, } \\
\text { sem comérc } \\
\text { local, nível alto }\end{array}$ & \$ $180 \mathrm{mil}$ & $\begin{array}{c}\text { Pça, grama, } \\
\text { bancos, } \\
\text { bosque, trilha } \\
\text { e qui }\end{array}$ \\
\hline 14 & $\begin{array}{c}3 \text { dorm (suite) - } \\
85 \mathrm{~m} 2\end{array}$ & isolado & $\begin{array}{c}\text { Qda, pisc, } \\
\text { acad, esp gmet } \\
\text { e lazer infant }\end{array}$ & $\begin{array}{c}\text { malha urbana, } \\
\text { comérc local, } \\
\text { nível médio }\end{array}$ & $\$ 200 \mathrm{mil}$ & $\begin{array}{c}\text { Pça arboriz, } \\
\text { grama e } \\
\text { bancos }\end{array}$ \\
\hline 15 & 2 dorm $-70 \mathrm{~m} 2$ & geminado & Qda e pisc & $\begin{array}{c}\text { malha urbana, } \\
\text { comérc local, } \\
\text { nível médio }\end{array}$ & $\$ 160 \mathrm{mil}$ & $\begin{array}{c}\text { Pça arboriz, } \\
\text { grama e } \\
\text { bancos }\end{array}$ \\
\hline 16 & 2 dorm $-70 \mathrm{~m} 2$ & isolado & Qda e pisc & $\begin{array}{c}\text { exp urbana, } \\
\text { sem comérc } \\
\text { local, nível alto }\end{array}$ & $\$ 160 \mathrm{mil}$ & $\begin{array}{l}\text { Pça arboriz, } \\
\text { grama e } \\
\text { bancos }\end{array}$ \\
\hline 17 & 2 dorm $-70 \mathrm{~m} 2$ & isolado & Qda e pisc & $\begin{array}{c}\text { malha urbana, } \\
\text { comérc local, } \\
\text { nível médio }\end{array}$ & \$ $200 \mathrm{mil}$ & $\begin{array}{l}\text { Pça arboriz, } \\
\text { grama e } \\
\text { bancos }\end{array}$ \\
\hline 18 & 2 dorm - $70 \mathrm{~m} 2$ & isolado & $\begin{array}{c}\text { Qda, pisc, } \\
\text { acad, esp gmet } \\
\text { e lazer infant }\end{array}$ & $\begin{array}{c}\text { malha urbana, } \\
\text { comérc local, } \\
\text { nível médio }\end{array}$ & \$ $180 \mathrm{mil}$ & $\begin{array}{l}\text { Pça arboriz, } \\
\text { grama e } \\
\text { bancos }\end{array}$ \\
\hline 19 & $\begin{array}{c}3 \text { dorm (suite } \\
\text { c/ coset) - } 95 \\
\text { m2 }\end{array}$ & geminado & Qda e pisc & $\begin{array}{c}\text { malha urbana, } \\
\text { comérc local, } \\
\text { nível médio }\end{array}$ & \$ $160 \mathrm{mil}$ & $\begin{array}{l}\text { Pça, grama, } \\
\text { bancos, } \\
\text { bosque, trilha } \\
\text { e qui }\end{array}$ \\
\hline
\end{tabular}


DESENHO ORTOGONAL

TABELA A1.03: Cartões de estímulo gerados - modo de apresentação aos respondentes.

Perfil 1

\begin{tabular}{|c|c|c|c|c|c|c|}
\hline Cartão & $\begin{array}{c}\text { Area da } \\
\text { unidade }\end{array}$ & Tipologia & $\begin{array}{c}\text { Equipamentos } \\
\text { de Lazer }\end{array}$ & Localização & Preço & Área Verde \\
\hline 1 & $\begin{array}{c}2 \text { dorm }-70 \\
\mathrm{~m} 2\end{array}$ & isolado & $\begin{array}{c}\text { Qda, pisc, } \\
\text { academia, } \\
\text { espaço } \\
\text { gourmet e } \\
\text { lazer infantil } \\
\text { completo }\end{array}$ & $\begin{array}{c}\text { exp urbana, sem } \\
\text { comércio local, } \\
\text { nível alto }\end{array}$ & \$160 mil & $\begin{array}{c}\text { Pça arboriz e } \\
\text { gramada, } \\
\text { bancos, Bosque } \\
\text { com trilha e } \\
\text { quiosques }\end{array}$ \\
\hline
\end{tabular}

Perfil 2

\begin{tabular}{|c|c|c|c|c|c|c|}
\hline Cartão & $\begin{array}{c}\text { Area da } \\
\text { unidade }\end{array}$ & Tipologia & $\begin{array}{c}\text { Equipamentos } \\
\text { de Lazer }\end{array}$ & Localização & Preço & Área Verde \\
\hline 2 & $\begin{array}{c}2 \text { dorm }-70 \\
\mathrm{~m} 2\end{array}$ & geminado & Qda e pisc & $\begin{array}{c}\text { exp urbana, sem } \\
\text { comércio local, } \\
\text { nível alto }\end{array}$ & \$ 200 mil & $\begin{array}{c}\text { Pça arboriz e } \\
\text { gramada, } \\
\text { bancos, Bosque } \\
\text { com trilha e } \\
\text { quiosques }\end{array}$ \\
\hline
\end{tabular}

Perfil 3

\begin{tabular}{|c|c|c|c|c|c|c|}
\hline Cartão & $\begin{array}{c}\text { Area da } \\
\text { unidade }\end{array}$ & Tipologia & $\begin{array}{c}\text { Equipamentos } \\
\text { de Lazer }\end{array}$ & Localização & Preço & Área Verde \\
\hline 3 & $\begin{array}{c}2 \text { dorm }-70 \\
\mathrm{~m} 2\end{array}$ & geminado & $\begin{array}{c}\text { Qda, pisc, } \\
\text { academia e } \\
\text { esp gourmet }\end{array}$ & $\begin{array}{c}\text { exp urbana, sem } \\
\text { comércio local, } \\
\text { nível alto }\end{array}$ & $\$ 200$ mil & $\begin{array}{c}\text { Pça arborizada, } \\
\text { gramada e com } \\
\text { bancos }\end{array}$ \\
\hline
\end{tabular}

Perfil 4

\begin{tabular}{|c|c|c|c|c|c|c|}
\hline Cartão & $\begin{array}{c}\text { Area da } \\
\text { unidade }\end{array}$ & Tipologia & $\begin{array}{c}\text { Equipamentos } \\
\text { de Lazer }\end{array}$ & Localização & Preço & Área Verde \\
\hline \multirow{4}{*}{4} & $\begin{array}{c}\text { 3 dorm. (suíte } \\
\text { com closet e } \\
\text { sala mais } \\
\text { ampla) -95 } \\
\text { m2 }\end{array}$ & geminado & $\begin{array}{c}\text { Qda, pisc, } \\
\text { academia, } \\
\text { espaço } \\
\text { gourmet e } \\
\text { lazer infantil } \\
\text { completo }\end{array}$ & $\begin{array}{c}\text { exp urbana, sem } \\
\text { comércio local, } \\
\text { nível alto }\end{array}$ & \$180 mil & $\begin{array}{c}\text { Pça arborizada, } \\
\text { gramada e com } \\
\text { bancos }\end{array}$ \\
\hline
\end{tabular}

\section{Perfil 5}

\begin{tabular}{|c|c|c|c|c|c|c|}
\hline Cartão & $\begin{array}{c}\text { Area da } \\
\text { unidade }\end{array}$ & Tipologia & $\begin{array}{c}\text { Equipamentos } \\
\text { de Lazer }\end{array}$ & Localização & Preço & Área Verde \\
\hline 5 & $\begin{array}{c}3 \text { dorm (suite) } \\
-85 \mathrm{~m} 2\end{array}$ & isolado & Qda e pisc & $\begin{array}{c}\text { exp urbana, sem } \\
\text { comércio local, } \\
\text { nível alto }\end{array}$ & \$160 mil & $\begin{array}{c}\text { Pça arborizada, } \\
\text { gramada e com } \\
\text { bancos }\end{array}$ \\
\hline
\end{tabular}


Perfil 6

\begin{tabular}{|c|c|c|c|c|c|c|}
\hline Cartão & $\begin{array}{c}\text { Area da } \\
\text { unidade }\end{array}$ & Tipologia & $\begin{array}{c}\text { Equipamentos } \\
\text { de Lazer }\end{array}$ & Localização & Preço & Área Verde \\
\hline 6 & $\begin{array}{c}3 \text { dorm (suite) } \\
-85 \mathrm{~m} 2\end{array}$ & geminado & $\begin{array}{c}\text { Qda, pisc, } \\
\text { academia e } \\
\text { esp gourmet }\end{array}$ & $\begin{array}{c}\text { malha urbana, } \\
\text { comércio local, } \\
\text { nível médio }\end{array}$ & \$160 mil & $\begin{array}{c}\text { Pça arboriz e } \\
\text { gramada, } \\
\text { bancos, Bosque } \\
\text { com trilha e } \\
\text { quiosques }\end{array}$ \\
\hline
\end{tabular}

Perfil 7

\begin{tabular}{|c|c|c|c|c|c|c|}
\hline Cartão & $\begin{array}{c}\text { Area da } \\
\text { unidade }\end{array}$ & Tipologia & $\begin{array}{c}\text { Equipamentos } \\
\text { de Lazer }\end{array}$ & Localização & Preço & Área Verde \\
\hline 7 & $\begin{array}{c}2 \mathrm{dorm}-70 \\
\mathrm{~m} 2\end{array}$ & isolado & Qda e pisc & $\begin{array}{c}\text { malha urbana, } \\
\text { comércio local, } \\
\text { nível médio }\end{array}$ & \$180 mil & $\begin{array}{c}\text { Pça arboriz e } \\
\text { gramada, } \\
\text { bancos, Bosque } \\
\text { com trilha e } \\
\text { quiosques }\end{array}$ \\
\hline
\end{tabular}

Perfil 8

\begin{tabular}{|c|c|c|c|c|c|c|}
\hline Cartão & $\begin{array}{c}\text { Area da } \\
\text { unidade }\end{array}$ & Tipologia & $\begin{array}{c}\text { Equipamentos } \\
\text { de Lazer }\end{array}$ & Localização & Preço & Área Verde \\
\hline 8 & $\begin{array}{c}2 \text { dorm }-70 \\
\mathrm{~m} 2\end{array}$ & isolado & $\begin{array}{c}\text { Qda, pisc, } \\
\text { academia e } \\
\text { esp gourmet }\end{array}$ & $\begin{array}{c}\text { malha urbana, } \\
\text { comércio local, } \\
\text { nível médio }\end{array}$ & \$180 mil & $\begin{array}{c}\text { Pça arborizada, } \\
\text { gramada e com } \\
\text { bancos }\end{array}$ \\
\hline
\end{tabular}

\section{Perfil 9}

\begin{tabular}{|c|c|c|c|c|c|c|}
\hline Cartão & $\begin{array}{c}\text { Area da } \\
\text { unidade }\end{array}$ & Tipologia & $\begin{array}{c}\text { Equipamentos } \\
\text { de Lazer }\end{array}$ & Localização & Preço & Área Verde \\
\hline 9 & $\begin{array}{c}3 \text { dorm. (suíte } \\
\text { com closet e } \\
\text { sala mais } \\
\text { ampla) }-95 \\
\mathrm{~m} 2\end{array}$ & isolado & $\begin{array}{c}\text { Qda, pisc, } \\
\text { academia e } \\
\text { esp gourmet }\end{array}$ & $\begin{array}{c}\text { exp urbana, sem } \\
\text { comércio local, } \\
\text { nível alto }\end{array}$ & \$160 mil & $\begin{array}{c}\text { Pça arboriz e } \\
\text { gramada, } \\
\text { bancos, Bosque } \\
\text { com trilha e } \\
\text { quiosques }\end{array}$ \\
\hline
\end{tabular}

\section{Perfil 10}

\begin{tabular}{|c|c|c|c|c|c|c|}
\hline Cartão & $\begin{array}{c}\text { Area da } \\
\text { unidade }\end{array}$ & Tipologia & $\begin{array}{c}\text { Equipamentos } \\
\text { de Lazer }\end{array}$ & Localização & Preço & Área Verde \\
\hline 10 & $\begin{array}{c}3 \text { dorm. (suíte } \\
\text { com closet e } \\
\text { sala mais } \\
\text { ampla) -95 } \\
\mathrm{m} 2\end{array}$ & isolado & Qda e pisc & $\begin{array}{c}\text { malha urbana, } \\
\text { comércio local, } \\
\text { nível médio }\end{array}$ & \$ 200 mil & $\begin{array}{c}\text { Pça arboriz e } \\
\text { gramada, } \\
\text { bancos, Bosque } \\
\text { com trilha e } \\
\text { quiosques }\end{array}$ \\
\hline
\end{tabular}

Perfil 11

\begin{tabular}{|c|c|c|c|c|c|c|}
\hline Cartão & $\begin{array}{c}\text { Area da } \\
\text { unidade }\end{array}$ & Tipologia & $\begin{array}{c}\text { Equipamentos } \\
\text { de Lazer }\end{array}$ & Localização & Preço & Área Verde \\
\hline 11 & $\begin{array}{c}3 \text { dorm. (suíte } \\
\text { com closet e } \\
\text { sala mais } \\
\text { ampla) -95 } \\
\text { m2 }\end{array}$ & geminado & Qda e pisc & $\begin{array}{c}\text { malha urbana, } \\
\text { comércio local, } \\
\text { nível médio }\end{array}$ & \$160 mil & $\begin{array}{c}\text { Pça arborizada, } \\
\text { gramada e com } \\
\text { bancos }\end{array}$ \\
\hline
\end{tabular}


Perfil 12

\begin{tabular}{|c|c|c|c|c|c|c|}
\hline Cartão & $\begin{array}{c}\text { Area da } \\
\text { unidade }\end{array}$ & Tipologia & $\begin{array}{c}\text { Equipamentos } \\
\text { de Lazer }\end{array}$ & Localização & Preço & Área Verde \\
\hline 12 & $\begin{array}{c}2 \text { dorm }-70 \\
\mathrm{~m} 2\end{array}$ & $\begin{array}{c}\text { Qda, pisc, } \\
\text { academia, } \\
\text { espaço } \\
\text { gourmet e } \\
\text { lazer infantil } \\
\text { completo }\end{array}$ & $\begin{array}{c}\text { malha urbana, } \\
\text { comércio local, } \\
\text { nível médio }\end{array}$ & geminado 160 mil & $\begin{array}{c}\text { Pça arboriz e } \\
\text { gramada, } \\
\text { bancos, Bosque } \\
\text { com trilha e } \\
\text { quiosques }\end{array}$ \\
\hline
\end{tabular}

Perfil 13

\begin{tabular}{|c|c|c|c|c|c|c|}
\hline Cartão & $\begin{array}{c}\text { Area da } \\
\text { unidade }\end{array}$ & Tipologia & $\begin{array}{c}\text { Equipamentos } \\
\text { de Lazer }\end{array}$ & Localização & Preço & Área Verde \\
\hline 13 & $\begin{array}{c}3 \text { dorm (suite) } \\
-85 \mathrm{~m} 2\end{array}$ & geminado & Qda e pisc & $\begin{array}{c}\text { exp urbana, sem } \\
\text { comércio local, } \\
\text { nível alto }\end{array}$ & \$180 mil & $\begin{array}{c}\text { Pça arboriz e } \\
\text { gramada, } \\
\text { bancos, Bosque } \\
\text { com trilha e } \\
\text { quiosques }\end{array}$ \\
\hline
\end{tabular}

Perfil 14

\begin{tabular}{|c|c|c|c|c|c|c|}
\hline Cartão & $\begin{array}{c}\text { Area da } \\
\text { unidade }\end{array}$ & Tipologia & $\begin{array}{c}\text { Equipamentos } \\
\text { de Lazer }\end{array}$ & Localização & Preço & Área Verde \\
\hline 14 & $\begin{array}{c}3 \text { dorm (suite) } \\
-85 \mathrm{~m} 2\end{array}$ & $\begin{array}{c}\text { Qda, pisc, } \\
\text { academia, } \\
\text { espaço } \\
\text { gourmet e } \\
\text { lazer infantil } \\
\text { completo }\end{array}$ & $\begin{array}{c}\text { malha urbana, } \\
\text { comércio local, } \\
\text { nível médio }\end{array}$ & \$ 200 mil & $\begin{array}{c}\text { Pça arborizada, } \\
\text { gramada e com } \\
\text { bancos }\end{array}$ \\
\hline
\end{tabular}

Perfil 15

\begin{tabular}{|c|c|c|c|c|c|c|}
\hline Cartão & $\begin{array}{c}\text { Area da } \\
\text { unidade }\end{array}$ & Tipologia & $\begin{array}{c}\text { Equipamentos } \\
\text { de Lazer }\end{array}$ & Localização & Preço & Área Verde \\
\hline 15 & $\begin{array}{c}2 \mathrm{dorm}-70 \\
\mathrm{~m} 2\end{array}$ & geminado & Qda e pisc & $\begin{array}{c}\text { malha urbana, } \\
\text { comércio local, } \\
\text { nível médio }\end{array}$ & $\$ 160$ mil & $\begin{array}{c}\text { Pça arborizada, } \\
\text { gramada e com } \\
\text { bancos }\end{array}$ \\
\hline
\end{tabular}

Perfil 16

\begin{tabular}{|c|c|c|c|c|c|c|}
\hline Cartão & $\begin{array}{c}\text { Area da } \\
\text { unidade }\end{array}$ & Tipologia & $\begin{array}{c}\text { Equipamentos } \\
\text { de Lazer }\end{array}$ & Localização & Preço & Área Verde \\
\hline 16 & $\begin{array}{c}2 \mathrm{dorm}-70 \\
\mathrm{~m} 2\end{array}$ & isolado & Qda e pisc & $\begin{array}{c}\text { exp urbana, sem } \\
\text { comércio local, } \\
\text { nível alto }\end{array}$ & $\$ 160$ mil & $\begin{array}{c}\text { Pça arborizada, } \\
\text { gramada e com } \\
\text { bancos }\end{array}$ \\
\hline
\end{tabular}

Perfil 17

\begin{tabular}{|c|c|c|c|c|c|c|}
\hline Cartão & $\begin{array}{c}\text { Area da } \\
\text { unidade }\end{array}$ & Tipologia & $\begin{array}{c}\text { Equipamentos } \\
\text { de Lazer }\end{array}$ & Localização & Preço & Área Verde \\
\hline 17 & $\begin{array}{c}2 \mathrm{dorm}-70 \\
\mathrm{~m} 2\end{array}$ & isolado & Qda e pisc & $\begin{array}{c}\text { malha urbana, } \\
\text { comércio local, } \\
\text { nível médio }\end{array}$ & \$ 200 mil & $\begin{array}{c}\text { Pça arborizada, } \\
\text { gramada e com } \\
\text { bancos }\end{array}$ \\
\hline
\end{tabular}


Perfil 18

\begin{tabular}{|c|c|c|c|c|c|c|}
\hline Cartão & $\begin{array}{c}\text { Area da } \\
\text { unidade }\end{array}$ & Tipologia & $\begin{array}{c}\text { Equipamentos } \\
\text { de Lazer }\end{array}$ & Localização & Preço & Área Verde \\
\hline 18 & $\begin{array}{c}2 \mathrm{dorm}-70 \\
\mathrm{~m} 2\end{array}$ & $\begin{array}{c}\text { Qda, pisc, } \\
\text { academia, } \\
\text { espaço } \\
\text { gourmet e } \\
\text { lazer infantil } \\
\text { completo }\end{array}$ & $\begin{array}{c}\text { malha urbana, } \\
\text { comércio local, } \\
\text { nível médio }\end{array}$ & $\$ 180$ mil & $\begin{array}{c}\text { Pça arborizada, } \\
\text { gramada e com } \\
\text { bancos }\end{array}$ \\
\hline
\end{tabular}

Perfil 19

\begin{tabular}{|c|c|c|c|c|c|c|}
\hline Cartão & $\begin{array}{c}\text { Area da } \\
\text { unidade }\end{array}$ & Tipologia & $\begin{array}{c}\text { Equipamentos } \\
\text { de Lazer }\end{array}$ & Localização & Preço & Área Verde \\
\hline 19 & $\begin{array}{c}3 \text { dorm. (suíte } \\
\text { com closet e } \\
\text { sala mais } \\
\text { ampla) - 95 } \\
\mathrm{m} 2\end{array}$ & geminado & Qda e pisc & $\begin{array}{c}\text { malha urbana, } \\
\text { comércio local, } \\
\text { nível médio }\end{array}$ & \$160 mil & $\begin{array}{c}\text { Pça arboriz e } \\
\text { gramada, } \\
\text { bancos, Bosque } \\
\text { com trilha e } \\
\text { quiosques }\end{array}$ \\
\hline
\end{tabular}




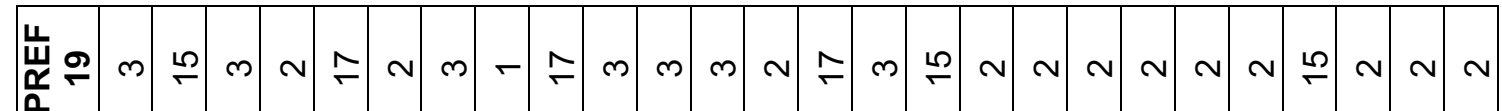

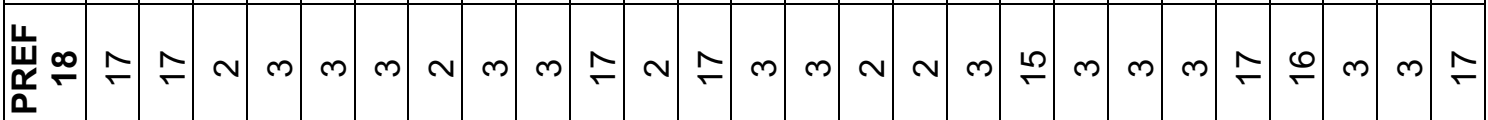

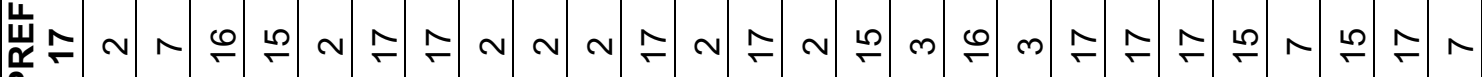
监

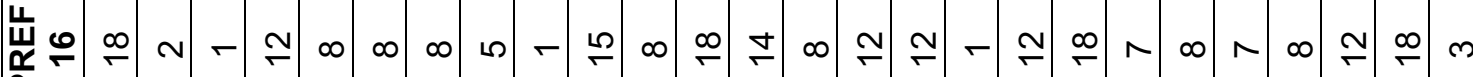
a

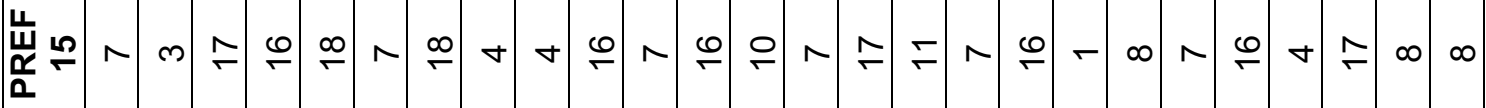

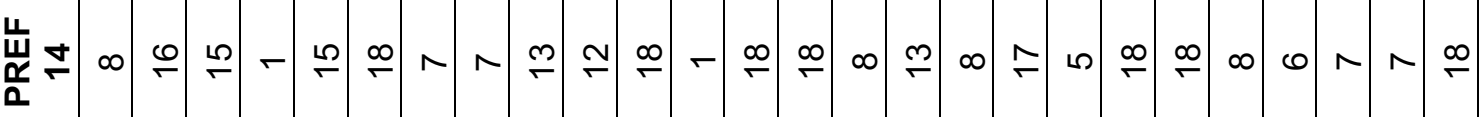

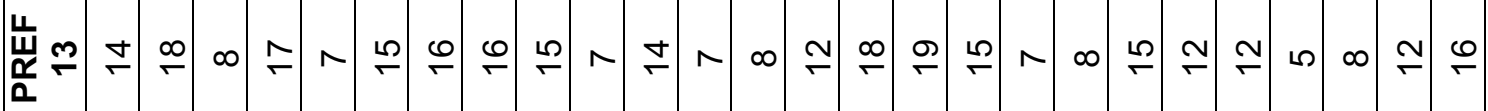

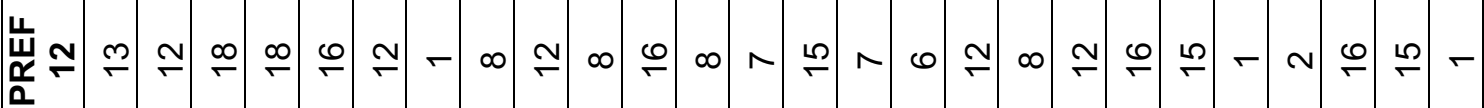

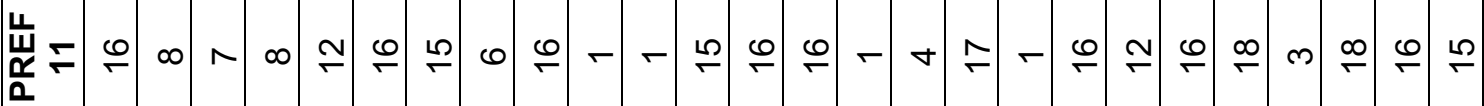

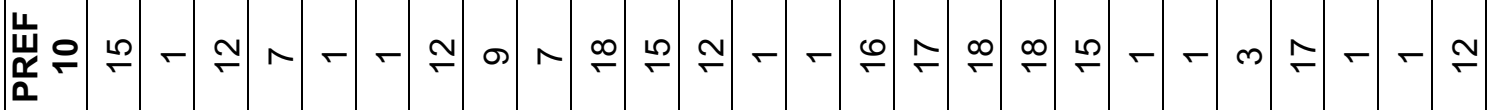

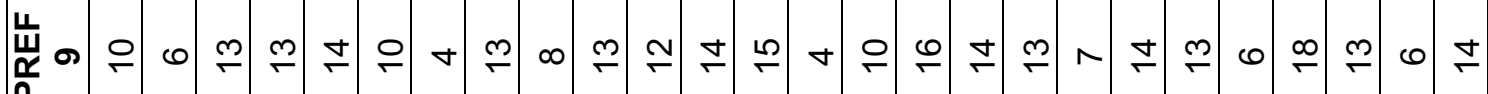
a

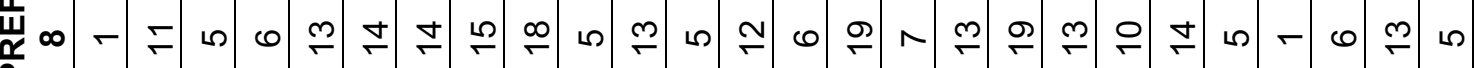

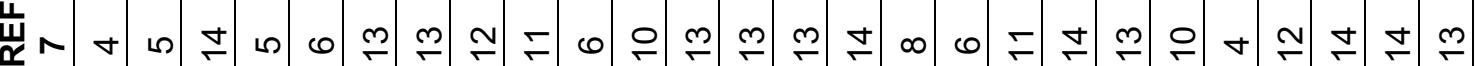
$\frac{\widetilde{\alpha}}{a}$

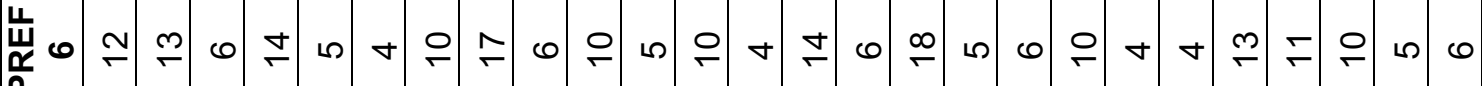

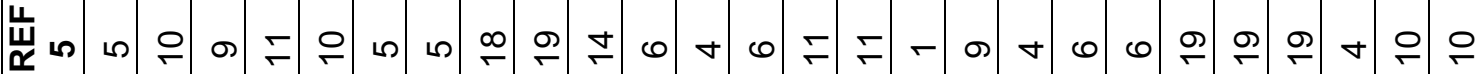
a

崖. $\frac{\pi}{\alpha}$

岀

贻 耑足 


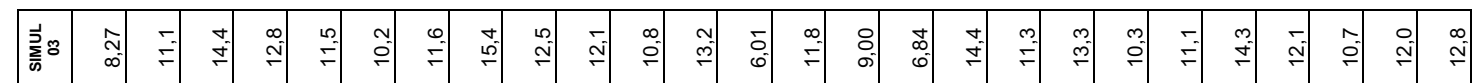

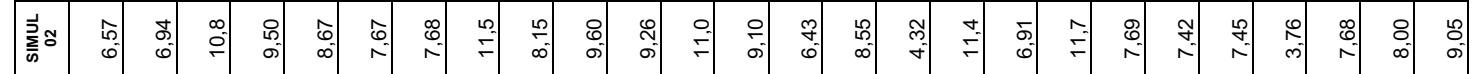

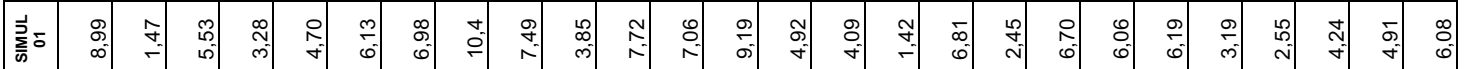

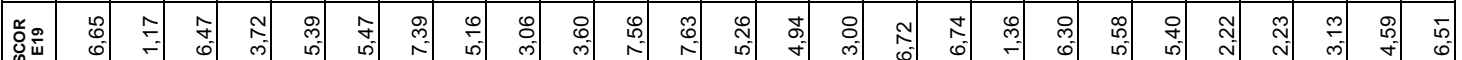

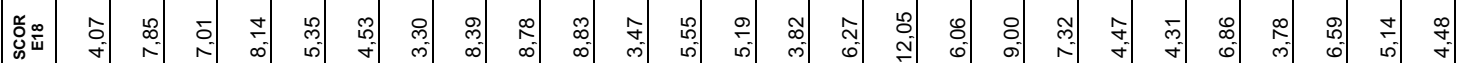

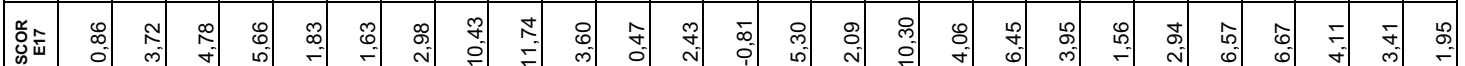

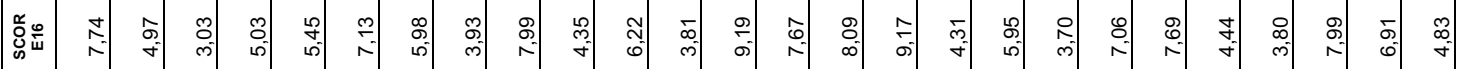

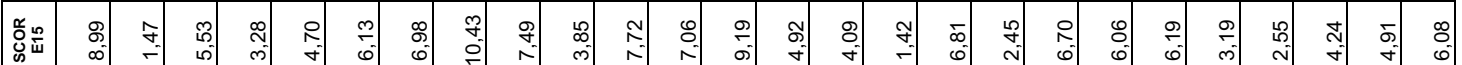

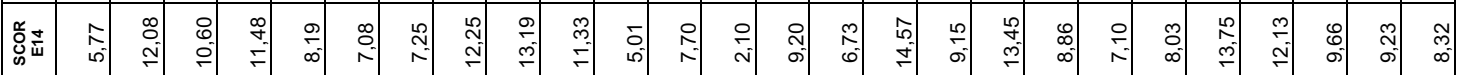

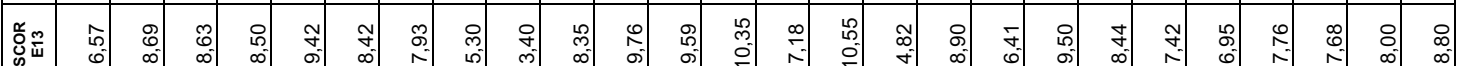

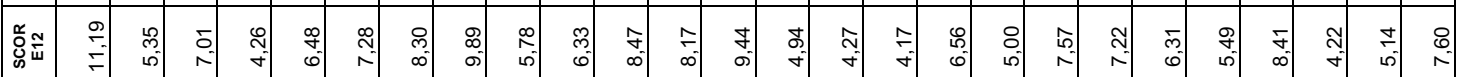

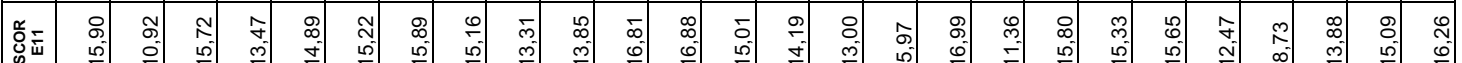

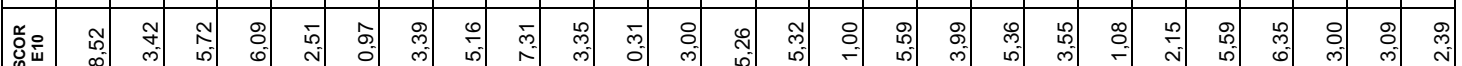

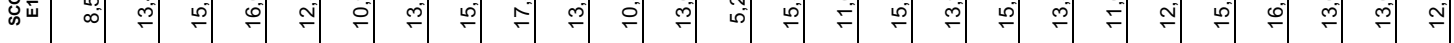

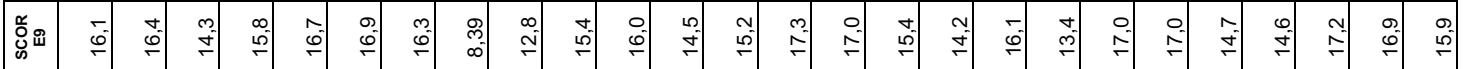

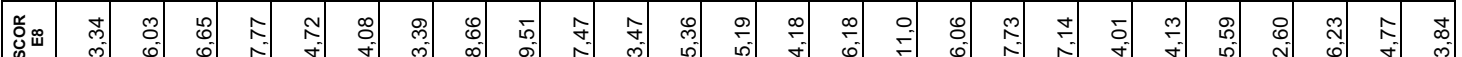

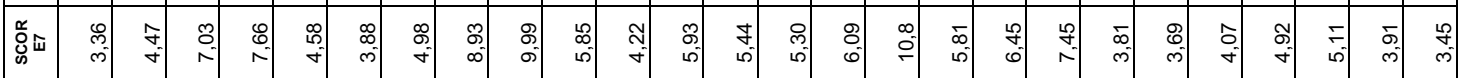

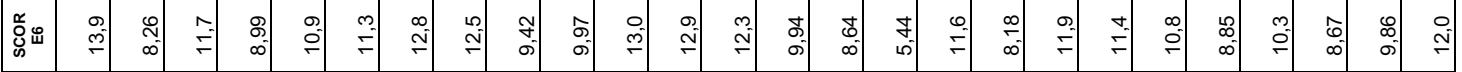

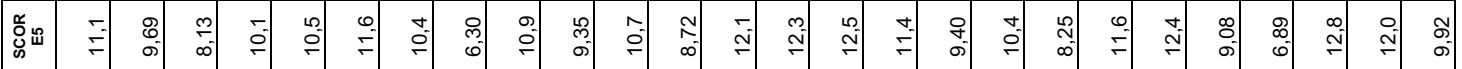

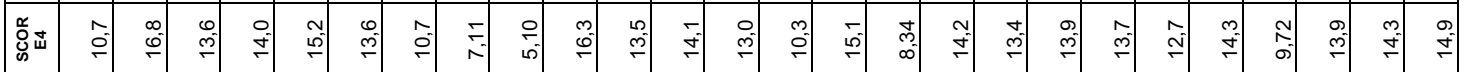

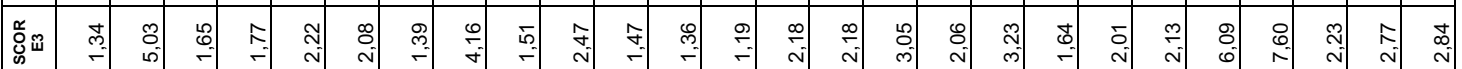

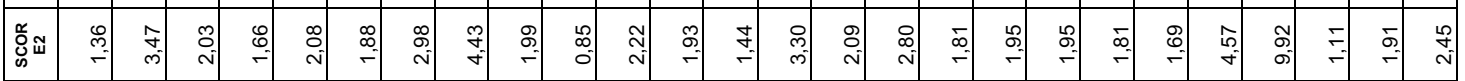

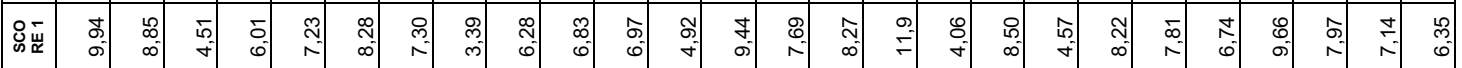

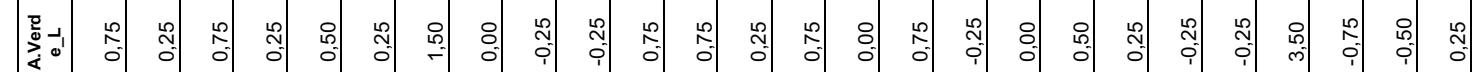

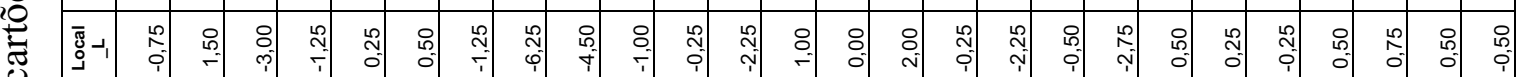

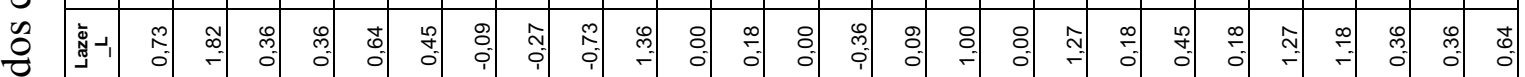

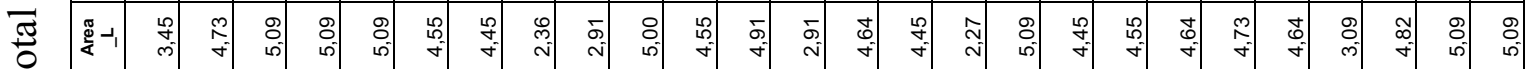

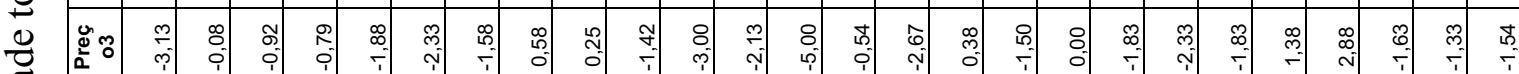

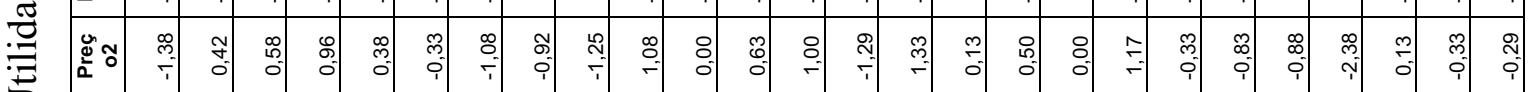

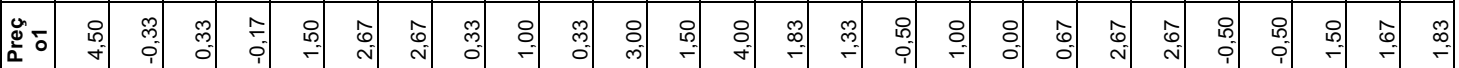

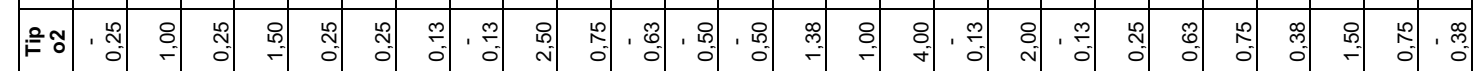

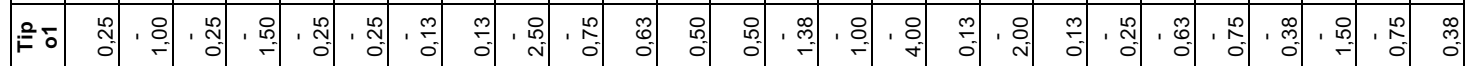

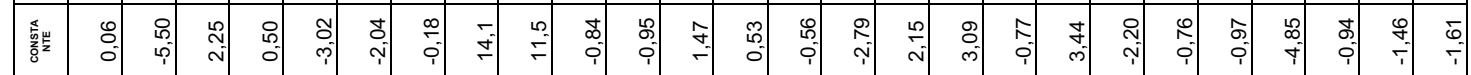

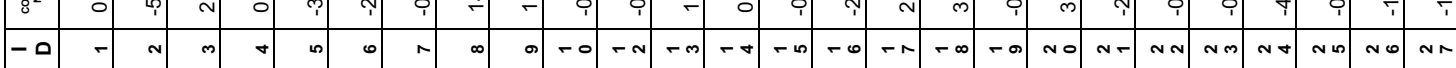


TABELA A1.06: Sintaxe do comando - Conjoint, no SPSS 17.0

CONJOINT PLAN='G:IMestrado SPSSIOrtho 30_08_09 LFP.sav'

IDATA='G:IMestrado SPSSICondomínio_prefs.sav'

ISEQUENCE=PREF1 TO PREF19

ISUBJECT $=$ ID

/FACTORS $=$ TIPO (DISCRETE)

PREÇO (DISCRETE)

AREA (LINEAR MORE) LAZER (LINEAR MORE) LOCAL (LINEAR LESS) A.VERDE(LINEAR MORE)

/PRINT=SUMMARYONLY /PLOT=ALL /UTILITY='G:IMestrado SPSSIUtil.sav'.

TABELA A1.07: Modelo adotado - descrição da relação dos níveis

\begin{tabular}{|c|c|c|}
\hline & Número de Níveis & Relação dos níveis \\
\hline Area & 3 & Linear (more) \\
Tipo & 2 & Discrete \\
Lazer & 3 & Linear (more) \\
Local & 2 & Linear (less) \\
Preço & 3 & Discrete \\
A.Verde & 2 & Linear (more) \\
\hline
\end{tabular}

Todos os fatores (atributos) são ortogonais.

TABELA A1.08: Coeficientes das variáveis com relação linear.

\begin{tabular}{|l|c|}
\hline \multirow{2}{*}{} & Coeficientes B \\
\cline { 2 - 2 } & Estimativa \\
\hline Area & 4,332 \\
Lazer &, 441 \\
Local &,- 740 \\
A.Verde &, 365 \\
\hline
\end{tabular}


TABELA A1.09: Utilidades estimadas para os níveis dos fatores.

\begin{tabular}{|c|c|c|c|}
\hline Fator & Nível & $\begin{array}{l}\text { Utilidade } \\
\text { estimada }\end{array}$ & Erro padrão \\
\hline Tipo & $\begin{array}{l}\text { geminado } \\
\text { Isolado }\end{array}$ & $\begin{array}{r}-, 639 \\
, 639\end{array}$ & $\begin{array}{l}, 302 \\
, 302\end{array}$ \\
\hline Preço & $\begin{array}{l}\$ 160 \mathrm{mil} \\
\$ 180 \mathrm{mil} \\
\$ 200 \mathrm{mil}\end{array}$ & $\begin{array}{l}1,346 \\
-, 115 \\
-1,231\end{array}$ & $\begin{array}{l}, 402 \\
, 472 \\
, 472\end{array}$ \\
\hline Area & $\begin{array}{l}2 \text { dorm }-70 \mathrm{~m} 2 \\
3 \text { dorm (suite) - } 85 \mathrm{~m} 2 \\
3 \text { dorm (suite c/ closet) - } 95 \\
\mathrm{~m} 2\end{array}$ & $\begin{array}{r}4,332 \\
8,664 \\
12,997\end{array}$ & $\begin{array}{r}, 364 \\
, 728 \\
1,092\end{array}$ \\
\hline \multirow[t]{2}{*}{ Lazer } & $\begin{array}{l}\text { Qda e pisc } \\
\text { Qda, pisc, academia e esp } \\
\text { gourmet }\end{array}$ & $\begin{array}{l}, 441 \\
, 881\end{array}$ & $\begin{array}{l}, 364 \\
, 728\end{array}$ \\
\hline & $\begin{array}{l}\text { Qda, pisc, acad, esp gmet e } \\
\text { lazer infant }\end{array}$ & 1,322 & 1,092 \\
\hline \multirow[t]{2}{*}{ Local } & $\begin{array}{l}\text { malha urbana, comérc local, } \\
\text { nível médio }\end{array}$ &,- 740 & 604 \\
\hline & $\begin{array}{l}\text { exp urbana, sem comérc } \\
\text { local, nível alto }\end{array}$ & $-1,481$ & 1,207 \\
\hline \multirow[t]{2}{*}{ A.Verde } & Pça arboriz, grama e bancos &, 365 & 604 \\
\hline & $\begin{array}{l}\text { Pça, grama, bancos, bosque, } \\
\text { trilha e qui }\end{array}$ &, 731 & 1,207 \\
\hline (Constant & & ,374 & 1,598 \\
\hline
\end{tabular}

TABELA A1.10: Coeficientes ${ }^{\mathbf{a}}$ de correlação do modelo

\begin{tabular}{|l|r|r|}
\hline & \multicolumn{1}{|c|}{ Value } & \multicolumn{1}{c|}{ Sig. } \\
\hline Pearson's R &, 976 &, 000 \\
Kendall's tau &, 950 &, 000 \\
Kendall's tau for Holdouts & 1,000 &, 059 \\
\hline
\end{tabular}

a. Correlações entre preferências obserrvadas e estimadas 
TABELA A1.11: Escores da simulação - Fase 1

\begin{tabular}{|l|r|r|}
\hline $\begin{array}{l}\text { Card } \\
\text { Number }\end{array}$ & ID & Score \\
\hline 1 & 1 & 5,478 \\
2 & 2 & 8,349 \\
3 & 3 & 11,566 \\
\hline
\end{tabular}

TABELA A1.12: Probabilidades de preferência da simulação - Fase 1

\begin{tabular}{|c|c|c|c|c|}
\hline $\begin{array}{c}\text { Card } \\
\text { Number }\end{array}$ & ID & Maximum Utility & $\begin{array}{c}\text { Bradley-Terry- } \\
\text { Luce }\end{array}$ & Logit \\
\hline 1 & 1 & $7,7 \%$ & $21,0 \%$ & $4,8 \%$ \\
2 & 2 &, $0 \%$ & $32,8 \%$ & $7,7 \%$ \\
3 & 3 & $92,3 \%$ & $46,2 \%$ & $87,5 \%$ \\
\hline
\end{tabular}

Os 26 respondentes são utilizados nos métodos Bradley-Terry-Luce e Logit porque todos os respondents tem escores positivos.

TABELA A1.13: Escores da simulação - Fase 2

\begin{tabular}{|c|c|c|}
\hline $\begin{array}{c}\text { Card } \\
\text { Number }\end{array}$ & ID & Score \\
\hline 1 & 1 & 11,566 \\
2 & 2 & 10,825 \\
\hline
\end{tabular}

TABELA A1.14: Probabilidades de preferência da simulação - Fase 2

\begin{tabular}{|l|r|r|r|r|}
\hline $\begin{array}{c}\text { Card } \\
\text { Number }\end{array}$ & ID & Maximum Utility & \multicolumn{2}{|c|}{$\begin{array}{c}\text { Bradley-Terry- } \\
\text { Luce }\end{array}$} \\
\hline 1 & 1 & $59,6 \%$ & $51,5 \%$ & $59,1 \%$ \\
2 & 2 & $40,4 \%$ & $48,5 \%$ & $40,9 \%$ \\
\hline
\end{tabular}

Os 26 respondentes são utilizados nos métodos Bradley-Terry-Luce e Logit porque todos os respondentes tem escores positivos. 
TABELA A1.15: Número de reversos

\begin{tabular}{|c|c|c|c|}
\hline & Local & & 10 \\
\hline & A.Verde & & 7 \\
\hline & Lazer & & 4 \\
\hline rator & Preço & & 0 \\
\hline & Tipo & & 0 \\
\hline & Area & & 0 \\
\hline & 1 & Respondente 1 & 0 \\
\hline & 2 & Respondente 2 & 1 \\
\hline & 3 & Respondente 3 & 0 \\
\hline & 4 & Respondente 4 & 0 \\
\hline & 5 & Respondente 5 & 1 \\
\hline & 6 & Respondente 6 & 1 \\
\hline & 7 & Respondente 7 & 1 \\
\hline & 8 & Respondente 8 & 1 \\
\hline & 9 & Respondente 9 & 2 \\
\hline & 10 & Respondente 10 & 1 \\
\hline & 11 & Respondente 12 & 0 \\
\hline & 12 & Respondente 13 & 0 \\
\hline & 13 & Respondente 14 & 1 \\
\hline Respondente & 14 & Respondente 15 & 1 \\
\hline & 15 & Respondente 16 & 1 \\
\hline & 16 & Respondente 17 & 0 \\
\hline & 17 & Respondente 18 & 1 \\
\hline & 18 & Respondente 19 & 0 \\
\hline & 19 & Respondente 20 & 0 \\
\hline & 20 & Respondente 21 & 1 \\
\hline & 21 & Respondente 22 & 2 \\
\hline & 22 & Respondente 23 & 1 \\
\hline & 23 & Respondente 24 & 1 \\
\hline & 24 & Respondente 25 & 2 \\
\hline & 25 & Respondente 26 & 2 \\
\hline & 26 & Respondente 27 & 0 \\
\hline
\end{tabular}

Fonte: Arquivo de saída do SPSS, versão 17.0
TABELA A1.16: Resumo de reversos

\begin{tabular}{|c|c|}
\hline $\begin{array}{c}\text { Número de } \\
\text { Reversos }\end{array}$ & $\begin{array}{c}\text { Número de } \\
\text { Respondentes }\end{array}$ \\
\hline 1 & 13 \\
2 & 4 \\
\hline
\end{tabular}


Individual Subject Utilities

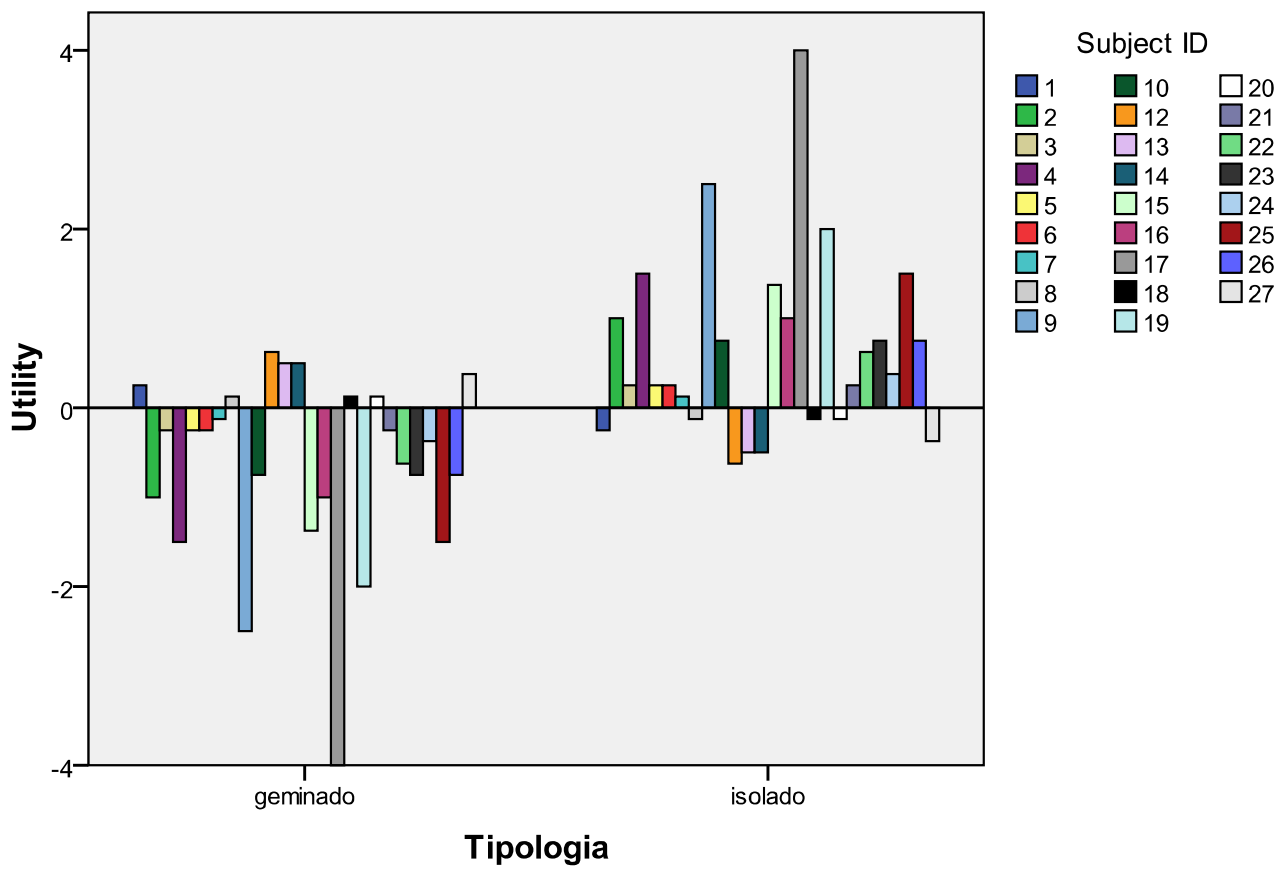

FIGURA A1.09: Utilidades individuais do atributo Tipologia.

Individual Subject Utilities

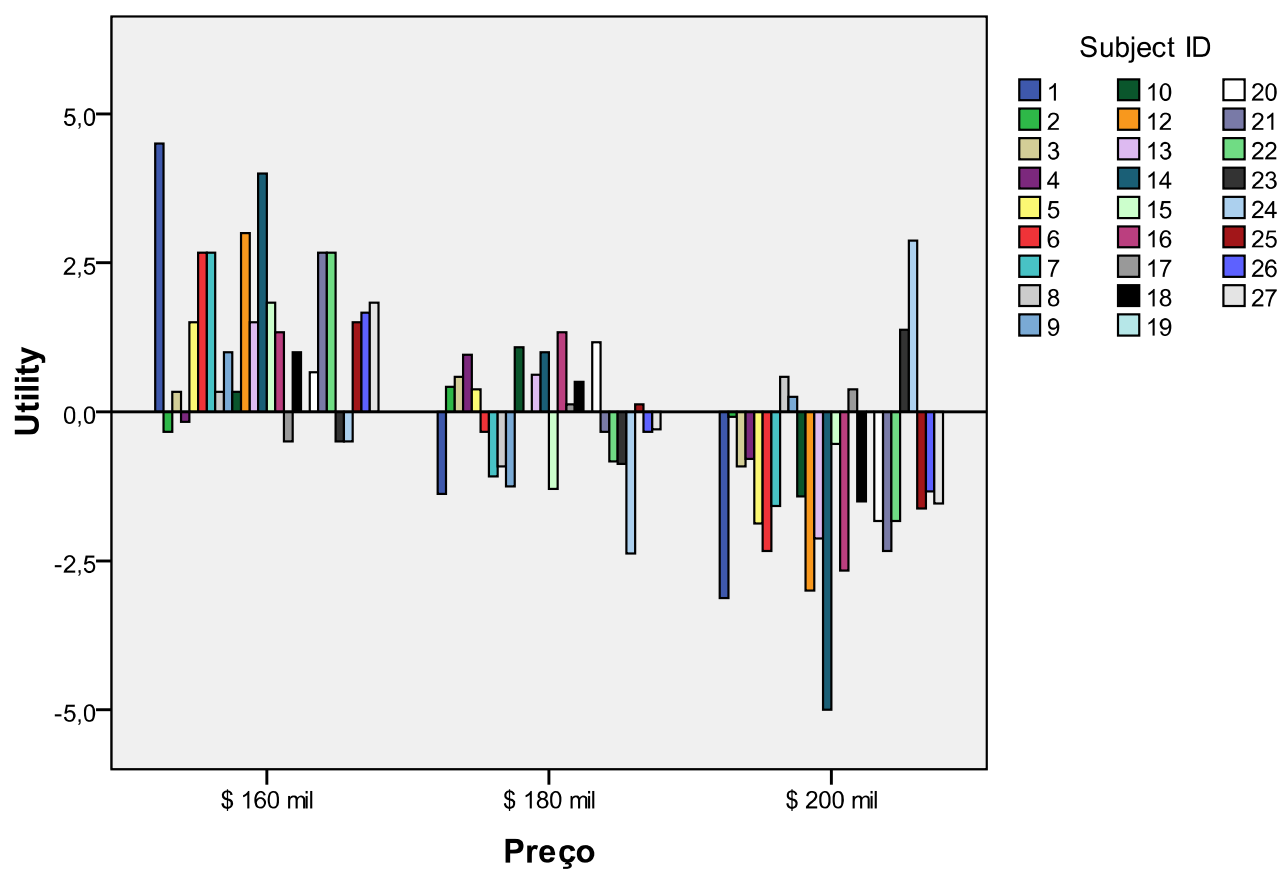

FIGURA A1.10: Utilidades individuais do atributo Preço 


\section{ANÁLISE CONJUNTA}

\section{Individual Subject Utilities}

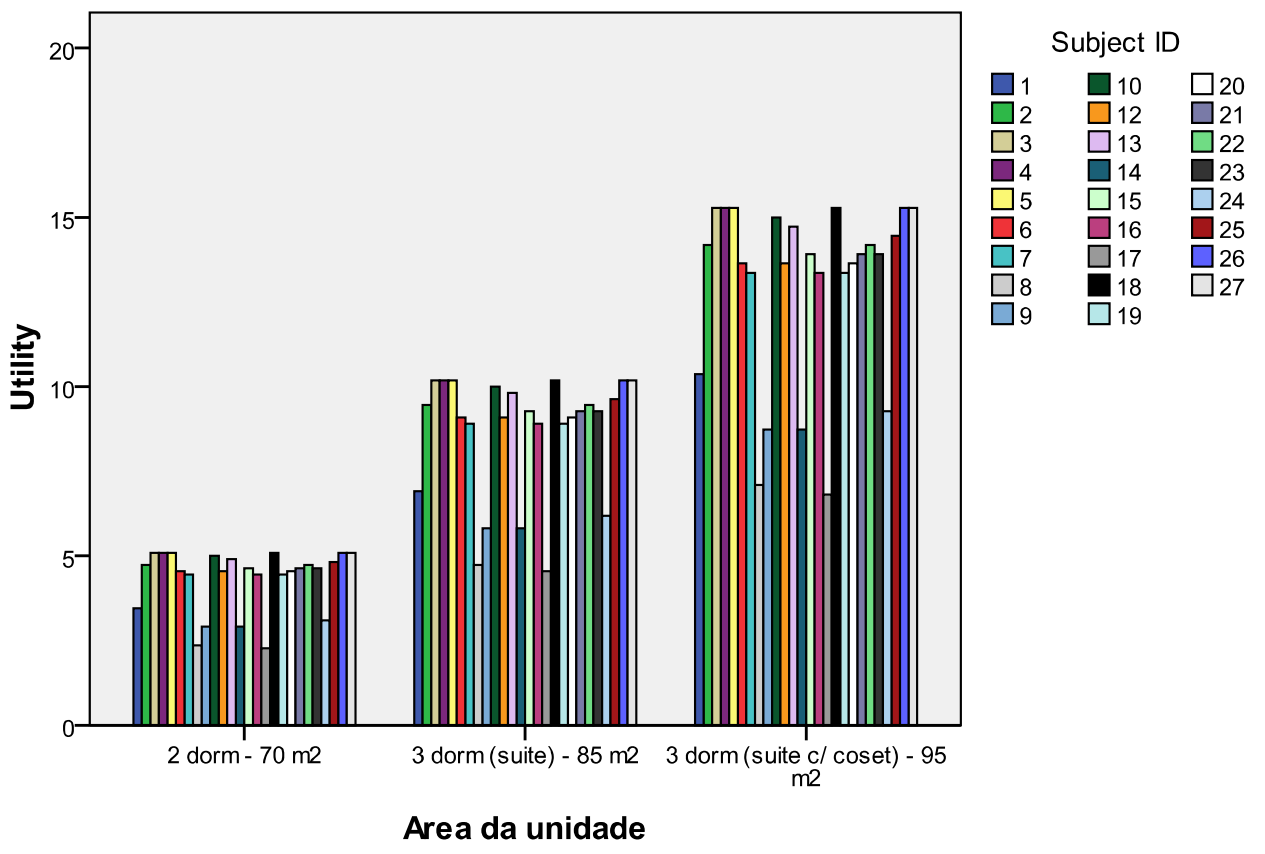

FIGURA A1.11: Utilidades individuais do atributo Área da unidade.

\section{Individual Subject Utilities}

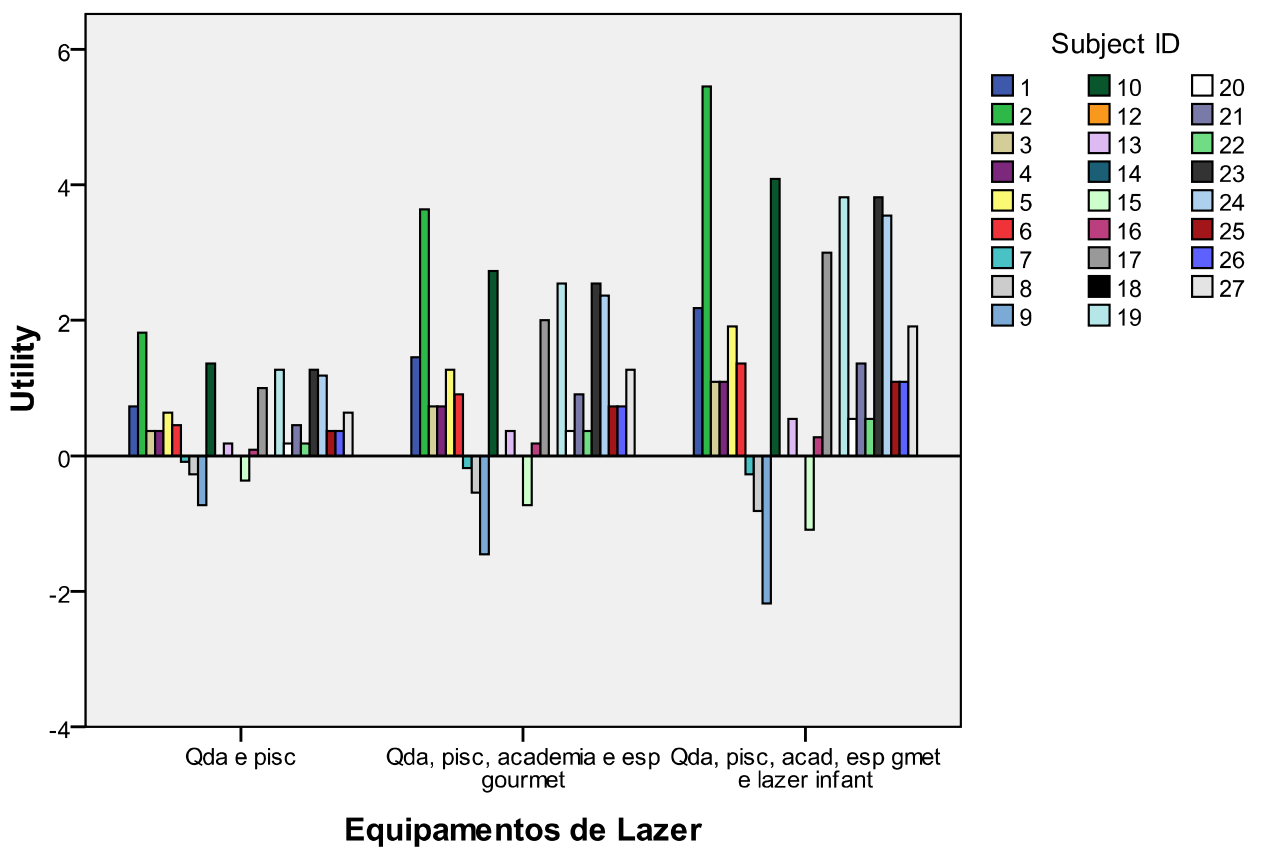

FIGURA A1.12: Utilidades individuais do atributo Equipamentos de Lazer. 
ANÁLISE CONJUNTA

\section{Individual Subject Utilities}

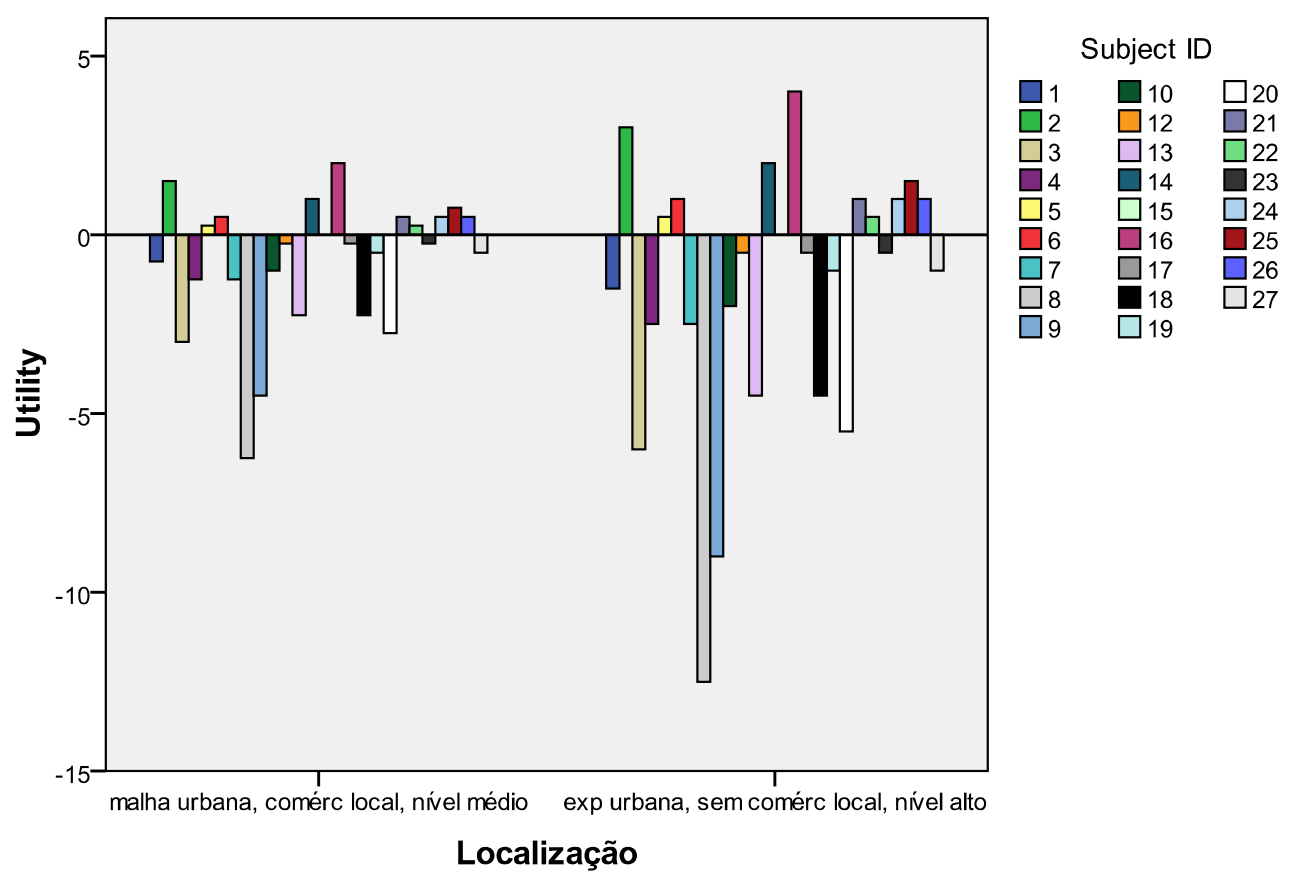

FIGURA A1.13: Utilidades individuais do atributo Localização.

\section{Individual Subject Utilities}

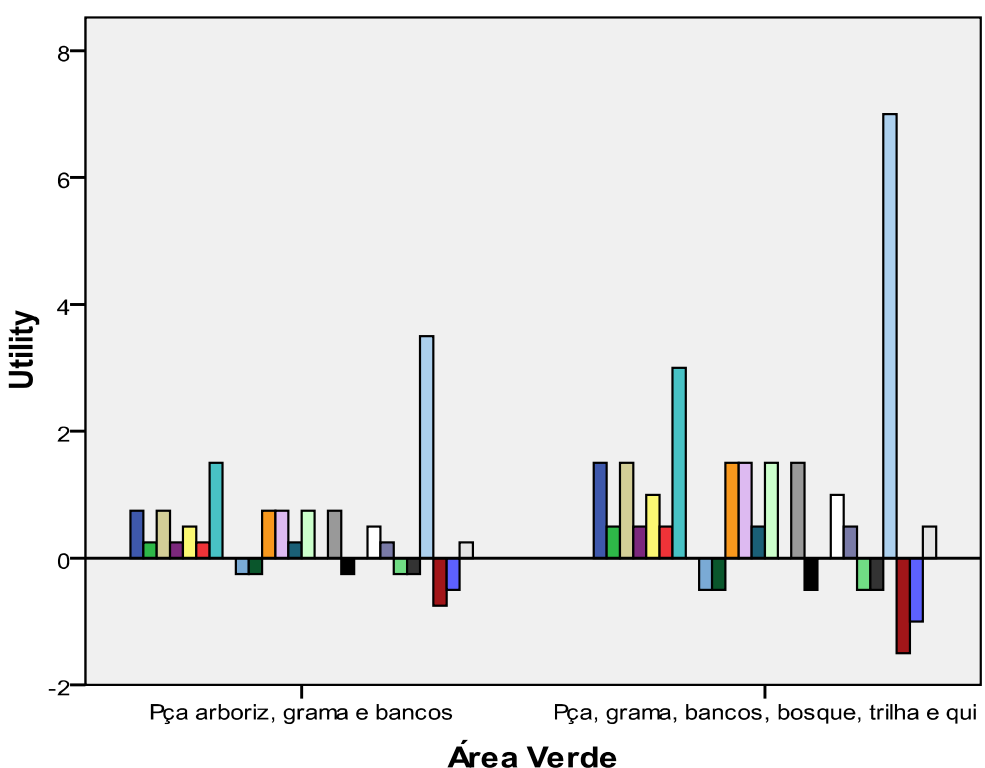

Subject ID

$\begin{array}{lll}\square & \square_{10} & \square_{20} \\ \square_{2} & \square_{12} & \square_{21} \\ \square_{3} & \square_{13} & \square_{22} \\ \square_{4} & \square_{14} & \square_{24} \\ \square^{2} & \square_{16} & \square_{25} \\ \square_{7} & \square_{17} & \square_{26} \\ \square_{8} & \square_{18} & \square 27 \\ \square 9 & \square 19 & \end{array}$

FIGURA A1.14: Utilidades individuais do atributo Área Verde. 
ANÁLISE CONJUNTA

Summary Utilities

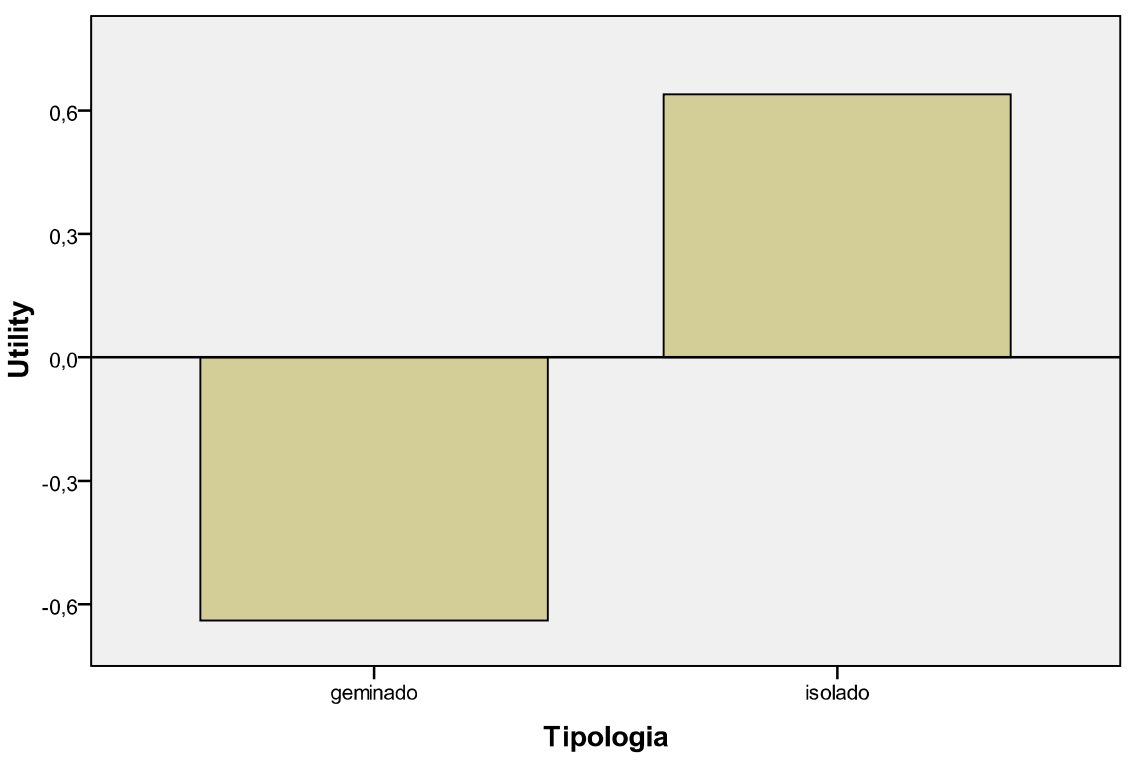

FIGURA A1.15: Utilidade agregada do atributo Tipologia

Summary Utilities

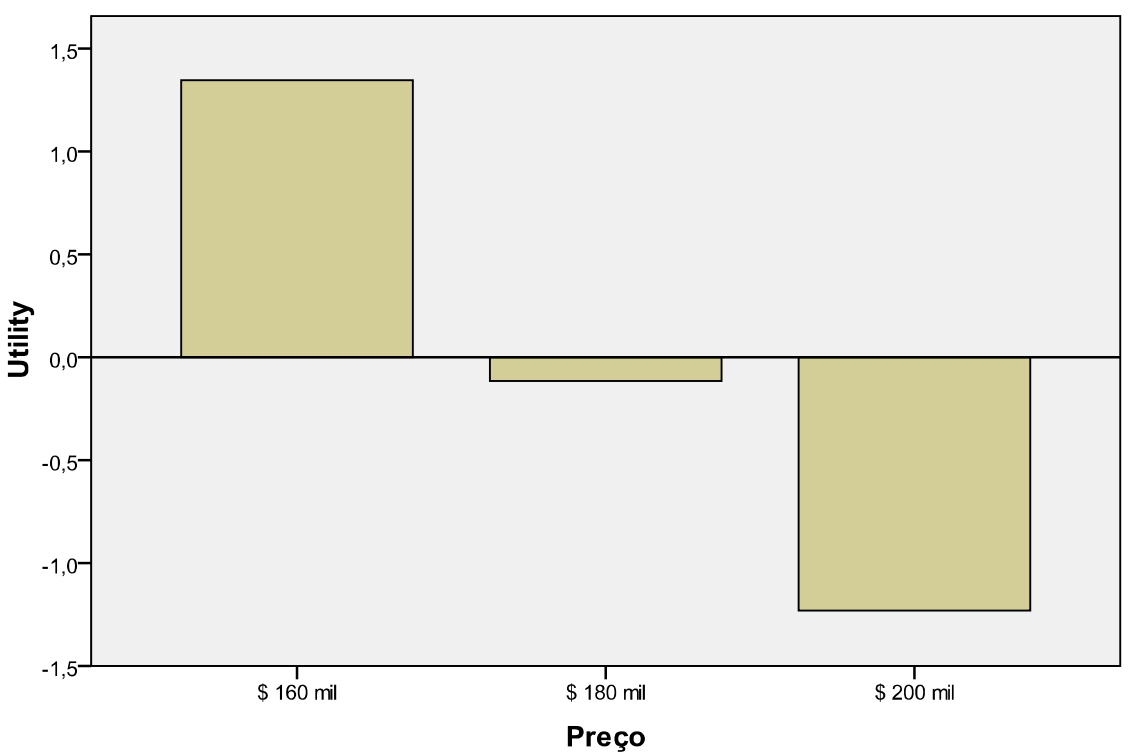

FIGURA A1.16: Utilidade agregada do atributo Preço. 


\section{Summary Utilities}

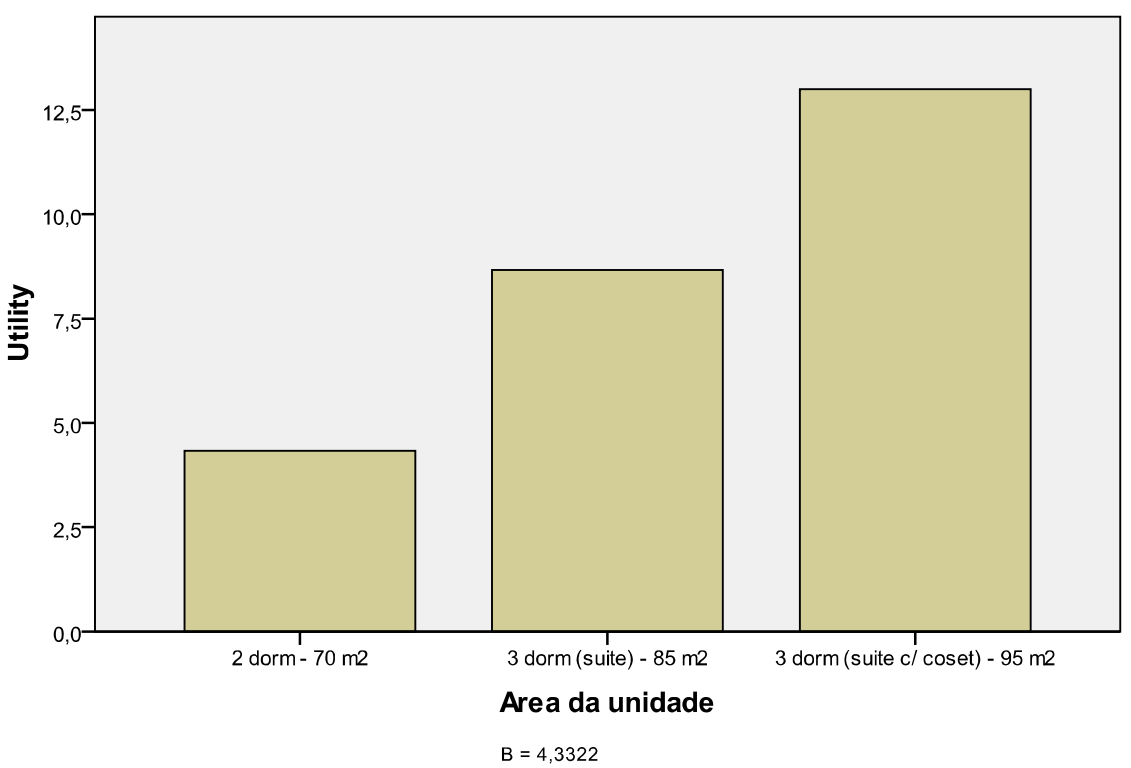

FIGURA A1.17: Utilidade agregada do atributo Área da unidade.

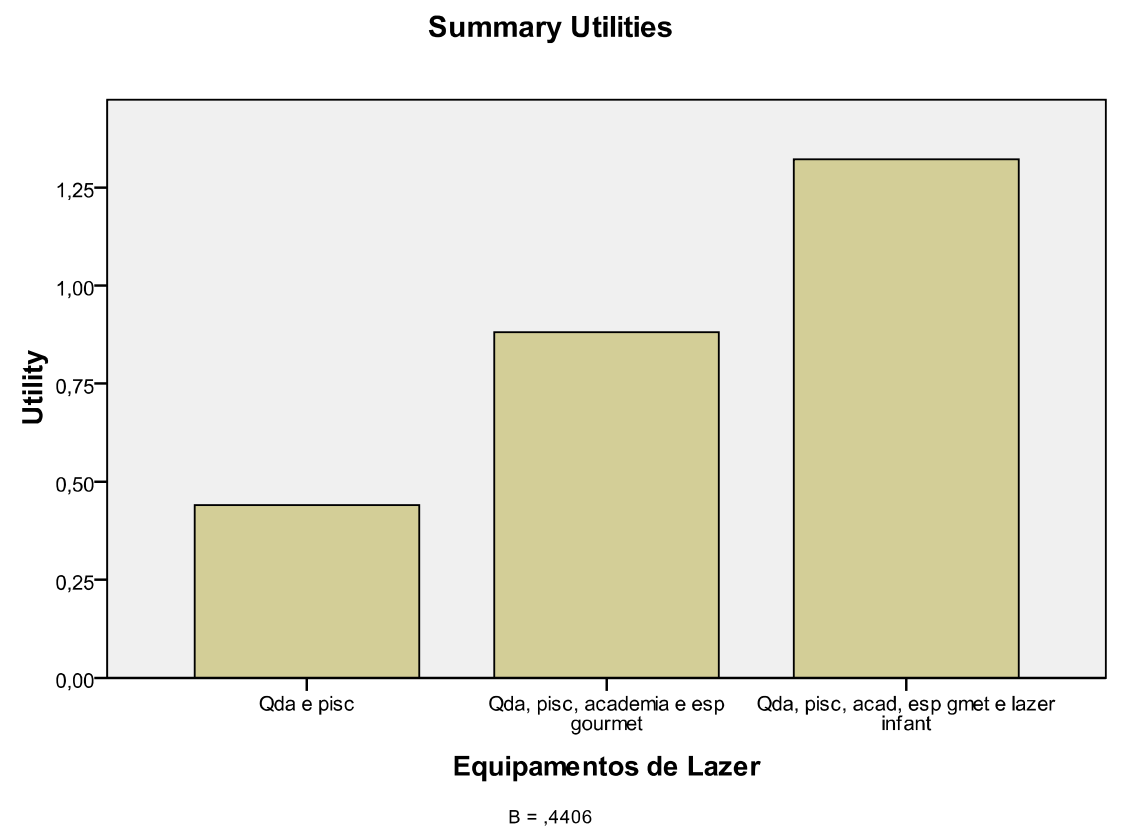

FIGURA A1.18: Utilidade agregada do atributo Equipamentos de Lazer. 
Summary Utilities

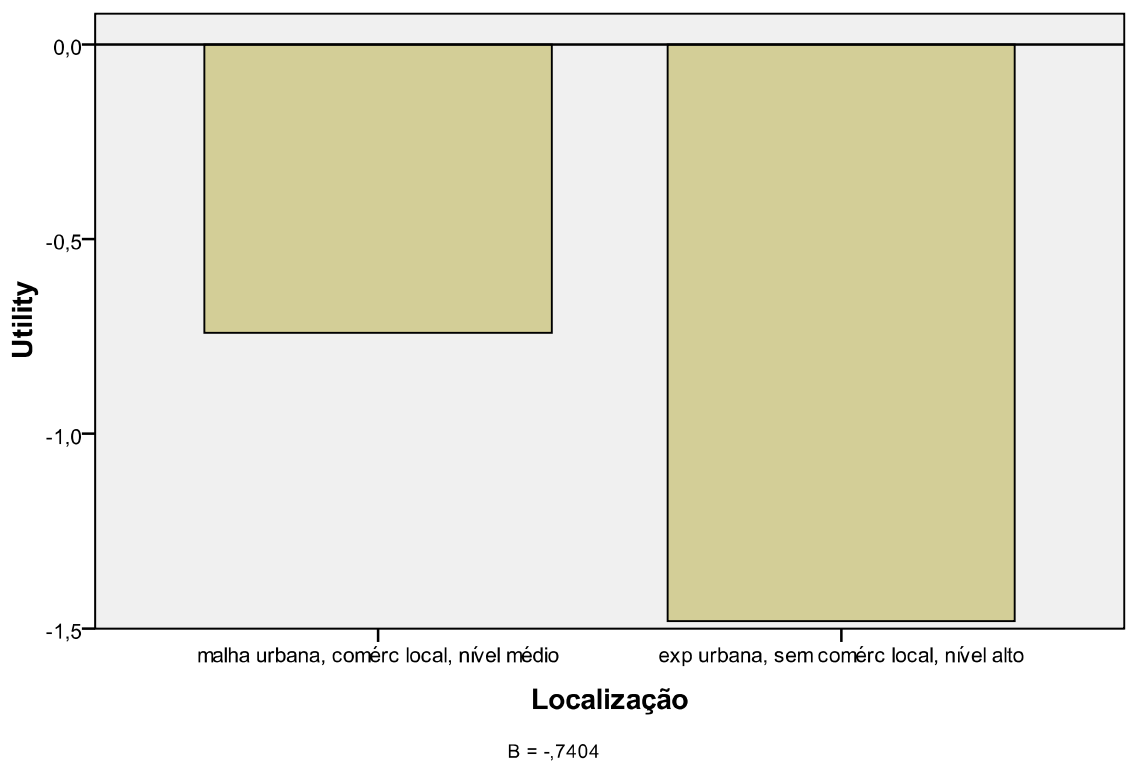

FIGURA A1.19: Utilidade agregada do atributo Localização.

Summary Utilities

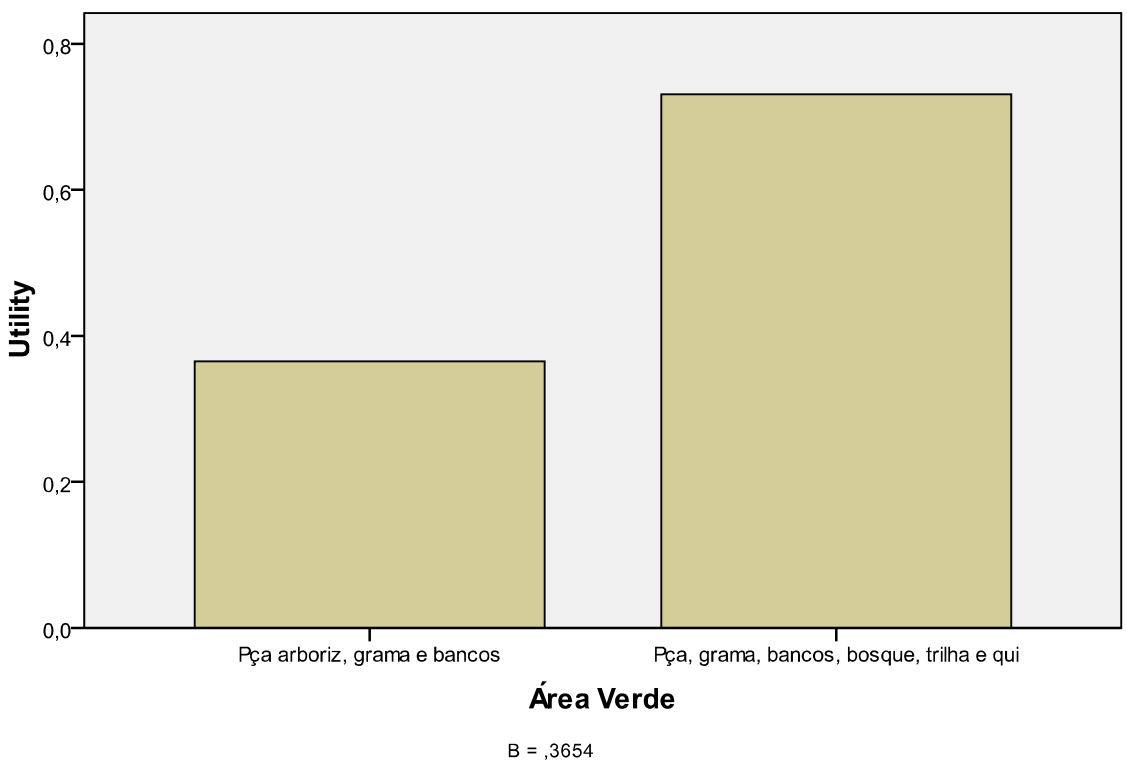

FIGURA A1.20: Utilidade agregada do atributo Área Verde. 
Importance summary

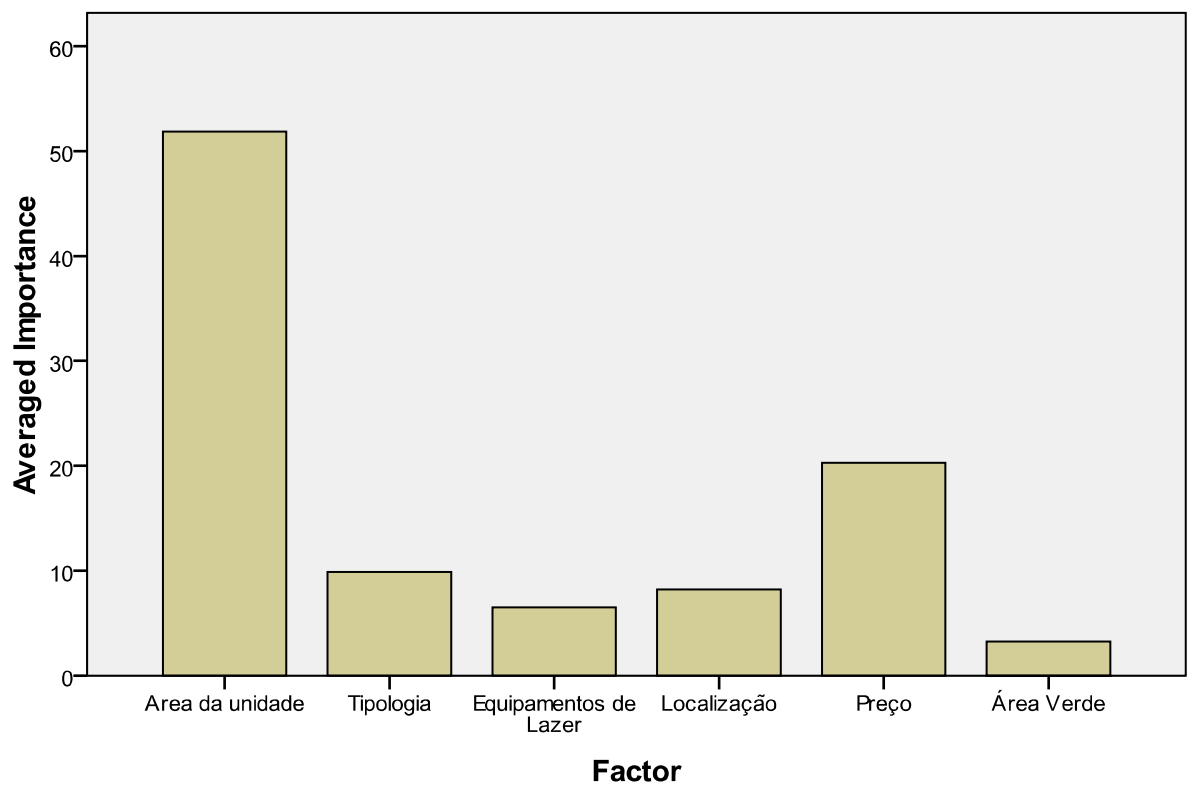

FIGURA A1.21: Utilidade agregada do experimento. 